\title{
Interval-valued hesitant fuzzy TODIM method for dynamic emergency responses
}

\author{
Quanyu Ding ${ }^{1,2}$ (1) $\cdot{\text { Mark } \text { Goh }^{2} \cdot \text { Ying-Ming Wang }}^{1,3,4}$
}

Accepted: 13 March 2021 / Published online: 27 April 2021

(C) The Author(s), under exclusive licence to Springer-Verlag GmbH Germany, part of Springer Nature 2021

\begin{abstract}
Emergency responses bear the characteristics of uncertainty and possess multi-attributes in decision making. This paper applies the interval evidential reasoning approach and the interval-valued hesitant fuzzy TODIM (IVHF-TODIM) method to tackle the dynamic emergency decision-making problem. We introduce a function to obtain the gain and loss degrees through the geometric area method. The gain and loss matrices of the interval belief degrees are found probabilistically. A new approach to obtaining the dominance degree matrix is proposed. From the IVHF-TODIM method, the overall dominance degree is established to provide the ranking of the decision alternatives. A recent case of selecting an emergency decision alternative for a large bushfire is used to validate the proposed method, followed by a comparative analysis.
\end{abstract}

Keywords Emergency decision making · Interval-valued hesitant fuzzy sets · TODIM · Interval evidential reasoning

\section{Introduction}

Destructive emergency events (EEs) are ubiquitous and often lead to unexpected catastrophic consequences (Wang et al. 2019; Zhang and Li 2019). Some recent examples include (1) the Liangshan forest fire in Sichuan in 2019 resulting in the deaths of 30 firefighters, (2) the great Australian bushfire in 2020 in three Australian states depleting 46 million acres of land, destroying nearly 6,000 homesteads, decimating half a billion native animals and unnecessary loss of lives, and (3) the Taal volcanic eruption in the Philippines which displaced residents, suspended flights through Manila, and causing air pollution.

Ying-Ming Wang

ymwang@fzu.edu.cn

1 Decision Sciences Institute, Fuzhou University, Fuzhou 350116, Fujian, People's Republic of China

2 NUS Business School and the Logistics Institute-Asia Pacific, National University of Singapore, Singapore, Singapore

3 Key Laboratory of Spatial Data Mining and Information Sharing of Ministry of Education, Fuzhou University, Fuzhou 350116, Fujian, People's Republic of China

4 School of Economics and Management, Fuzhou University, Fuzhou 350116, Fujian, People's Republic of China
Therefore, emergency response, delivered in a timely manner, is vital in mitigating the loss of property and lives affected by the emergencies. Governments are increasingly concerned over such catastrophic events. Academia likewise have developed a rich and meaningful fodder of research (Wang et al. 2017; Ding et al. 2019). To mitigate the negative impact on human lives and the socioeconomic development caused by the emergency events, it is expedient for emergency response planners to select a desirable decision alternative to respond to emergency events (Peng and Garg 2018; Li and Wei 2019; Ren et al. 2017). Furthermore, as different experts hold different opinions on the decision alternatives and the inherent uncertainty of the decision information, the emergency decision-making problem (EDMP) is subset to the multi-attribute group decision-making (MAGDM) problem. However, different from the other MAGDM problems, such as supply chain management decisions (Baptista et al. 2019; Hatzisymeon et al. 2019), investment risk decision making (Hong et al. 2019; Cheng et al. 2018), EEs often require the decision makers (DMs) to make critical decisions within very tight time windows (Peng and Garg 2018) and sometimes under risks and much uncertainty (Ding et al. 2019). The outcomes of the decision making may adversely affect other courses of action ( $\mathrm{Li}$ and Cao 2019). Therefore, knowing how to objectively choose an appropriate decision 
alternative is strategic to emergency management. Putting forward novel EDM methods can help to improve the allocative and operational efficiency of emergency management, alleviate the negative externality of EEs on society, and subsequently reduce the loss of human lives and property.

Most times, there is uncertainty arising from the vagueness of the expressions used by the DMs. Torra (2010) first presented the hesitant fuzzy sets (HFS) that permit the DMs to employ real numbers in the interval [0, 1] to form judgment. Using the hesitant fuzzy approach to model the uncertainty and vagueness of the information using real numbers has yielded successful outcomes in pragmatic decision making (Mardani et al. 2020; Farhadinia and Herrera-Viedma 2019) and has served as a basis for various hesitant fuzzy computational models (Garg and Kaur 2020; Alcantud and Giarlotta 2019). Most of these models use hesitant fuzzy sets to reflect expert opinions. However, it is sometimes difficult to specify the precise membership degree of an element to a set as there exist much complexity and uncertainty, and sometimes due to the lack of information and time limitation, the DMs need to express their knowledge among the interval values and relying on only real values cannot inadequately reflect their opinions. As such, some studies (Li et al. 2018; Yang et al. 2020) have sought to overcome this limitation through interval-valued models to improve the flexibility of the information elicitation.

However, when a DM is hesitant among several interval numbers, the interval expressions generated by most of these approaches can sit far from the common evaluation of the DMs, and it is not easy for the DM to provide a single interval number as the DM's evaluation. To address this shortcoming, the interval-valued HFS (IVHFS) has been successfully applied (Tang and Meng 2018). For instance, Chen et al. (2013) introduced the IVHFS to extend the domain of HFS to intervals in $[0,1]$. Since then, other studies have followed suit (Asan et al. 2018; Zeng et al. 2019; Liu et al. 2019). At the same time, Asan et al. (2018) proposed a new approach to DEMATEL based on IVHFS to deal with uncertainty in decision making, while Zeng et al. (2019) introduced the hesitance degree of the weighted IVHF element and proposed four operators to aggregate the weighted interval-valued hesitant fuzzy information to handle MADM problems. To evaluate the co-creative value propositions or smart product service systems, Liu et al. (2019) employed the IVHFS-DEMATEL method to obtain the total relation of the co-creative value propositions. Clearly, introducing the IVHFS not only enriches the theoretical concept of the HFS, but it is also applicable to many decision-making problems. As such, the IVHFS is suitable and useful when the DMs hesitate during the elicitation process of their interval preferences, as the IVHFS is a reasonable format for expressing imprecise and uncertain information.

Since a DM's hesitation may reflect the DM's psychological state, it is only logical that the psychological behavior of a DM should feature in the decision-making process. Following from Simon's bounded rationality (Simon 1955), Tversky and Kahneman (1979, 1992) applied prospect theory (PT) to depict the way in which DMs choose between probabilistic alternatives that involve risk when the probabilities of the outcomes are known. However, research has shown that prospect theory cannot sufficiently express a DM's psychological behavioral operation as prospect theory requires the aspiration levels of the attributes to be known a priori (Nagarajan and Shechter 2014). As an attempt to address this issue, we consider the TODIM method widely studied in decision making (Gomes and Lima 1992). As the classical TODIM method can only be used to cope with the MADM problem in which the attribute values are stated as crisp numbers, we supplement this with IVHF sets. Besides, due to the complexity and uncertainty of the decision-making problems, the DMs often find it difficult to ascribe preference information in the form of crisp numbers (Pramanik and Mallick 2019; Niu et al. 2020). The approach proposed in (Pramanik and Mallick 2019) modeled the uncertainty and vagueness of the information through trapezoidal neutrosophic variables, and it has served as a basis to define different decision-making computational models. Niu et al. (2020) considered the psychological behavior of the DMs and proposed methods in interval-valued intuitionistic fuzzy environments to handle MCDM problems. Though Pramanik and Mallick 2019; Niu et al. 2020 considered the DM's psychological behavior using score functions, the score functions cannot distinguish whether two objects have equal accuracy functions. Hence, we develop a new technique, which combines the interval evidential reasoning (IER) approach (Wang et al. 2006) by aggregating multiple attributes based on a belief decision matrix, and the evidence combination rule of the Dempster-Shafer theory (Dempster 1967; Shafer 1976) to yield the intervalvalued hesitant fuzzy TODIM (IVHF-TODIM) method to handle the EDM problem in which the preference information is given as an IVHFS (Asan et al. 2018; Zeng et al. 2019). Currently, there is no IVHF MADM method that comprehensively considers the DM's psychological behavior and employs IER to tackle EDM problems. We hope to address this shortcoming using our proposed method.

Specifically, our work contributes to the extant knowledge by:

1. Introducing a function to find the gain and loss degrees based on the geometric area method. 
2. Applying the probability density function and geometric area method to specify the gain and loss matrices of the interval belief degrees.

3. Establishing a way to develop the dominance degree matrix to obtain the ranking of the decision alternatives.

The rest of this paper is set as follows: Section 2 introduces the IER and TODIM methods. Section 3 presents an IVHF-TODIM method for solving the EDM problem. A case study of a decision alternative selection issue is used in Sect. 4 to illustrate the novelty and validity of the proposed method. This followed by a comparison with the other extant methods. Section 5 concludes the paper.

\section{Preliminaries: concepts and definitions}

We introduce the following to this paper as shown below.

\begin{tabular}{|c|c|}
\hline Notation & \\
\hline$\beta_{n, i}\left(a_{l}\right)$ & $\begin{array}{l}\text { Belief degree of alternative } a_{l} \text { evaluated as } \\
\text { class } H_{n} \text { under attribute } e_{i}\end{array}$ \\
\hline$\beta_{H, i}\left(a_{l}\right)$ & Belief degree assigned to the whole set \\
\hline$m_{n, i}$ & $\begin{array}{l}\text { Interval basic probability assignment of } \\
\text { attribute } i\end{array}$ \\
\hline $\bar{m}_{H, i}$ & $\begin{array}{l}\text { Uncertainty caused by the relative } \\
\text { importance of attribute } i\end{array}$ \\
\hline$\tilde{m}_{H, i}$ & $\begin{array}{l}\text { Uncertainty caused by the incompleteness } \\
\text { of belief degree in attribute } i\end{array}$ \\
\hline$D=\left[d_{i j}\right]_{n \times m}$ & Decision-making matrix \\
\hline$R=\left[r_{i j}\right]_{n \times m}$ & Normalized decision-making matrix \\
\hline$\omega_{j r}$ & $\begin{array}{l}\text { Relative weight of attribute } C_{j} \text { to reference } \\
\text { attribute } C_{r}\end{array}$ \\
\hline$\varphi_{i q}^{j}$ & $\begin{array}{l}\text { Dominance degree of alternative a } \tilde{A_{i}} \text { over } \\
\tilde{A_{q}} \text { for attribute } C_{j}\end{array}$ \\
\hline$\phi_{i q}$ & $\begin{array}{l}\text { Overall dominance degree of alternative } \tilde{A_{i}} \\
\text { over alternative } \tilde{A_{q}}\end{array}$ \\
\hline$\xi\left(\tilde{A_{i}}\right)$ & Overall dominance value of alternative $\tilde{A_{i}}$ \\
\hline$E=\left\{e_{1}, \ldots, e_{e}\right\}$ & $\begin{array}{l}\text { Set of decision makers, where } e_{l} \text { denotes } \\
\text { DM } l, l=1, \ldots,\end{array}$ \\
\hline$A=\left\{A_{1}, \ldots, A_{n}\right\}$ & Set of decision alternatives, $i=1, \ldots, \mathrm{n}$ \\
\hline$C=\left\{C_{1}, \ldots, C_{m}\right\}$ & $\begin{array}{l}\text { Set of attributes, where } C_{j} \text { is attribute } j \text {, } \\
\quad j=1, \ldots, m\end{array}$ \\
\hline$W_{E}=\left\{\omega_{e 1}, \ldots, \omega_{e e}\right\}$ & Weight vector for the experts \\
\hline$W_{C}=\left\{\omega_{1}, \ldots, \omega_{m}\right\}$ & Weight vector for the attributes \\
\hline$Z=\left\{Z_{1}, \ldots, Z_{t}\right\}$ & Set of emergency states \\
\hline$\tilde{h_{A}}\left(x_{i}\right)=\left\{\tilde{\gamma} \mid \tilde{\gamma} \in \tilde{h_{A}}\left(x_{i}\right)\right\}$ & $\begin{array}{l}\tilde{h}_{A}\left(x_{i}\right) \text { (Liu et al. 2019) is an IVHF } \\
\text { element, and } \tilde{\gamma}=\left[\tilde{\gamma}^{L}, \tilde{\gamma}^{U}\right] \text { is an interval } \\
\text { number }\end{array}$ \\
\hline
\end{tabular}

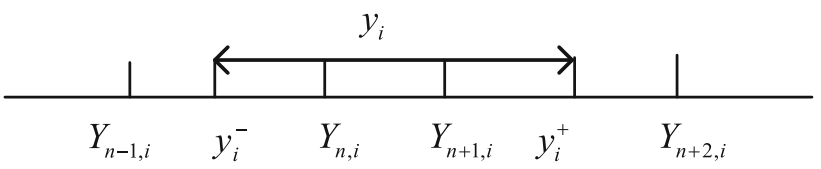

Fig. 1 Relationship among interval values and evaluation grades $\left(y_{i}\right.$ includes $Y_{n, i}$ and $Y_{n+1, i}$ )

\subsection{Interval evidential reasoning (IER)}

In this paper, the ER approach using interval belief degrees (Wang et al. 2006) is labelled as the IER approach, which will allow both quantitative and qualitative attributes to be modeled using interval data. This is a generalization of the Dempster-Shafer theory (Dempster 1967; Shafer 1976).

Definition 1 (Wang et al. 2006). Suppose $S\left(e_{i}\left(a_{l}\right)\right)=$ $\left\{\left(H_{n},\left[\beta_{n, i}^{-}\left(a_{l}\right), \beta_{n, i}^{+}\left(a_{l}\right)\right]\right), \quad n=1, \ldots, N\right\}$ is an incomplete interval-valued distribution evaluation vector. Then, the interval belief degree, $\beta_{H, i}\left(a_{l}\right)$, assigned to the set $H$ can be expressed as

$$
\left\{\begin{array}{l}
\beta_{H, i}^{-}\left(a_{l}\right)=\max \left(0,1-\sum_{n=1}^{N} \beta_{n, i}^{+}\left(a_{l}\right)\right) \\
\beta_{H, i}^{+}\left(a_{l}\right)=1-\sum_{n=1}^{N} \beta_{n, i}^{-}\left(a_{l}\right)
\end{array}\right.
$$

Definition 2 (Wang et al. 2006). Let $y_{i} \in\left[y_{i}^{-}, y_{i}^{+}\right]$be an interval number, which contains one or more assessment levels. Without any loss of generality, consider a situation with two evaluation levels $Y_{n, i}$ and $Y_{n+1, i}$ in the interval $\left[y_{i}^{-}, y_{i}^{+}\right]$(see ?tic=?>Fig. 1).

Let $\quad \beta_{n-1, i} \in\left[\beta_{n-1, i}^{-}, \beta_{n-1, i}^{+}\right], \quad \beta_{n, i} \in\left[\beta_{n, i}^{-}, \beta_{n, i}^{+}\right]$, $\beta_{n+1, i} \in\left[\beta_{n+1, i}^{-}, \beta_{n+1, i}^{+}\right]$, and $\beta_{n+2, i} \in\left[\beta_{n+2, i}^{-}, \beta_{n+2, i}^{+}\right]$be the interval belief degrees in which $y_{i} \in\left[y_{i}^{-}, y_{i}^{+}\right]$may be assessed. $Y_{n-1, i}, Y_{n, i}, Y_{n+1, i}$ and $Y_{n+2, i}$ are interval numbers. As $y_{i}$ can only lie in one of the three intervals, namely $\left[y_{i}^{-}, Y_{n, i}\right),\left[Y_{n, i}, Y_{n+1, i}\right]$ and $\left[Y_{n, i}, Y_{n+1, i}\right]$, we need to introduce the following $0-1$ binary variables:

$I_{k-1 . k}=\left\{\begin{array}{cc}1 & y_{i} \in\left[Y_{k-1, i}, Y_{k, i}\right] \\ 0 & \text { otherwise }\end{array} \quad k=n, n+1, n+2\right.$

The interval belief degrees are presented as follows:

$$
\begin{aligned}
& \beta_{n-1, i}^{-}=0 \text { and } \beta_{n-1, i}^{+}=\frac{y_{i}^{-}-Y_{n-1, i}}{Y_{n, i}-Y_{n-1, i}} \cdot I_{n-1, n} \\
& \beta_{n, i}^{-}=0 \text { and } \beta_{n, i}^{+}=I_{n-1, n}+I_{n, n+1}
\end{aligned}
$$


$\beta_{n+1, i}^{-}=0$ and $\beta_{n+1, i}^{+}=I_{n, n+1}+I_{n+1, n+2}$

$\beta_{n+2, i}^{-}=0$ and $\beta_{n+2, i}^{+}=\frac{y_{i}^{+}-Y_{n+1, i}}{Y_{n+2, i}-Y_{n+1, i}} \cdot I_{n+1, n+2}$

We have $I_{n-1, n}+I_{n, n+1}+I_{n+1, n+2}=1$, and only one of $0-1$ binary variables are nonzero.

For the sake of aggregating the multiple interval belief structures correctly, the ER nonlinear optimization models are formed.

First, through the weights $\omega_{i}$ and interval belief degrees, the interval belief degrees are transformed into interval probability mass functions $(m)$ using the following relations:

$$
\begin{aligned}
m_{n, i} & =m_{i}\left(H_{n}\right) \in\left[m_{n, i}^{-}, m_{n, i}^{+}\right]=\left[\omega_{i} \beta_{n, i}^{-}\left(a_{l}\right), \omega_{i} \beta_{n, i}^{+}\left(a_{l}\right)\right], \\
n & =1, \ldots, N ; \quad i=1, \ldots, L,
\end{aligned}
$$

$$
\begin{aligned}
\bar{m}_{H, i} & =\bar{m}_{i}(H)=1-\omega_{i}, i=1, \ldots, L, \\
\tilde{m}_{H, i} & =\tilde{m}_{i}(H) \in\left[\tilde{m}_{H, i}^{-}, \tilde{m}_{H, i}^{+}\right]=\left[\omega_{i} \beta_{H, i}^{-}\left(a_{l}\right), \omega_{i} \beta_{H, i}^{+}\left(a_{l}\right)\right], \\
i & =1, \ldots, L
\end{aligned}
$$

where $\sum_{n=1}^{N} m_{n, i}+\bar{m}_{H, i}+\tilde{m}_{H, i}=1$ for $i=1$ to $L$ and $\sum_{i=1}^{L} \omega_{i}=1$.

Next, from the nonlinear optimization models, the interval probability masses on $L$ basic attributes are aggregated and transformed into overall interval belief degrees for each $n, n=1, \ldots, N$ :

$\max / \min \quad \beta_{n}\left(a_{l}\right)=\frac{m_{n}}{1-\bar{m}_{H}}$

s.t.

$$
\begin{aligned}
& m_{n}=k\left[\prod_{i=1}^{L}\left(m_{n, i}+\bar{m}_{H, i}+\tilde{m}_{H, i}\right)-\prod_{i=1}^{L}\left(\bar{m}_{H, i}+\tilde{m}_{H, i}\right)\right], \\
& n=1, \ldots, N
\end{aligned}
$$

$\tilde{m}_{H}=k\left[\prod_{i=1}^{L}\left(\bar{m}_{H, i}+\tilde{m}_{H, i}\right)-\prod_{i=1}^{L} \bar{m}_{H, i}\right]$

$\bar{m}_{H}=k\left[\prod_{i=1}^{L} \bar{m}_{H, i}\right]$

$k=\left[\sum_{n=1}^{N} \prod_{i=1}^{L}\left(m_{n, i}+\bar{m}_{H, i}+\tilde{m}_{H, i}\right)-(N-1) \prod_{i=1}^{L}\left(\bar{m}_{H, i}+\tilde{m}_{H, i}\right)\right]^{-1}$

$m_{n, i}^{-} \leq m_{n, i} \leq m_{n, i}^{+}, \quad n=1, \ldots, N ; \quad i=1, \ldots, L$
$\bar{m}_{H, i}=1-\omega_{i}$ and $\tilde{m}_{H, i}^{-} \leq \tilde{m}_{H, i} \leq \tilde{m}_{H, i}^{+}, \quad i=1, \ldots, L$

$\sum_{n=1}^{N} m_{n, i}+\bar{m}_{H, i}+\tilde{m}_{H, i}=1, \quad i=1, \ldots, L$

where $\beta_{n}^{-}\left(a_{l}\right)$ and $\beta_{n}^{+}\left(a_{l}\right)$ are the optimal objective function values of the above nonlinear optimization model, which constitutes an overall interval belief degree $\left[\beta_{n}^{-}\left(a_{l}\right), \beta_{n}^{+}\left(a_{l}\right)\right]$. The aggregated assessment is denoted by $S\left(y\left(a_{l}\right)\right)=\left\{\left(H_{n},\left[\beta_{n}^{-}\left(a_{l}\right), \beta_{n}^{+}\left(a_{l}\right)\right]\right)\right\}, n=1, \ldots, N$. When $\beta_{H}\left(a_{l}\right)=\frac{\tilde{m}_{H}}{1-\bar{m}_{H}}$ is the objective function instead of $\beta_{n}\left(a_{l}\right)=\frac{m_{n}}{1-\bar{m}_{H}}$, we obtain the interval belief degree for $\beta_{H}\left(a_{l}\right)$, which can be written as $\left[\beta_{H}^{-}\left(a_{l}\right), \beta_{H}^{+}\left(a_{l}\right)\right]$.

\subsection{Classical TODIM method}

The classical TODIM is an MADM method proposed by Gomes and Lima (1992), based on prospect theory. The gist of the classical TODIM is to establish a dominance degree of each alternative over the other alternatives based on the value function of prospect theory.

The steps of the TODIM method are as follows.

Step 2.2.1 Normalize the decision matrix $D=\left[d_{i j}\right]_{n \times m}$ into matrix $R=\left[r_{i j}\right]_{n \times m}$.

Step 2.2.2 Compute the relative weight $\omega_{j r}$ of attribute $C_{j}$ to the reference attribute $C_{r}, \omega_{j r}=\omega_{j} / \omega_{r}$, where $\omega_{r}=\max \left\{\omega_{j} \mid j, r=1, \ldots, m\right\}$.

Step 2.2.3 The dominance degree $\varphi_{i q}^{j}$ of alternative $\tilde{A_{i}}$ over alternative $\tilde{A_{q}}$ for attribute $C_{j}$ is given by

$\varphi_{i q}^{j}=\left\{\begin{array}{cc}\sqrt{\frac{\left(r_{i j}-r_{q j}\right) \omega_{j r}}{\sum_{j=1}^{m} \omega_{j r}},} & r_{i j}-r_{q j}>0 \\ 0, & r_{i j}-r_{q j}=0 \\ -\frac{1}{\theta} \sqrt{\frac{\left(r_{q j}-r_{i j}\right) \sum_{j=1}^{m} \omega_{j r}}{\omega_{j r}},} & r_{i j}-r_{q j}<0\end{array}\right.$

where $\theta$ is the attenuation coefficient of the losses.

If $r_{i j}-r_{q j}>(<) 0$, then $r_{i j}-r_{q j}$ represents the gain (loss) of alternative $\tilde{A_{i}}$ over alternative $\tilde{A_{q}}$ for attribute $C_{j}$, respectively.

Step 2.2.4 The comprehensive dominance degree $\phi_{i q}$ of alternative $\tilde{A_{i}}$ over alternative $\tilde{A_{q}}$ is found from $\phi_{i q}=\sum_{j=1}^{m} \phi_{i q}^{j}(i, q=1, \ldots, n)$.

Step 2.2.5 The overall dominance value $\xi\left(\tilde{A_{i}}\right)$ of alternative $\tilde{A_{i}}$ is obtained using 
$\xi\left(\tilde{A_{i}}\right)=\frac{\sum_{q=1}^{m} \phi_{i q}-\min _{i}\left\{\sum_{q=1}^{m} \phi_{i q}\right\}}{\max _{i}\left\{\sum_{q=1}^{m} \phi_{i q}\right\}-\min _{i}\left\{\sum_{q=1}^{m} \phi_{i q}\right\}}$

Step 2.2.6 The rank order of the alternatives is formed using Eq. (19). The larger the $\xi\left(\tilde{A_{i}}\right)$ is, the better alternative $\tilde{A_{i}}$ will be.

\section{IVHF-TODIM method based on IER}

We now present an IVHF-TODIM method, which is different from the existing methods (Asan et al. 2018; Xue et al. 2019; Zhou et al. 2018; Zhang 2000), to address the EDM problem by including a DM's psychological behavior.

\subsection{Gain and loss functions based on geometric area method}

Using the geometric area method, the gain matrix and loss matrix of the interval belief degrees are set. Let $\beta_{r k}\left(A_{i}\right)=$ $\left[\beta_{r k}^{-}\left(A_{i}\right), \beta_{r k}^{+}\left(A_{i}\right)\right]$ be the aggregated result of decision alternative $A_{i}$, given that emergency state $Z_{k}$ has occurred concerning the evaluation level $m_{s}(s=1, \ldots, r)$ as obtained from Eqs. (10)-(17).

By aggregating the results of the alternatives, the gain (loss) matrix for each interval belief degree can be constructed by measuring the gain (loss) degree of one interval belief degree relative to another, respectively. To solve for the interval belief degrees, we need to clarify the positional relationship of these interval belief degrees (see Table 1).

Table 1 Positional relationship between $\beta_{r_{1} k}\left(A_{i}\right)$ and $\beta_{r_{2} k}\left(A_{j}\right)$

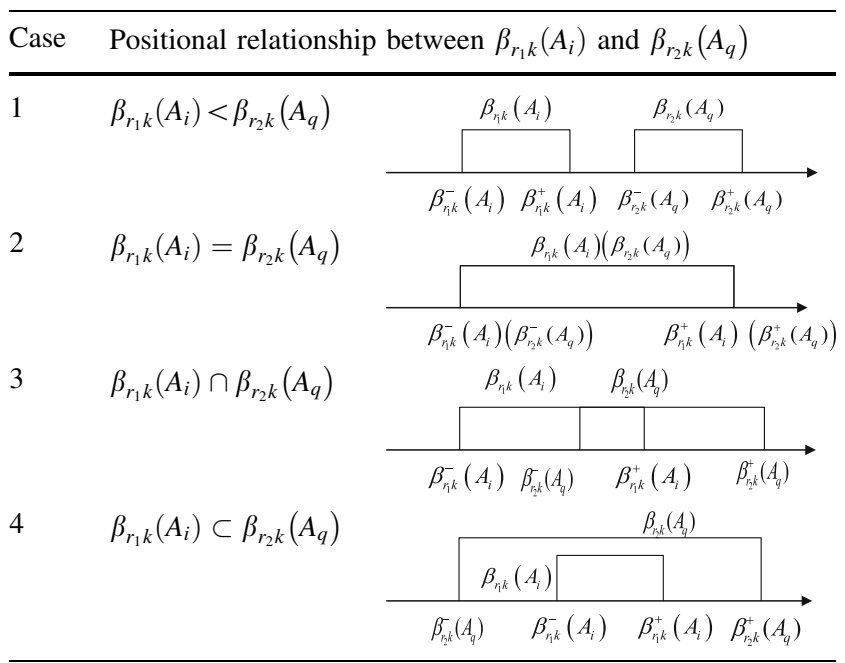

Definition 3. Suppose $\beta_{r_{1} k}\left(A_{i}\right)=\left[\beta_{r_{1} k}^{-}\left(A_{i}\right), \quad \beta_{r_{1} k}^{+}\left(A_{i}\right)\right]$ and $\beta_{r_{2} k}\left(A_{q}\right)=\left[\beta_{r_{2} k}^{-}\left(A_{q}\right), \quad \beta_{r_{2} k}^{+}\left(A_{q}\right)\right] \quad$ are arbitrary interval belief degrees, $S_{\beta_{r_{1} k}\left(A_{i}\right)}$ and $S_{\beta_{r_{2} k}\left(A_{q}\right)}$ denote the area of $\beta_{r_{1} k}\left(A_{i}\right)$ and $\beta_{r_{2} k}\left(A_{q}\right)$, respectively, and $S_{\beta_{r_{1} k}\left(A_{i}\right)}^{1}$ and $S_{\beta_{r_{2} k}\left(A_{q}\right)}^{2}$ denote the non-overlapping part that belongs to $\beta_{r_{1} k}\left(A_{i}\right)$ and $\beta_{r_{2} k}\left(A_{q}\right)$, respectively. Then, $S$ is the area of the intersection of two interval belief degrees. Let $g_{i q s}^{k}\left(l_{i q s}^{k}\right)$ and be the gain (loss) degree of decision alternative $A_{i}$ relative to $A_{q}$, given that emergency state $Z_{k}$ has occurred under evaluation level $m_{s}$, respectively. The gain (and loss) degree $g_{i q s}^{k}$ (and $l_{i q s}^{k}$ ) of $A_{i}$ relative to $A_{q}$, respectively, can be expressed as

$$
\begin{aligned}
& g_{i q s}^{k}\left(\beta_{r_{1} k}\left(A_{i}\right) \geq \beta_{r_{2} k}\left(A_{q}\right)\right)=\frac{1}{2}\left(\frac{S_{\beta_{r_{1} k}\left(A_{i}\right)}^{1}+S / 2}{S_{\beta_{r_{1} k}\left(A_{i}\right)}}+\frac{S_{\beta_{r_{2} k}\left(A_{q}\right)}^{2}+S / 2}{S_{\beta_{r_{2} k}\left(A_{q}\right)}}\right) \\
& l_{i q s}^{k}\left(\beta_{r_{1} k}\left(A_{i}\right)<\beta_{r_{2} k}\left(A_{q}\right)\right)=1-g_{i q s}^{k}\left(\beta_{r_{1} k}\left(A_{i}\right) \geq \beta_{r_{2} k}\left(A_{q}\right)\right)
\end{aligned}
$$

The areas of $S_{\beta_{r_{1} k}\left(A_{i}\right)}, S_{\beta_{r_{2} k}\left(A_{q}\right)}, S_{\beta_{r_{1} k}\left(A_{i}\right)}^{1}, S_{\beta_{r_{2} k}\left(A_{q}\right)}^{2}$, and $S$ are denoted by the probability density function $f(x)$. Next, we use the following definition.

Definition 3 Fan and Liu 2010). Let $x$ be a variable in the interval belief degree $\beta_{r k}\left(A_{i}\right)=\left[\beta_{r k}^{-}\left(A_{i}\right), \beta_{r k}^{+}\left(A_{i}\right)\right]$, $\beta_{r k}^{-}\left(A_{i}\right) \leq x \leq \beta_{r k}^{+}\left(A_{i}\right)$. The probability density function of $x$ is stated as:

$f(x)=\left\{\begin{array}{cl}\frac{1}{b-a}, & a \leq x \leq b, \\ 0, & \text { otherwise }\end{array}\right.$

where $\int_{a}^{b} f(x)=1$ and $f(x) \geq 0$ for all $x \in[a, b]$.

Table 2 contains the expressions used to obtain the gains and losses for the interval belief degrees for the cases stated in Table 1. The steps are detailed in "Appendix".

Based on the gain (and loss) degree of alternative $A_{i}$ to $A_{q}$, the gain matrix $g_{s}^{k}=\left[g_{i q s}^{k}\right]_{n \times n}$ and loss matrix $l_{s}^{k}=\left[l_{i q s}^{k}\right]_{n \times n}$, given that emergency state $Z_{k}$ has occurred under evaluation level $m_{s}$ is thus 
Table 2 Gains and losses for all possible cases

\begin{tabular}{|c|c|c|c|}
\hline Case & & Gain $g_{i q s}^{k}$ & Loss $l_{i q s}^{k}$ \\
\hline 1 & $\beta_{r_{1} k}\left(A_{i}\right)<\beta_{r_{2} k}\left(A_{q}\right)$ & 0 & 1 \\
\hline 2 & $\beta_{r_{1} k}\left(A_{i}\right)=\beta_{r_{2} k}\left(A_{q}\right)$ & $\frac{1}{2}$ & $\frac{1}{2}$ \\
\hline 3 & $\beta_{r_{1} k}\left(A_{i}\right) \cap \beta_{r_{2} k}\left(A_{q}\right)$ & $g_{i q s}^{k}=\frac{1}{2}\left(\frac{\beta_{r_{2}}^{-}\left(A_{q}\right)-\beta_{r_{k}}^{-}\left(A_{i}\right)}{\beta_{r_{1}}^{+}\left(A_{i}\right)-\beta_{r_{1} k}^{-}\left(A_{i}\right)}\right)+\frac{1}{2}$ & $l_{i q s}^{k}=\frac{1}{2}-\frac{1}{2}\left(\frac{\beta_{r_{2} k}^{-}\left(A_{q}\right)-\beta_{r_{k}}^{-}\left(A_{i}\right)}{\beta_{r_{1} k}^{+}\left(A_{i}\right)-\beta_{r_{1} k}^{-}\left(A_{i}\right)}\right)$ \\
\hline 4 & $\beta_{r_{1} k}\left(A_{i}\right) \subset \beta_{r_{2} k}\left(A_{q}\right)$ & $g_{i q s}^{k}=\frac{3}{4}-\frac{1}{4}\left(\frac{\beta_{r_{k}}^{+}\left(A_{i}\right)-\beta_{r_{k} k}^{-}\left(A_{i}\right)}{\beta_{r^{\prime}}^{+}\left(A_{q}\right)-\beta_{r^{k} k}^{+}\left(A_{q}\right)}\right)$ & $l_{i q s}^{k}=\frac{1}{4}+\frac{1}{4}\left(\frac{\beta_{r^{\prime} k}^{+}\left(A_{i}\right)-\beta_{r_{1} k}^{-}\left(A_{i}\right)}{\beta_{r_{2}}^{+}\left(A_{q}\right)-\beta_{r^{k} k}^{-}\left(A_{q}\right)}\right)$ \\
\hline
\end{tabular}

$\varphi_{i q s}^{k}=\left\{\begin{array}{cc}\varphi_{i q s}^{k(+)}=\sqrt{\left(\bar{g}_{i q s}^{k}\right)^{\alpha}}, & \beta_{r_{1} k}\left(A_{i}\right) \geq \beta_{r_{2} k}\left(A_{q}\right) \\ \varphi_{i q s}^{k(-)}=-\frac{1}{\theta} \sqrt{-\lambda\left(-\bar{l}_{i q s}^{k}\right)^{\beta}}, & \beta_{r_{1} k}\left(A_{i}\right)<\beta_{r_{2} k}\left(A_{q}\right)\end{array}\right.$

$$
\begin{aligned}
& \begin{array}{llll}
A_{1} & A_{2} & \ldots & A_{n}
\end{array} \\
& l_{s}^{k}=\begin{array}{c}
A_{1} \\
A_{2} \\
\vdots \\
A_{n}
\end{array}\left[\begin{array}{cccc}
l_{11 s}^{k} & l_{12 s}^{k} & \cdots & l_{1 n s}^{k} \\
l_{21 s}^{k} & l_{22 s}^{k} & \cdots & l_{2 n s}^{k} \\
\vdots & \vdots & \vdots & \vdots \\
l_{n 1 s}^{k} & l_{n 2 s}^{k} & \cdots & l_{n n s}^{k}
\end{array}\right], \quad k=1, \ldots, t ; s=1, \ldots, r
\end{aligned}
$$

where $g_{\text {iis }}^{k}=l_{i i s}^{k}=0$ for all $i \in N$.

To facilitate analysis and computation, it is necessary to normalize the gain and loss matrices. Therefore, the terms $\bar{g}_{i q s}^{k}$ and $\bar{l}_{i q s}^{k}$ can be obtained from

$\bar{g}_{i q s}^{k}=\frac{g_{i q s}^{k}}{g_{k s}^{\max }}, \quad i, q=1, \ldots, n ; \quad k=1, \ldots, t ; \quad s=1, \ldots r$

$$
\bar{l}_{i q s}^{k}=\frac{l_{i q s}^{k}}{l_{k s}^{\max }}, \quad i, q=1, \ldots, n ; \quad k=1, \ldots t ; \quad s=1, \ldots r
$$

\subsection{Dominance degree matrix}

Prior studies assume that the DMs are often bounded rational under risk and uncertainty, and their behavior influences the decision-making process. We extend prospect theory to find the relative gains and losses of two alternatives under the evaluation level, to better reflect reality. The dominance degree is obtained as where $\alpha$ and $\beta$ are the power parameters related to the gains and losses, and $\alpha$ is a concave degree parameter related to gains, and $\beta$ is convex degree parameter related to losses, respectively; $\lambda$ denotes the risk-aversion parameter, $0 \leq \alpha, \beta \leq 1, \lambda>1$, and $\theta$ is an attenuation factor of the loss. If $\theta>(<) 1$, then the influence of loss will decrease (increase). In this paper, $\theta=1$. Following from previous studies such as Tversky and Kahneman (1992) who used $\alpha=0.89, \beta=0.92 \lambda=2.25$; Abdellaoui et al. (2007) applied $\alpha=0.725, \beta=0.717, \lambda=2.04$; Liu et al. (2014) used $\alpha=0.85, \beta=0.85, \lambda=4.1$. In this paper, we choose the parameter values of Simon (1955).

\subsection{Comprehensive dominance value}

Furthermore, the overall dominance degree of alternative $A_{i}$ over alternative $A_{q}$, given that emergency state $Z_{k}$ has occurred, is expressed by

$\Phi_{i q}^{k}=\sum_{s=1}^{r} \varphi_{i q s}^{k(+)}+\sum_{s=1}^{r} \varphi_{i q s}^{k(-)}$

Thus, the comprehensive dominance degree matrix is as follows

$$
\begin{aligned}
& \begin{array}{llll}
A_{1} & A_{2} & \ldots & A_{n}
\end{array} \\
& \Phi_{k}=\left[\Phi_{i q}^{k}\right]_{n \times n}=\begin{array}{c}
A_{1} \\
A_{2} \\
\vdots \\
A_{n}
\end{array}\left[\begin{array}{cccc}
\Phi_{11}^{k} & \Phi_{12}^{k} & \cdots & \Phi_{1 n}^{k} \\
\Phi_{21}^{k} & \Phi_{22}^{k} & \cdots & \Phi_{2 n}^{k} \\
\vdots & \vdots & \vdots & \vdots \\
\Phi_{n 1}^{k} & \Phi_{n 2}^{k} & \cdots & \Phi_{n n}^{k}
\end{array}\right], \quad k=1, \ldots, t .
\end{aligned}
$$

According to $\Phi_{k}$, the comprehensive dominance value of alternative $A_{i}$ over alternative $A_{q}$, given that emergency state $Z_{k}$ has occurred, is expressed by 
$\xi^{k}\left(A_{i}\right)=\frac{\psi^{k}\left(A_{i}\right)-\min _{i \in N}\left\{\psi^{k}\left(A_{i}\right)\right\}}{\max _{i \in N}\left\{\psi^{k}\left(A_{i}\right)\right\}-\min _{i \in N}\left\{\psi^{k}\left(A_{i}\right)\right\}}, \quad i \in N$.

where $\psi^{k}\left(A_{i}\right)=\sum_{q=1}^{n} \Phi_{i q}^{k}$.

To facilitate the solution, the following algorithm is proposed.

Step 1 Establish the framework for assessing the EDM.

Step 2 The DMs provide individual preference information on the decision alternatives.

Step 3 Aggregate the various evaluation information from the DMs using the IVHF-weighted geometric (IVHFWG) operator in Chen et al. 2013.

Step 4 Aggregate the evaluation level information from the decision alternatives using Eqs. (2)-(17).

Step 4.1 Obtain the interval belief degrees using Eqs. (2)-(6).

Step 4.2 Convert the interval belief degrees into interval probability masses using Eqs. (7)-(9).

Step 4.3 Aggregate and transform the interval probability masses into the overall interval belief degrees using Eqs. (10)-(17).

Step 5 Obtain the gains and losses using Tables 1 and 2. Step 6 Obtain the dominance degree matrix using Eq. (27).

Step 7 Find the overall dominance degree for ranking the decision alternatives using Eqs. (28)-(30).

\section{Numerical example and comparison}

To validate the proposed method, we provide an example of selecting an emergency decision alternative for a massive bushfire. Then, we perform a comparative analysis to illustrate the novelty and superiority of our method compared to some existing methods.

\subsection{Emergency decision making for large bushfire}

A massive regional bushfire has occurred in summer, threatening the lives and properties of many people and native animals in the vicinity. A certain highway is labelled as the line of containment to control the spread of the bushfire. Because of the dry and unpredictable wind conditions, the fire can transition to three states: (1) the fire spreads to the highway and onto the city; (2) the fire engulfs the farms and homes in the vicinity; (3) heavy rain occurs in the vicinity, which can douse the fire. To obtain the evaluation information of this large bushfire, this paper adopts the methods of expert surveys and questionnaires to obtain the decision alternatives and attribute values. The expert panel consists of three stakeholder groups. Stakeholder group $D_{1}$ comprises experts from regional government, stakeholder group $D_{2}$ is composed of the experts from resident communities, and stakeholder group $D_{3}$ comprises the experts from the regional firefighting services. In this paper, the role of the expert panel is to evaluate the qualitative evaluation attributes of each crisis solution alternative and provide the evaluation values in the form of an IVHFS for a better selection of the optimal choices to solve the bushfire crisis. Three emergency decision alternatives $A=\left\{A_{1}, A_{2}, A_{3}\right\}$ are given by three stakeholder groups for each state, namely

$A_{1}$ : Close the highway completely, launch large-scale firefighting to contain the fire;

$A_{2}$ : Close the highway partially, introduce controlled firefighting to contain the fire, and evacuate people and animals using what is left of the highway;

$A_{3}$ : Leave the highway open, continue to fight the fire using the region's emergency fire services, and send out fire advisories to the residents in the vicinity to be on the alert.

Each decision alternative has five attributes $C=\left\{C_{1}, C_{2}, C_{3}, C_{4}, C_{5}\right\}$, with $C_{1}$ : spread of the fire, $C_{2}$ : weather, $C_{3}$ : size of the bushland, $C_{4}$ : topography, and $C_{5}$ : social condition. The weights of the DMs are assigned a priori as $W_{E}=\{0.2722,0.2561,0.4717\}$. The DMs express their evaluations using the IVHFS found in Tables 3, 4, and 5. Table 6 shows the assessment level for each attribute, as revised by the DMs.

Using the weight vector $W_{E}$, the overall information is obtained by aggregating the evaluation information from the experts using the IVHFWG operator in Chen et al. (2013) (see Table 7). For example, the value of alternative $A_{1}$ in state $Z_{1}$ with respect to attribute $C_{1}$ is obtained as: $0.8 \wedge 0.2722 \times 0.7 \wedge 0.2561 \times 0.6 \wedge 0.4717 \approx 0.68$, $0.9 \wedge 0.2722 \times 0.8 \wedge 0.2561 \times 0.7 \wedge 0.4717 \approx 0.78$.

Suppose the attribute weights are $\left(\omega_{1}, \omega_{2}, \omega_{3}, \omega_{4}\right.$, $\left.\omega_{5}\right)^{\mathrm{T}}=(0.274,0.077,0.075,0.281,0.293)^{\mathrm{T}}$. Aggregate the evaluation level information from the decision alternatives using Eqs. (5)-(12) as follows:

First, aggregate IVHF numbers as interval-valued numbers (IVNs) for the three states, as shown in Tables 8 , 9, and 10 (e.g., the value of alternative $A_{1}$ in state $Z_{1}$ with respect to attribute $C_{1}$ is obtained as $0.68 \wedge 0.27 \times 0.28 \wedge 0.27=0.63)$ :

Using Step 4.1, the interval belief degrees can be obtained as Tables 11, 12, and 13, with the help of Table 6 . For instance, take the interval belief degree of $A_{1}$ under state $Z_{1}$ with respect to $C_{1}$. The evaluation value of $C_{1} A_{1}$ after aggregating is an interval value [0.63, 0.72], which 
Table 3 Decision matrix from DMs under state $Z_{1}$

\begin{tabular}{|c|c|c|c|c|c|c|}
\hline \multirow[t]{2}{*}{ Alternative } & \multirow[t]{2}{*}{$\mathrm{DM}$} & \multicolumn{5}{|l|}{ Attribute } \\
\hline & & $C_{1}$ & $C_{2}$ & $C_{3}$ & $C_{4}$ & $C_{5}$ \\
\hline \multirow[t]{3}{*}{$A_{1}$} & $D_{1}$ & $\{[0.8,0.9],[0.1,0.2]\}$ & $\{[0.8,0.9],[0.1,0.2]\}$ & $\{[0.3,0.4],[0.6,0.7]\}$ & $\{[0.3,0.4],[0.6,0.7]\}$ & $\{[0.8,0.9],[0.1,0.2]\}$ \\
\hline & $D_{2}$ & $\{[0.7,0.8]\}$ & $\{[0.3,0.4],[0.6,0.7]\}$ & $\{[0.5,0.6],[0.4,0.5]\}$ & $\{[0.6,0.7]\}$ & $\{[0.3,0.4],[0.6,0.7]\}$ \\
\hline & $D_{3}$ & $\{[0.6,0.7],[0.3,0.4]\}$ & $\{[0.2,0.3]\}$ & $\{[0.3,0.4]\}$ & $\{[0.6,0.7],[0.3,0.4]\}$ & $\{[0.3,0.4],[0.6,0.7]\}$ \\
\hline \multirow[t]{3}{*}{$A_{2}$} & $D_{1}$ & $\{[0.2,0.3],[0.7,0.8]\}$ & $\{[0.5,0.6],[0.4,0.5]\}$ & $\{[0.7,0.8],[0.2,0.3]\}$ & $\{[0.7,0.8],[0.2,0.3]\}$ & $\{[0.7,0.8],[0.2,0.3]\}$ \\
\hline & $D_{2}$ & $\{[0.8,0.9],[0.1,0.2]\}$ & $\{[0.8,0.9]\}$ & $\{[0.3,0.4],[0.6,0.7]\}$ & $\{[0.2,0.3],[0.7,0.8]\}$ & $\{[0.8,0.9],[0.1,0.2]\}$ \\
\hline & $D_{3}$ & $\{[0.6,0.7]\}$ & $\{[0.3,0.4],[0.6,0.7]\}$ & $\{[0.3,0.4],[0.6,0.7]\}$ & $\{[0.7,0.8],[0.2,0.3]\}$ & $\{[0.7,0.8]\}$ \\
\hline \multirow[t]{3}{*}{$A_{3}$} & $D_{1}$ & $\{[0.8,0.9],[0.1,0.2]\}$ & $\{[0.2,0.3],[0.7,0.8]\}$ & $\{[0.6,0.7]\}$ & $\{[0.6,0.7],[0.3,0.4]\}$ & $\{[0.2,0.3],[0.7,0.8]\}$ \\
\hline & $D_{2}$ & $\{[0.1,0.2],[0.8,0.9]\}$ & $\{[0.3,0.4],[0.6,0.7]\}$ & $\{[0.7,0.8],[0.2,0.3]\}$ & $\{[0.8,0.9],[0.1,0.2]\}$ & $\{[0.8,0.9]\}$ \\
\hline & $D_{3}$ & $\{[0.7,0.8],[0.2,0.3]\}$ & $\{[0.8,0.9],[0.1,0.2]\}$ & $\{[0.6,0.7],[0.3,0.4]\}$ & $\{[0.5,0.7]\}$ & $\{[0.6,0.7],[0.3,0.4]\}$ \\
\hline
\end{tabular}

Table 4 Decision matrix for DMs under state $Z_{2}$

\begin{tabular}{lllllll}
\hline Alternative & DM & Attribute & & & \\
\cline { 3 - 6 } & & $C_{1}$ & $C_{2}$ & $C_{3}$ & $C_{4}$ & $C_{5}$ \\
\hline$A_{1}$ & $D_{1}$ & $\{[0.2,0.3][0.7,0.8]\}$ & $\{[0.5,0.6],[0.4,0.5]\}$ & $\{[0.7,0.8],[0.2,0.3]\}$ & $\{[0.7,0.8],[0.2,0.3]\}$ & $\{[0.7,0.8],[0.2,0.3]\}$ \\
& $D_{2}$ & $\{[0.8,0.9],[0.1,0.2]\}$ & $\{[0.8,0.9]\}$ & $\{[0.3,0.4],[0.6,0.7]\}$ & $\{[0.2,0.3],[0.7,0.8]\}$ & $\{[0.8,0.9],[0.1,0.2]\}$ \\
& $D_{3}$ & $\{[0.6,0.7]\}$ & $\{[0.3,0.4][0.6,0.7]\}$ & $\{[0.3,0.4],[0.6,0.7]\}$ & $\{[0.7,0.8],[0.2,0.3]\}$ & $\{[0.7,0.8]\}$ \\
$A_{2}$ & $D_{1}$ & $\{[0.8,0.9],[0.1,0.2]\}$ & $\{[0.2,0.3],[0.7,0.8]\}$ & $\{[0.6,0.7]\}$ & $\{[0.6,0.7],[0.3,0.4]\}$ & $\{[0.2,0.3],[0.7,0.8]\}$ \\
& $D_{2}$ & $\{[0.1,0.2],[0.8,0.9]\}$ & $\{[0.3,0.4],[0.6,0.7]\}$ & $\{[0.7,0.8],[0.2,0.3]\}$ & $\{[0.8,0.9],[0.1,0.2]\}$ & $\{[0.8,0.9]\}$ \\
& $D_{3}$ & $\{[0.7,0.8],[0.2,0.3]\}$ & $\{[0.8,0.9],[0.1,0.2]\}$ & $\{[0.6,0.7],[0.3,0.4]\}$ & $\{[0.5,0.7]\}$ & $\{[0.6,0.7],[0.3,0.4]\}$ \\
$A_{3}$ & $D_{1}$ & $\{[0.8,0.9],[0.1,0.2]\}$ & $\{[0.8,0.9],[0.1,0.2]\}$ & $\{[0.3,0.4][0.6,0.7]\}$ & $\{[0.3,0.4][0.6,0.7]\}$ & $\{[0.8,0.9],[0.1,0.2]\}$ \\
& $D_{2}$ & $\{[0.7,0.8]\}$ & $\{[0.3,0.4],[0.6,0.7]\}$ & $\{[0.5,0.6],[0.4,0.5]\}$ & $\{[0.6,0.7]\}$ & $\{[0.3,0.4],[0.6,0.7]\}$ \\
& $D_{3}$ & $\{[0.6,0.7],[0.3,0.4]\}$ & $\{[0.2,0.3]\}$ & $\{[0.3,0.4]\}$ & $\{[0.6,0.7],[0.3,0.4]\}$ & $\{[0.3,0.4],[0.6,0.7]\}$ \\
& & & & & &
\end{tabular}

Table 5 Decision matrix for DMs under state $Z_{3}$

\begin{tabular}{lllllll}
\hline Alternative & DM & Attribute & & & \\
\cline { 3 - 6 } & & $C_{1}$ & $C_{2}$ & $C_{3}$ & $C_{4}$ & $C_{5}$ \\
\hline$A_{1}$ & $D_{1}$ & $\{[0.8,0.9]\}$ & $\{[0.7,0.8],[0.2,0.3]\}$ & $\{[0.3,0.4]\}$ & $\{[0.3,0.4],[0.6,0.7]\}$ & $\{[0.6,0.7],[0.3,0.4]\}$ \\
& $D_{2}$ & $\{[0.6,0.7],[0.3,0.4]\}$ & $\{[0.3,0.4],[0.6,0.7]\}$ & $\{[0.6,0.7],[0.3,0.4]\}$ & $\{[0.7,0.8],[0.2,0.3]\}$ & $\{[0.3,0.4],[0.6,0.7]\}$ \\
& $D_{3}$ & $\{[0.3,0.4],[0.6,0.7]\}$ & $\{[0.3,0.4]\}$ & $\{[0.3,0.4],[0.6,0.7]\}$ & $\{[0.3,0.4],[0.6,0.7]\}$ & $\{[0.3,0.4],[0.6,0.7]\}$ \\
$A_{2}$ & $D_{1}$ & $\{[0.8,0.9],[0.1,0.2]\}$ & $\{[0.8,0.9],[0.1,0.2]\}$ & $\{[0.3,0.4],[0.6,0.7]\}$ & $\{[0.3,0.4],[0.6,0.7]\}$ & $\{[0.8,0.9],[0.1,0.2]\}$ \\
& $D_{2}$ & $\{[0.7,0.8]\}$ & $\{[0.3,0.4],[0.6,0.7]\}$ & $\{[0.5,0.6][0.4,0.5]\}$ & $\{[0.6,0.7]\}$ & $\{[0.3,0.4],[0.6,0.7]\}$ \\
& $D_{3}$ & $\{[0.6,0.7],[0.3,0.4]\}$ & $\{[0.2,0.3]\}$ & $\{[0.3,0.4]\}$ & $\{[0.6,0.7],[0.3,0.4]\}$ & $\{[0.3,0.4],[0.6,0.7]\}$ \\
$A_{3}$ & $D_{1}$ & $\{[0.2,0.3],[0.7,0.8]\}$ & $\{[0.5,0.6],[0.4,0.5]\}$ & $\{[0.7,0.8],[0.2,0.3]\}$ & $\{[0.7,0.8],[0.2,0.3]\}$ & $\{[0.7,0.8],[0.2,0.3]\}$ \\
& $D_{2}$ & $\{[0.8,0.9],[0.1,0.2]\}$ & $\{[0.8,0.9]\}$ & $\{[0.3,0.4],[0.6,0.7]\}$ & $\{[0.2,0.3],[0.7,0.8]\}$ & $\{[0.8,0.9],[0.1,0.2]\}$ \\
& $D_{3}$ & $\{[0.6,0.7]\}$ & $\{[0.3,0.4],[0.6,0.7]\}$ & $\{[0.3,0.4],[0.6,0.7]\}$ & $\{[0.7,0.8],[0.2,0.3]\}$ & $\{[0.7,0.8]\}$ \\
\hline
\end{tabular}


Table 6 Assessment level for attribute $C_{j}$

\begin{tabular}{llllll}
\hline Assessment level & Poor $(\mathrm{P})$ & Average $(\mathrm{A})$ & Good $(\mathrm{G})$ & Very Good $(\mathrm{V})$ & Excellent $(\mathrm{E})$ \\
\hline$C_{1}$ & 0 & 0.4 & 0.6 & 0.8 & 1.0 \\
$C_{2}$ & 0.2 & 0.4 & 0.6 & 0.8 & 1.0 \\
$C_{3}$ & 0.1 & 0.3 & 0.5 & 0.7 & 0.9 \\
$C_{4}$ & 0.3 & 0.5 & 0.7 & 0.9 & 1.0 \\
$C_{5}$ & 0 & 0.2 & 0.4 & 0.6 & 0.8 \\
\hline
\end{tabular}

lies between assessment levels $\mathrm{G}$ and $\mathrm{V}$. The interval belief degrees, on which $C_{1} A_{1}$ is assessed to lie between $\mathrm{G}$ and $\mathrm{V}$, can be found as follows:

$$
\begin{aligned}
\beta_{3,1}^{-}\left(A_{1}\right) & =\frac{0.8-0.72}{0.8-0.6}=0.38 \text { and } \beta_{3,1}^{+}\left(A_{1}\right)=\frac{0.8-0.63}{0.8-0.6} \\
& =0.84 \\
\beta_{4,1}^{-}\left(A_{1}\right) & =\frac{0.63-0.6}{0.8-0.6}=0.16 \text { and } \beta_{4,1}^{+}\left(A_{1}\right)=\frac{0.72-0.6}{0.8-0.6}=0.62
\end{aligned}
$$

Therefore, $C_{1} A_{1}$ under state $Z_{1}$ can be modeled by using an interval belief structure as $\{(\mathrm{G},[0.38,0.84]),(\mathrm{V},[0.16$, $0.62])\}$.

Next, using Step 4.2, convert the interval belief degrees to interval probability masses using Eqs. (7)-(9). For instance, for $C_{1} A_{1}$ under state $Z_{1}$, we have

$$
\begin{aligned}
& m_{1,1}=m_{2,1}=m_{5,1}=0 \\
& m_{3,1}=\left[m_{3,1}^{-}, m_{3,1}^{+}\right]=\omega_{1} \times\left[\beta_{3,1}^{-}, \beta_{3,1}^{+}\right] \\
& =0.274 \times[0.38,0.84]=[0.105,0.231] \\
& m_{4,1}=\left[m_{4,1}^{-}, m_{4,1}^{+}\right]=\omega_{1} \times\left[\beta_{4,1}^{-}, \beta_{4,1}^{+}\right] \\
& =0.274 \times[0.16,0.62]=[0.043,0.169] \\
& \bar{m}_{H, 1}=\bar{m}_{1}(H)=1-\omega_{1}=1-0.27=0.73 \\
& \tilde{m}_{H, 1}=\tilde{m}_{1}(H) \in\left[\tilde{m}_{H, 1}^{-}, \tilde{m}_{H, 1}^{+}\right]=\left[\omega_{1} \beta_{H, 1}^{-}\left(a_{l}\right), \omega_{1} \beta_{H, 1}^{+}\left(a_{l}\right)\right] \\
& =[0.27 \times 0,0.27 \times 0.46]=[0,0.13] \\
& \left\{\begin{array}{l}
\beta_{H, 1}^{-}\left(a_{l}\right)=\max \left(0,1-\sum_{n=1}^{N} \beta_{n, 1}^{+}\left(a_{l}\right)\right)=\max (0,1-0.84-0.62)=0 \\
\beta_{H, i}^{+}\left(a_{l}\right)=1-\sum_{n=1}^{N} \beta_{n, i}^{-}\left(a_{l}\right)=1-0.38-0.16=0.46
\end{array}\right.
\end{aligned}
$$

Using Step 4.3, aggregate and transform the interval probability masses to the overall interval belief degrees using Eqs. (10)-(17). Table 14 shows the aggregated interval-valued distribution assessment for each alternative.

Based on the positional relationship between each of the interval belief degrees shown in Table 1, the gains and losses can be computed according to Tables 1 and 2 . In the interest of space, we will list only the results of $Z_{1}$ as shown in Table 15.
The dominance value of alternative $A_{i}$ over alternative $A_{q}$, given that state $Z_{k}$ occurs for attribute $C_{j}$ can be obtained from Eq. (27) (see Table 16).

The overall dominance degree is found from Eqs. (28)(30), and Table 17 shows the ranking.

From Table 17, it is apparent that the decision alternatives are state dependent. The optimal decision alternatives for states $Z_{1}, Z_{2}$, and $Z_{3}$ are $A_{1}, A_{3}$, and $A_{2}$, respectively. Clearly, as the bushfire is highly dependent on the realization of the states which can change rapidly over time, it is preferable to offer a suite of "good" solutions for the DMs to consider rather than to point to a single "optimal" solution as suggested by the extant literature. Flexibility during an emergency response to mega disasters is needed especially when dealing with the capriciousness of such states as the recent incident of emergency events in many actual life-threatening bushfires, e.g., China and Australia have testified. The outcome of this numerical example validates the proposed method.

\subsection{Comparison analysis}

To highlight the effectiveness of the proposed method, this section compares the proposed method with two existing methods, namely

(1) The proposed method is compared with a groupbased method based on prospect theory (Wang et al. 2017), which excludes the dynamic factors.

(2) The proposed approach is compared with a distancebased group decision-making method (Yu and Lai 2011), which ignores the psychological behavior of the DMs.

Table 18 provides the rankings of the three emergency alternatives based on the three states.

From Table 18, when the proposed method is compared against the group method based on prospect theory (Wang et al. 2017) and with a distance-based group decisionmaking method (Yu and Lai 2011), there is a difference in the outcomes. There are some reasons for this difference:

(1) The group-based method, based on prospect theory (Wang et al. 2017), does not take into account the 


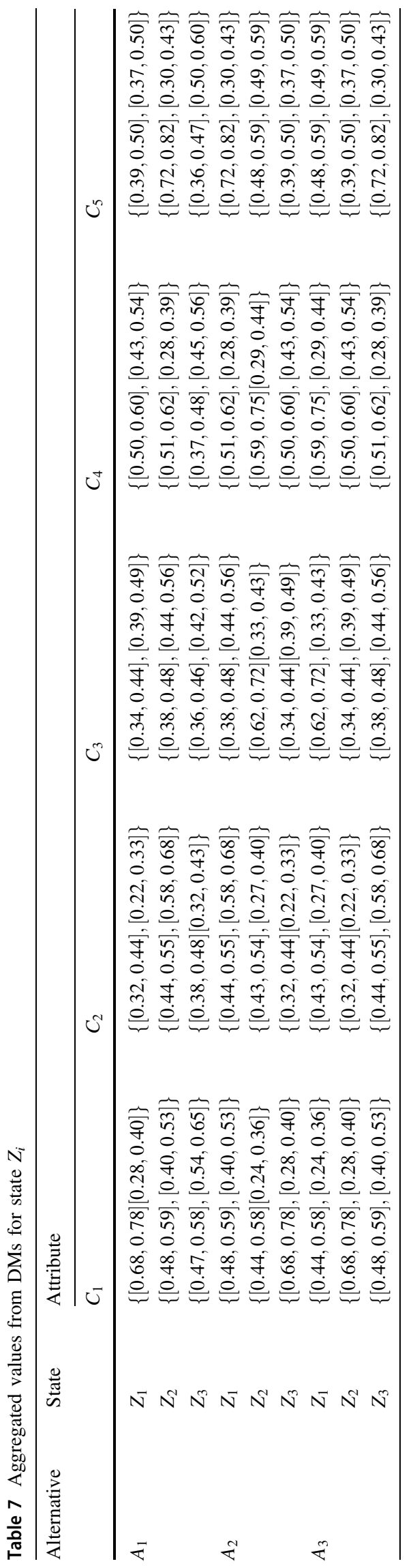

nature of emergency events. In reality, emergency decisions should be dynamically adjusted to improve the emergency response levels as bushfire emergencies can rapidly transition between states in a short time window of hours, as more information from the field is collected in that time. So, decision making must reflect that nuance of the bushfire situation felt by the DMs. From Table 18, the optimal decision alternative changes with state $Z_{i}$ as the assessment levels vary. Therefore, the dynamic evolution of the emergencies must be captured during the emergency decision-making process. This is the main benefit of using the proposed method in dynamic emergency decision making.

(2) The method in Yu and Lai 2011 focuses on exact values to make a fair comparison, lower bound, average point, upper bound of the interval values, which are aggregated from the interval-valued fuzzy hesitant numbers, to compute the rankings. It is thus important to note that the DMs exercised bounded rationality even in the context of risk and uncertainty. However, in extreme emergency response situations such as large bushfires, some DMs, for one reason or another, may be guided by their psychological behavior. However, the method in Yu and Lai 2011 ignores the psychological behavior of the DMs. What we have shown through this example is that ignoring the behavior of the DMs (e.g., sudden and untimely death of the firefighters during an emergency response) can lead to the wrong ranking results and hence an inferior final decision selection.

From the analysis, the proposed approach can offer several benefits, namely:

(1) By using an IVHF set, the proposed method can better reflect the uncertainty of the DMs on the evaluation information. This is especially helpful for emergency decision-making problems characterized by incomplete information, uncertainty, and limited expertise.

(2) The proposed method takes full account of the dynamics of the emergency events; the optimal choice can be adjusted dynamically based on the state. In this way, the DMs can exercise realistic judgement calls and improve the applicability of the proposed method.

(3) The IVHF-TODIM method accommodates the DM's psychological behavior in the context of risk and uncertainty for a large-scale emergency response situation and hence is better calibrated to accommodate the qualitative attributes of the DMs. 
Table 8 Aggregated IVHFNs into IVNs under state $Z_{1}$

\begin{tabular}{llllll}
\hline Alternative & $Z_{1}$ & \multicolumn{4}{l}{ Attribute } \\
\cline { 2 - 6 } & $C_{1}$ & $C_{2}$ & $C_{3}$ & $C_{4}$ & $C_{5}$ \\
\hline$A_{1}$ & {$[0.63,0.72]$} & {$[0.82,0.86]$} & {$[0.86,0.89]$} & {$[0.65,0.73]$} & {$[0.57,0.66]$} \\
$A_{2}$ & {$[0.63,0.73]$} & {$[0.90,0.93]$} & {$[0.88,0.91]$} & {$[0.58,0.67]$} & {$[0.64,0.74]$} \\
$A_{3}$ & {$[0.54,0.65]$} & {$[0.85,0.89]$} & {$[0.89,0.92]$} & {$[0.61,0.73]$} & {$[0.65,0.74]$} \\
\hline
\end{tabular}

Table 9 Aggregated IVHFNs into IVNs under state $Z_{2}$

\begin{tabular}{llllll}
\hline Alternative & $Z_{2}$ & \multicolumn{5}{l}{ Attribute } & & & \\
\cline { 2 - 6 } & $C_{1}$ & $C_{2}$ & $C_{3}$ & $C_{4}$ & $C_{5}$ \\
\hline$A_{1}$ & {$[0.63,0.73]$} & {$[0.90,0.93]$} & {$[0.88,0.91]$} & {$[0.58,0.67]$} & {$[0.64,0.74]$} \\
$A_{2}$ & {$[0.54,0.65]$} & {$[0.85,0.89]$} & {$[0.89,0.92]$} & {$[0.61,0.73]$} & {$[0.65,0.74]$} \\
$A_{3}$ & {$[0.63,0.72]$} & {$[0.82,0.86]$} & {$[0.86,0.89]$} & {$[0.65,0.73]$} & {$[0.57,0.66]$} \\
\hline
\end{tabular}

Table 10 Aggregated IVHFNs into IVNs under state $Z_{3}$

\begin{tabular}{llllll}
\hline Alternative & $Z_{3}$ & \multicolumn{5}{l}{ Attribute } & & & \\
\cline { 2 - 6 } & $C_{1}$ & $C_{2}$ & $C_{3}$ & $C_{4}$ & $C_{5}$ \\
\hline$A_{1}$ & {$[0.69,0.76]$} & {$[0.85,0.89]$} & {$[0.87,0.90]$} & {$[0.61,0.69]$} & {$[0.60,0.69]$} \\
$A_{2}$ & {$[0.63,0.72]$} & {$[0.82,0.86]$} & {$[0.86,0.89]$} & {$[0.65,0.73]$} & {$[0.57,0.66]$} \\
$A_{3}$ & {$[0.63,0.73]$} & {$[0.90,0.93]$} & {$[0.88,0.91]$} & {$[0.58,0.67]$} & {$[0.64,0.74]$} \\
\hline
\end{tabular}

Table 11 Interval belief degrees under state $Z_{1}$

\begin{tabular}{lllll}
\hline Attribute & $Z_{1}$ & Alternative & & \\
\cline { 2 - 4 } & $A_{1}$ & $A_{2}$ & $A_{3}$ \\
\hline$C_{1}$ & $\{(\mathrm{G},[0.38,0.84]),(\mathrm{V},[0.16,0.62])\}$ & $\{(\mathrm{G},[0.37,0.83]),(\mathrm{V},[0.17,0.63])\}$ & $\{(\mathrm{A},[0,0]),(\mathrm{G},[0,1]),(\mathrm{V},[0,1])\}$ \\
$C_{2}$ & $\{(\mathrm{~V},[0.69,0.92]),(\mathrm{E},[0.08,0.31])\}$ & $\{(\mathrm{V},[0.36,0.50]),(\mathrm{E},[0.50,0.64])\}$ & $\{(\mathrm{V},[0.55,0.77]),(\mathrm{E},[0.23,0.45])\}$ \\
$C_{3}$ & $\{(\mathrm{~V},[0.04,0.20]),(\mathrm{E},[0.80,0.96])\}$ & $\{(\mathrm{V},[0.00,0.12]),(\mathrm{E},[0.88,1])\}$ & $\{(\mathrm{V},[0.06,0.09]),(\mathrm{E},[0.94,1])\}$ \\
$C_{4}$ & $\{(\mathrm{~A},[0,0]),(\mathrm{G},[0,1]),(\mathrm{V},[0,0])\}$ & $\{(\mathrm{A},[0.15,0.62]),(\mathrm{G},[0.38,0.85])\}$ & $\{(\mathrm{A},[0,0]),(\mathrm{G},[0,1]),(\mathrm{V},[0,0])\}$ \\
$C_{5}$ & $\{(\mathrm{G},[0,0]),(\mathrm{V},[0,1]),(\mathrm{E},[0,0])\}$ & $\{(\mathrm{V},[0.31,0.80]),(\mathrm{E},[0.20,0.69])\}$ & $\{(\mathrm{V},[0.32,0.74]),(\mathrm{E},[0.26,0.68])\}$ \\
\hline
\end{tabular}

Table 12 Interval belief degrees under state $Z_{2}$

\begin{tabular}{llll}
\hline Attribute & $Z_{2}$ & Alternative & \\
\cline { 2 - 4 } & $A_{1}$ & $A_{2}$ & $A_{3}$ \\
\hline$C_{1}$ & $\{(\mathrm{G},[0.37,0.83]),(\mathrm{V},[0.17,0.63])\}$ & $\{(\mathrm{A},[0,0]),(\mathrm{G},[0,1]),(\mathrm{V},[0,1])\}$ & $\{(\mathrm{G},[0.38,0.84]),(\mathrm{V},[0.16,0.62])\}$ \\
$C_{2}$ & $\{(\mathrm{~V},[0.36,0.50]),(\mathrm{E},[0.50,0.64])\}$ & $\{(\mathrm{V},[0.55,0.77]),(\mathrm{E},[0.23,0.45])\}$ & $\{(\mathrm{V},[0.69,0.92]),(\mathrm{E},[0.08,0.31])\}$ \\
$C_{3}$ & $\{(\mathrm{~V},[0.00,0.12]),(\mathrm{E},[0.88,1])\}$ & $\{(\mathrm{V},[0.06,0.09]),(\mathrm{E},[0.94,1])\}$ & $\{(\mathrm{V},[0.04,0.20]),(\mathrm{E},[0.80,0.96])\}$ \\
$C_{4}$ & $\{(\mathrm{~A},[0.15,0.62]),(\mathrm{G},[0.38,0.85])\}$ & $\{(\mathrm{A},[0,0]),(\mathrm{G},[0,1]),(\mathrm{V},[0,0])\}$ & $\{(\mathrm{A},[0,0]),(\mathrm{G},[0,1]),(\mathrm{V},[0,0])\}$ \\
$C_{5}$ & $\{(\mathrm{~V},[0.31,0.80]),(\mathrm{E},[0.20,0.69])\}$ & $\{(\mathrm{V},[0.32,0.74]),(\mathrm{E},[0.26,0.68])\}$ & $\{(\mathrm{G},[0,0]),(\mathrm{V},[0,1]),(\mathrm{E},[0,0])\}$ \\
\hline
\end{tabular}


Table 13 Interval belief degrees under state $Z_{3}$

\begin{tabular}{lllll}
\hline Attribute & $Z_{3}$ & Alternative & & \\
\cline { 2 - 5 } & $A_{1}$ & $A_{2}$ & $A_{3}$ \\
\hline$C_{1}$ & $\{(\mathrm{G},[0.18,0.56]),(\mathrm{V},[0.44,0.82])\}$ & $\{(\mathrm{G},[0.25,0.64]),(\mathrm{V},[0.36,0.75])\}$ & $\{(\mathrm{A},[0,0]),(\mathrm{G},[0,1]),(\mathrm{V},[0,0])\}$ \\
$C_{2}$ & $\{(\mathrm{~V},[0.57,0.75]),(\mathrm{E},[0.25,0.43])\}$ & $\{(\mathrm{V},[0.52,0.68]),(\mathrm{E},[0.32,0.48])\}$ & $\{(\mathrm{V},[0.47,0.62]),(\mathrm{E},[0.38,0.53])\}$ \\
$C_{3}$ & $\{(\mathrm{~V},[0.041,0.16]),(\mathrm{E},[0.84,1])\}$ & $\{(\mathrm{V},[0.04,0.10]),(\mathrm{E},[0.96,1])\}$ & $\{(\mathrm{V},[0.03,, 0.11]),(\mathrm{E},[0.97,1])\}$ \\
$C_{4}$ & $\{(\mathrm{~A},[0.04,0.47]),(\mathrm{G},[0.53,0.96])\}$ & $\{(\mathrm{A},[0.15,0.62]),(\mathrm{G},[0.38,0.85])\}$ & $\{(\mathrm{A},[0,0]),(\mathrm{G},[0,1]),(\mathrm{V},[0,0])\}$ \\
$C_{5}$ & $\{(\mathrm{~V},[0.56,0.98]),(\mathrm{E},[0.02,0.44])\}$ & $\{(\mathrm{V},[0.14,0.53]),(\mathrm{E},[0.47,0.86])\}$ & $\{(\mathrm{G},[0,0]),(\mathrm{V},[0,1]),(\mathrm{E},[0,0])\}$ \\
\hline
\end{tabular}

Table 14 Aggregated intervalvalued belief degrees for each decision alternative

\begin{tabular}{llllllll}
\hline Alternative & State & \multicolumn{2}{l}{ Attribute } & & & \\
\cline { 3 - 7 } \cline { 3 - 7 } & & $\mathrm{P}$ & $\mathrm{A}$ & $\mathrm{G}$ & $\mathrm{V}$ & $\mathrm{E}$ & $\mathrm{H}$ \\
\hline$A_{1}$ & $Z_{1}$ & {$[0.00,0.00]$} & {$[0.00,0.26]$} & {$[0.10,0.83]$} & {$[0.07,0.67]$} & {$[0.04,0.22]$} & {$[0.00,0.65]$} \\
& $Z_{2}$ & {$[0.00,0.00]$} & {$[0.04,0.20]$} & {$[0.20,0.54]$} & {$[0.12,0.51]$} & {$[0.14,0.36]$} & {$[0.00,0.37]$} \\
& $Z_{3}$ & {$[0.00,0.00]$} & {$[0.01,0.14]$} & {$[0.18,0.47]$} & {$[0.33,0.65]$} & {$[0.07,0.24]$} & {$[0.00,0.31]$} \\
& $Z_{2}$ & {$[0.00,0.00]$} & {$[0.04,0.20]$} & {$[0.20,0.54]$} & {$[0.12,0.51]$} & {$[0.14,0.36]$} & {$[0.00,0.37]$} \\
& $Z_{2}$ & {$[0.00,0.00]$} & {$[0.00,0.24]$} & {$[0.00,0.42]$} & {$[0.13,0.40]$} & {$[0.16,0.39]$} & {$[0.11,0.61]$} \\
& $Z_{3}$ & {$[0.00,0.00]$} & {$[0.00,0.26]$} & {$[0.10,0.83]$} & {$[0.07,0.67]$} & {$[0.04,0.22]$} & {$[0.00,0.65]$} \\
$A_{3}$ & $Z_{1}$ & {$[0.00,0.00]$} & {$[0.00,0.24]$} & {$[0.00,0.42]$} & {$[0.13,0.40]$} & {$[0.16,0.39]$} & {$[0.11,0.61]$} \\
& $Z_{2}$ & {$[0.00,0.00]$} & {$[0.00,0.26]$} & {$[0.10,0.83]$} & {$[0.07,0.67]$} & {$[0.04,0.22]$} & {$[0.00,0.65]$} \\
& $Z_{3}$ & {$[0.00,0.00]$} & {$[0.04,0.20]$} & {$[0.20,0.54]$} & {$[0.12,0.51]$} & {$[0.14,0.36]$} & {$[0.00,0.37]$} \\
\hline
\end{tabular}

Table 15 Gain and loss values for each decision alternative under state $Z_{1}$

\begin{tabular}{|c|c|c|c|c|c|c|c|c|c|c|c|c|c|c|c|c|c|c|c|}
\hline & & \multicolumn{3}{|l|}{$\mathrm{P}$} & \multicolumn{3}{|l|}{ A } & \multicolumn{3}{|l|}{$\mathrm{G}$} & \multicolumn{3}{|l|}{ V } & \multicolumn{3}{|l|}{$\mathrm{E}$} & \multicolumn{3}{|l|}{$\mathrm{H}$} \\
\hline & & $A_{1}$ & $A_{2}$ & $A_{3}$ & $A_{1}$ & $A_{2}$ & $A_{3}$ & $A_{1}$ & $A_{2}$ & $A_{3}$ & $A_{1}$ & $A_{2}$ & $A_{3}$ & $A_{1}$ & $A_{2}$ & $A_{3}$ & $A_{1}$ & $A_{2}$ & $A_{3}$ \\
\hline \multirow[t]{3}{*}{ Gain } & $A_{1}$ & 0.50 & 0.50 & 0.50 & 0.50 & 0.59 & 0.52 & 0.50 & 0.63 & 0.61 & 0.50 & 0.59 & 0.64 & 0.50 & 0.77 & 0.83 & 0.50 & 0.61 & 0.56 \\
\hline & $A_{2}$ & 0.50 & 0.50 & 0.50 & 0.36 & 0.50 & 0.38 & 0.21 & 0.50 & 0.21 & 0.36 & 0.50 & 0.58 & 0.28 & 0.50 & 0.54 & 0.31 & 0.50 & 0.38 \\
\hline & $A_{3}$ & 0.50 & 0.50 & 0.50 & 0.48 & 0.58 & 0.50 & 0.44 & 0.73 & 0.50 & 0.20 & 0.39 & 0.50 & 0.25 & 0.46 & 0.50 & 0.42 & 0.66 & 0.50 \\
\hline \multirow[t]{3}{*}{ Loss } & $A_{1}$ & 0.50 & 0.50 & 0.50 & 0.50 & 0.41 & 0.48 & 0.50 & 0.37 & 0.39 & 0.50 & 0.41 & 0.36 & 0.50 & 0.23 & 0.17 & 0.50 & 0.39 & 0.44 \\
\hline & $A_{2}$ & 0.50 & 0.50 & 0.50 & 0.64 & 0.50 & 0.62 & 0.79 & 0.50 & 0.79 & 0.64 & 0.50 & 0.42 & 0.72 & 0.50 & 0.46 & 0.69 & 0.50 & 0.62 \\
\hline & $A_{3}$ & 0.50 & 0.50 & 0.50 & 0.52 & 0.42 & 0.50 & 0.56 & 0.27 & 0.50 & 0.80 & 0.61 & 0.50 & 0.75 & 0.54 & 0.50 & 0.58 & 0.34 & 0.50 \\
\hline
\end{tabular}

\section{Conclusion}

The emergency decision selection problem is important to emergency management, as the decisions made at critical moments can directly influence the performance of the emergency response. From this perspective, the proposed method offers much value. Many MADM methods have been used for emergency alternative selection problems, but they often neglect the DM's psychological behavior. For that, the IVHF-TODIM method solves the dynamic emergency response problem by considering the DM's psychological behavior. Compared to prospect theory which also considers the psychological behavior of the $\mathrm{DM}$, the proposed method does not need to predetermine the aspiration levels of the attributes.

In this paper, the IVHF-TODIM method is introduced to handle the EDM problems under an IVHF environment, in which all attribute information provided to the DMs is in the form of IVHF sets. A new function to compute the degrees of gain and loss based on the geometric area 


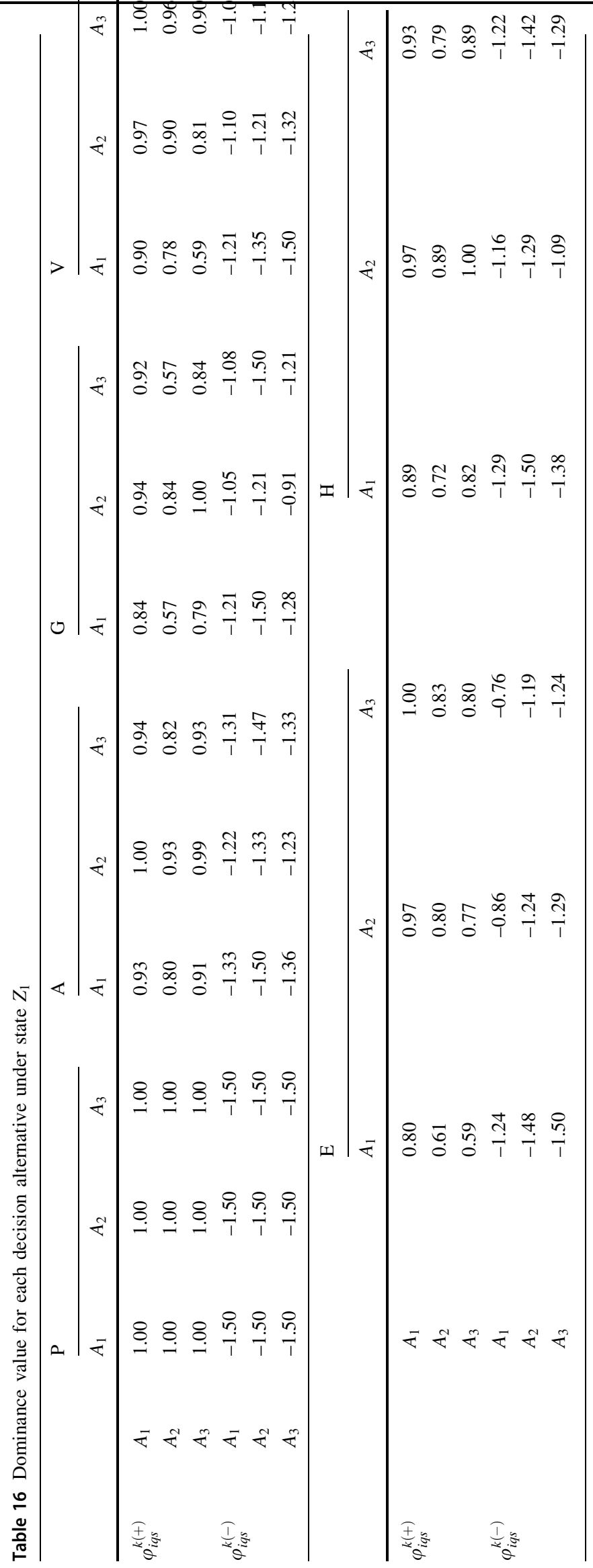


Table 17 Overall dominance degree values and corresponding ranking

\begin{tabular}{llll}
\hline Alternative & $\xi^{1}\left(A_{i}\right)($ Rank) & $\xi^{2}\left(A_{i}\right)($ Rank) & $\xi^{3}\left(A_{i}\right)$ (Rank) \\
\hline$A_{1}$ & $1.00(\mathbf{1})$ & $0.00(\mathbf{3})$ & $0.00(\mathbf{3})$ \\
$A_{2}$ & $0.00(\mathbf{3})$ & $0.37(\mathbf{2})$ & $1.00(\mathbf{1})$ \\
$A_{3}$ & $0.37(\mathbf{2})$ & $1.00(\mathbf{1})$ & $0.61(\mathbf{2})$ \\
\hline
\end{tabular}

method is used. Applying the probability density function and geometric area method, the gain and loss matrices of the interval belief degrees are developed. Next, we put forward a new expression to form the dominance degree matrix. The validity of the proposed method has been demonstrated using a recent example of an emergency alternative selection of a large bushfire in Australia during the start of summer. The novelty and value of the proposed method are shown through a comparative analysis.

Naturally, the proposed method has its limitations too. First, the weight of attributes is known in advance. Next, the proposed method only considers the attribute values to be in the form of IVHF sets. In some complex EDM problems, the attribute weights may be unknown or partially known, and the format of the attribute values may not be a single expression. Thus, for future work, one research direction is to supply a rigorous and realistic method for obtaining the attribute weights. We can also combine the proposed the interval-valued hesitant fuzzy TODIM method with other MADM techniques to deal with MADM problems posed under extreme uncertainty such as COVID-19.

\section{Appendix}

We show how to obtain the gain and loss degrees for Table 2. Let $g_{i q s}^{k}\left(l_{i q s}^{k}\right)$ be the gain (loss) degree of alternative $A_{i}$ relative to $A_{q}$, given that emergency state $Z_{k}$ occurs under assessment level $m_{s}$, respectively. By Definition $4, x$ is a random variable in the interval belief degree $\beta_{r k}\left(A_{i}\right)=\left[\beta_{r k}^{-}\left(A_{i}\right), \beta_{r k}^{+}\left(A_{i}\right)\right]$.

Case 1 As $\beta_{r_{1} k}\left(A_{i}\right)<\beta_{r_{2} k}\left(A_{q}\right)$, then $\beta_{r_{1} k}^{-}\left(A_{i}\right) \leq \beta_{r_{1} k}^{+}\left(A_{i}\right) \leq \beta_{r_{2} k}^{-}\left(A_{q}\right) \leq \beta_{r_{2} k}^{+}\left(A_{q}\right)$. [ $\left[l_{i q s}^{k}, g_{i q s}^{k}\right]$ can be given as follows:

$S_{\beta_{r_{1} k}\left(A_{i}\right)}^{1}=0, S=0 S_{\beta_{r_{2} k}\left(A_{q}\right)}^{2}=0$,

$S_{\beta_{r_{1} k}\left(A_{i}\right)}=\int_{\beta_{r_{1} k}^{-}\left(A_{i}\right)}^{\beta_{r_{1} k}^{+}\left(A_{i}\right)} \frac{1}{\beta_{r_{1} k}^{+}\left(A_{i}\right)-\beta_{r_{1} k}^{-}\left(A_{i}\right)} \mathrm{d} x=1$,

$S_{\beta_{r_{2} k}\left(A_{q}\right)}=\int_{\beta_{r_{2} k}^{-}\left(A_{q}\right)}^{\beta_{r_{2} k}^{+}\left(A_{q}\right)} \frac{1}{\beta_{r_{2} k}^{+}\left(A_{q}\right)-\beta_{r_{2} k}^{-}\left(A_{q}\right)} \mathrm{d} x=1$,

$g_{i q s}^{k}\left(\beta_{r_{1} k}\left(A_{i}\right) \geq \beta_{r_{2} k}\left(A_{q}\right)\right)=\frac{1}{2}\left(\frac{S_{\beta_{r_{1} k}\left(A_{i}\right)}^{1}+S / 2}{S_{\beta_{r_{1}}\left(A_{i}\right)}}+\frac{S_{\beta_{r_{2} k}\left(A_{q}\right)}^{2}+S / 2}{S_{\beta_{r_{2} k}\left(A_{q}\right)}}\right)=0$

$l_{i q s}^{k}\left(\beta_{r_{1} k}\left(A_{i}\right)<\beta_{r_{2} k}\left(A_{q}\right)\right)=1-g_{i q s}^{k}\left(\beta_{r_{1} k}\left(A_{i}\right) \geq \beta_{r_{2} k}\left(A_{q}\right)\right)$

$$
=1
$$

$i, q=1, \ldots, n ; k=1, \ldots, t ; r_{1}, r_{2}=1, \ldots, r$.

Case 2 Since $\beta_{r_{1} k}\left(A_{i}\right)=\beta_{r_{2} k}\left(A_{q}\right)$, we have $\beta_{r_{1} k}^{-}\left(A_{i}\right)=\beta_{r_{2} k}^{-}\left(A_{q}\right), \beta_{r_{1} k}^{+}\left(A_{i}\right)=\beta_{r_{2} k}^{+}\left(A_{q}\right)$, and $\left[l_{i q s}^{k}, g_{i q s}^{k}\right]$ can be stated as follows:

$S_{\beta_{r_{1} k}\left(A_{i}\right)}^{1}=S_{\beta_{r_{2} k}\left(A_{q}\right)}^{2}=0$,

Table 18 Comparison results between proposed method and other methods

\begin{tabular}{llll}
\hline Method & Ranking of alternatives for $Z_{1}$ & Ranking of alternatives for $Z_{2}$ & Ranking of alternatives for $Z_{3}$ \\
\hline Proposed & $A_{1}>A_{3}>A_{2}$ & $A_{3}>A_{2}>A_{1}$ & $A_{3}>A_{1}>A_{2}$ \\
Wang et al. (2017) & $A_{2}>A_{3}>A_{1}$ & $A_{1}>A_{2}>A_{3}$ & $A_{1}>A_{3}>A_{2}$ \\
Yu and Lai (2011) & Lower bound: $A_{2}>A_{1}>A_{3}$ & Lower bound: $A_{1}>A_{3}>A_{2}$ & Lower bound: $A_{1}>A_{3}>A_{2}$ \\
& Average point: $A_{2}>A_{1}>A_{3}$ & Average point: $A_{1}>A_{3}>A_{2}$ & Average point: $A_{1}>A_{3}>A_{2}$ \\
& Upper bound: $A_{2}>A_{1}>A_{3}$ & Upper bound: $A_{1}>A_{3}>A_{2}$ & Upper bound: $A_{1}>A_{3}>A_{2}$ \\
\hline
\end{tabular}


$i, q=1, \ldots, n ; k=1, \ldots, t ; r_{1}, r_{2}=1, \ldots, r$.

Case 3 As $\beta_{r_{1} k}\left(A_{i}\right) \cap \beta_{r_{2} k}\left(A_{q}\right)$, we have $\beta_{r_{1} k}^{-}\left(A_{i}\right)<\beta_{r_{2} k}^{-}\left(A_{q}\right)<\beta_{r_{1} k}^{+}\left(A_{i}\right)<\beta_{r_{2} k}^{+}\left(A_{q}\right)$, and $\left[l_{i q s}^{k}, g_{i q s}^{k}\right]$ can be written as:

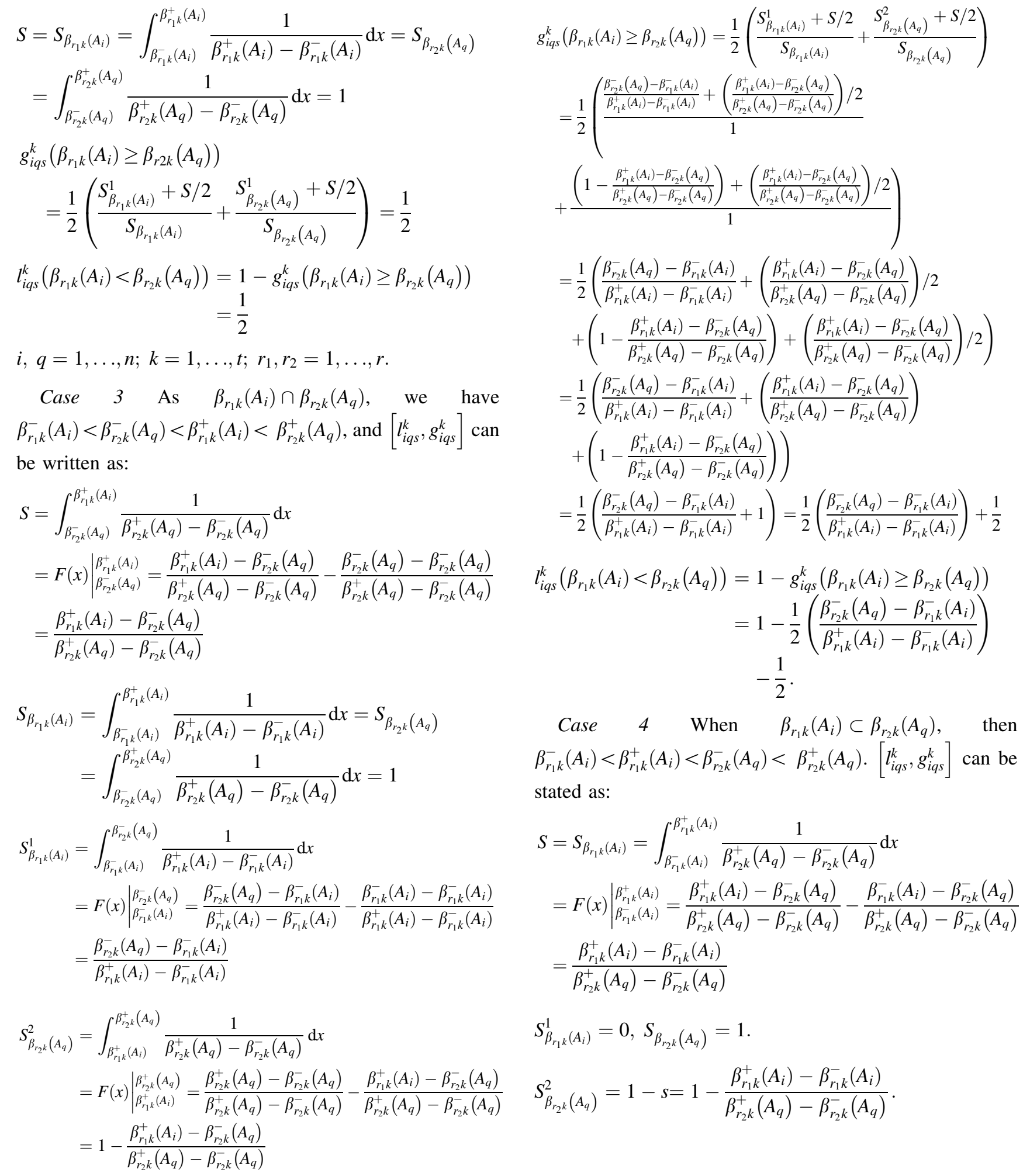

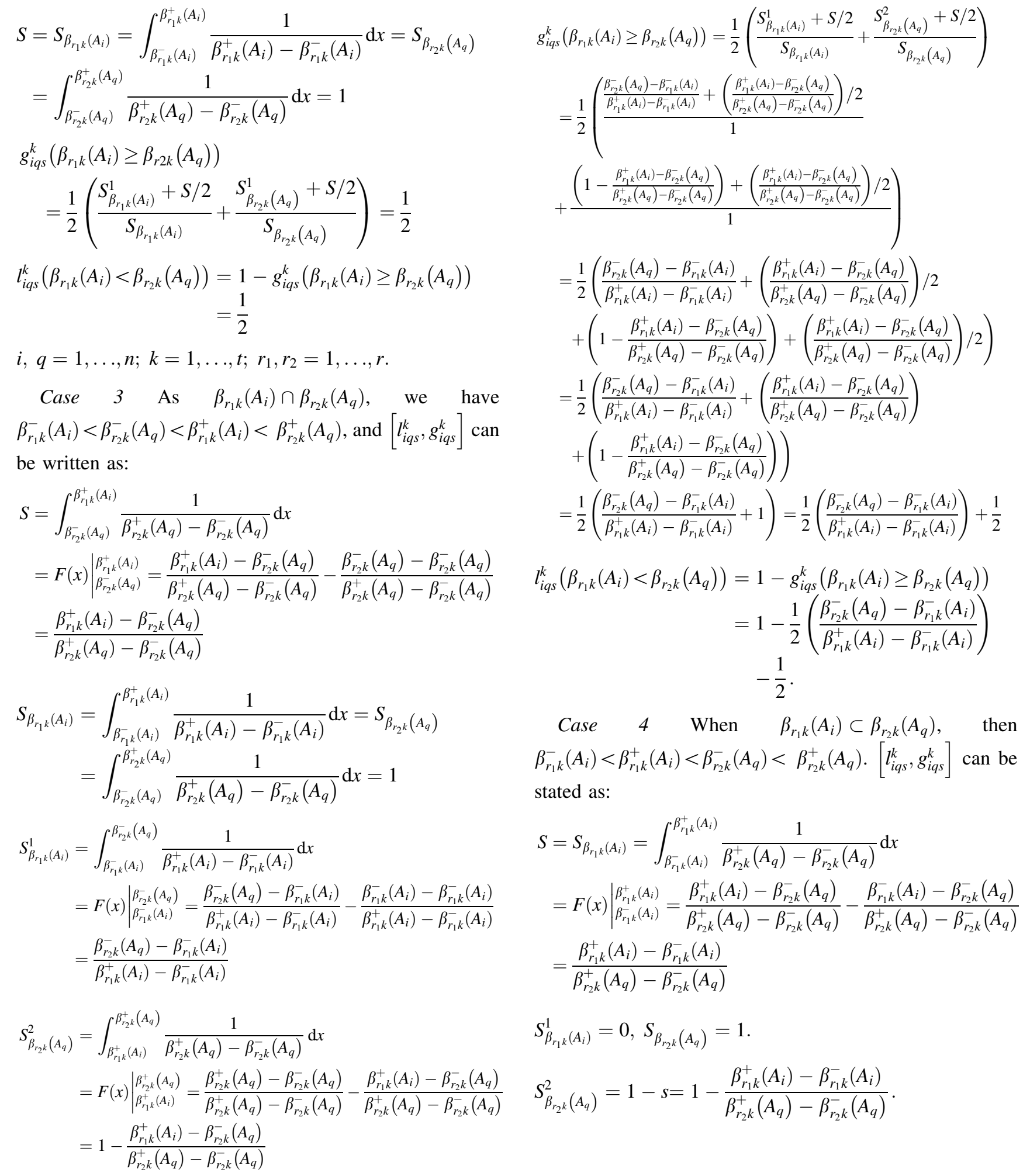

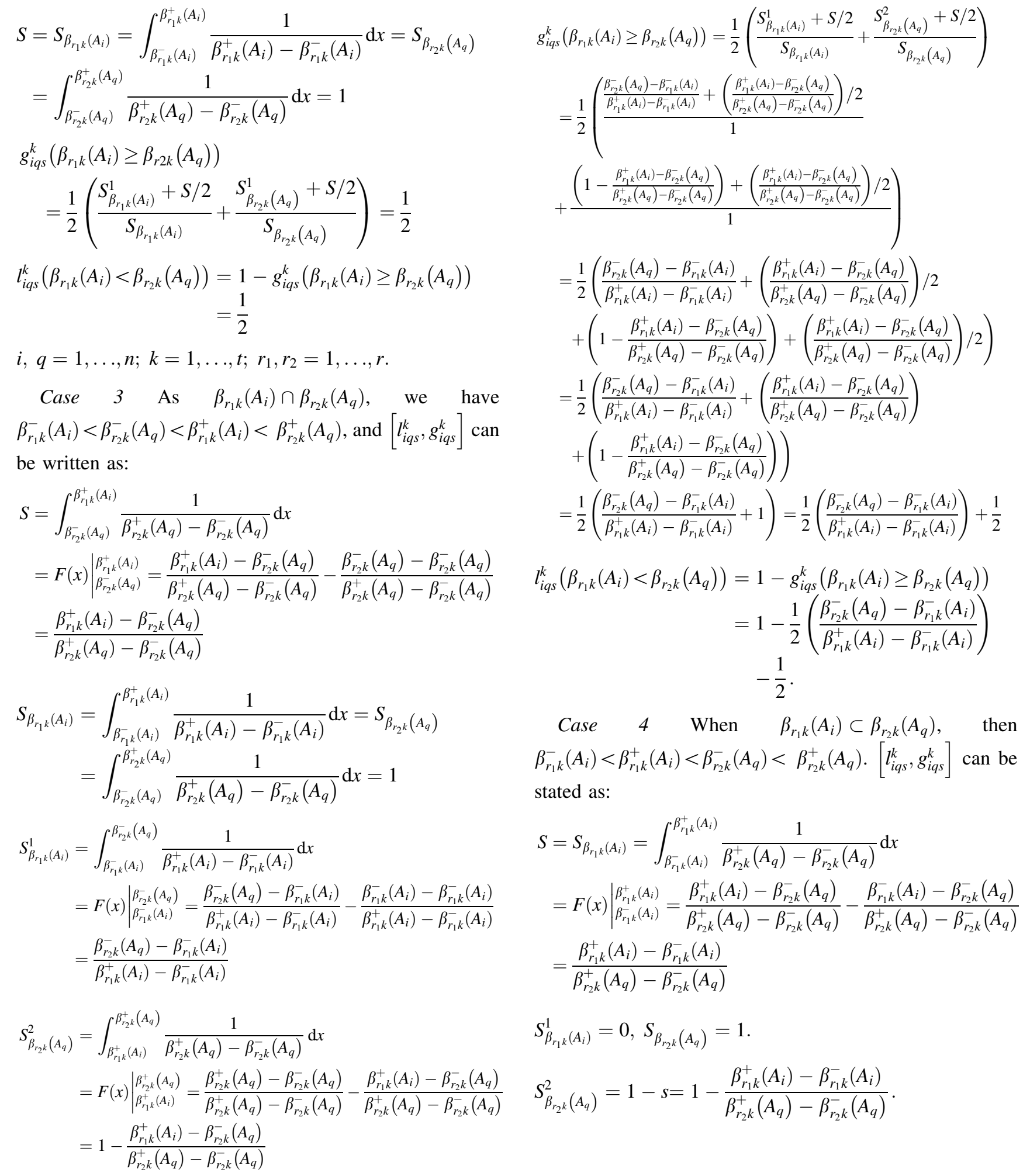

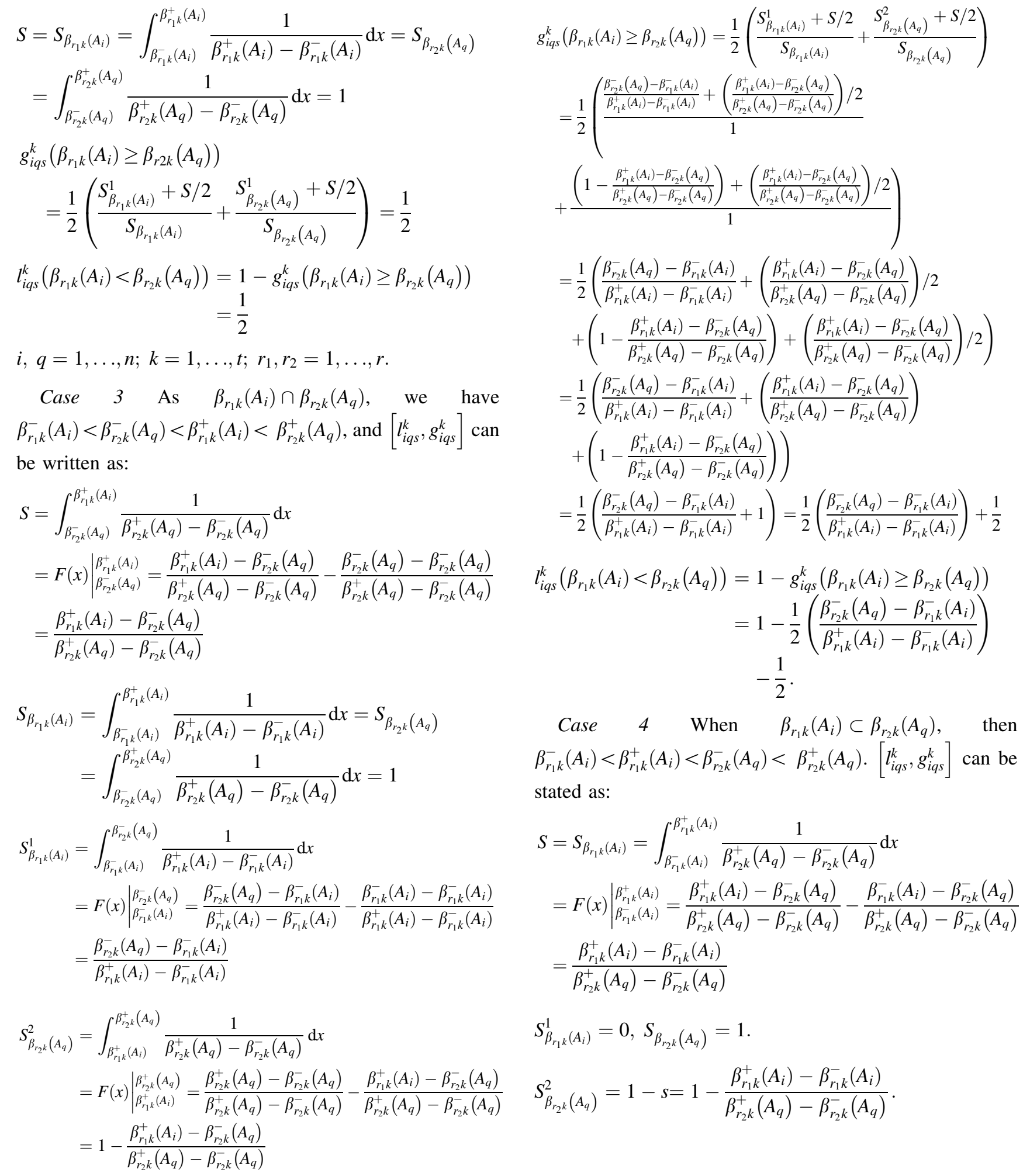

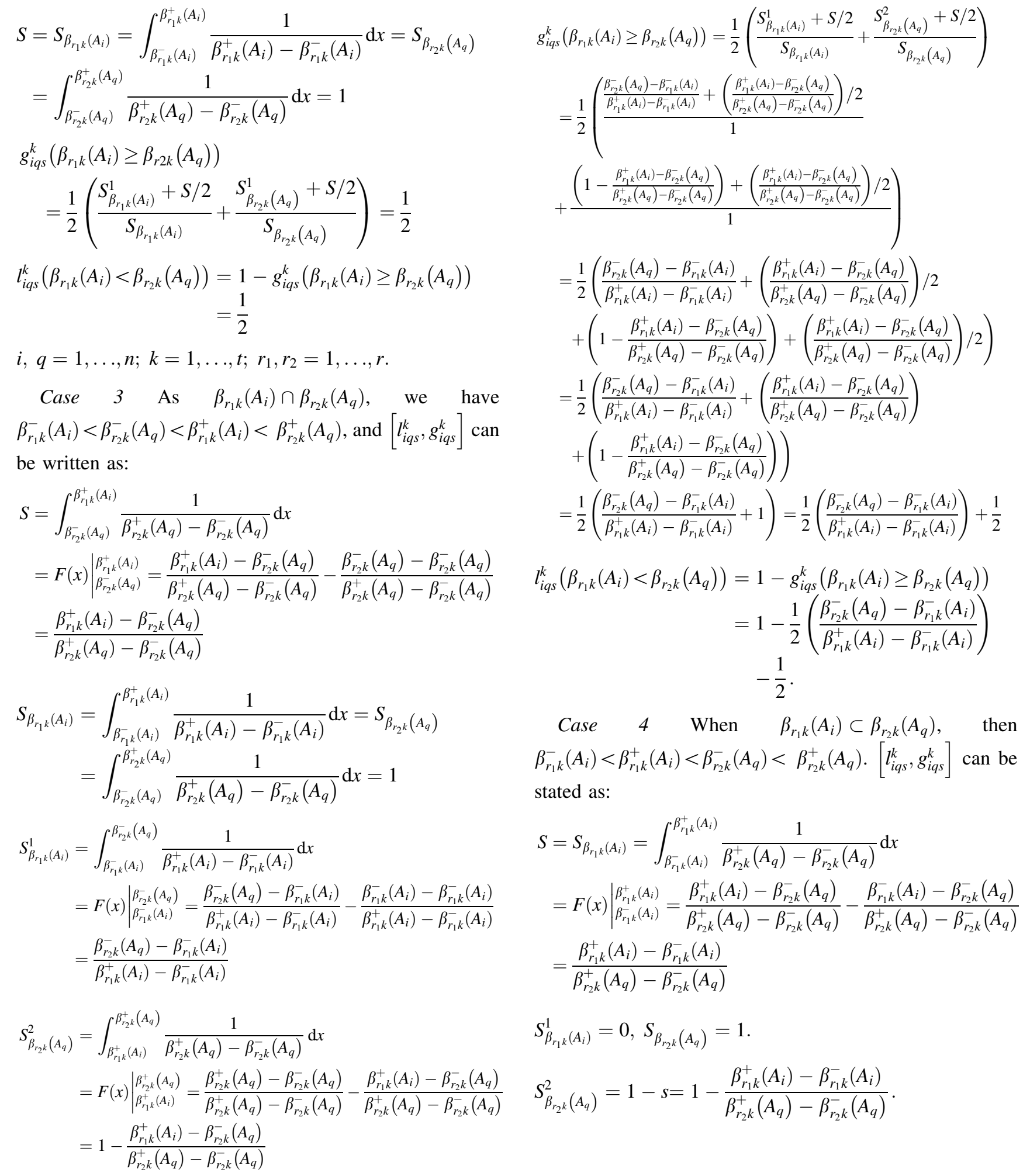

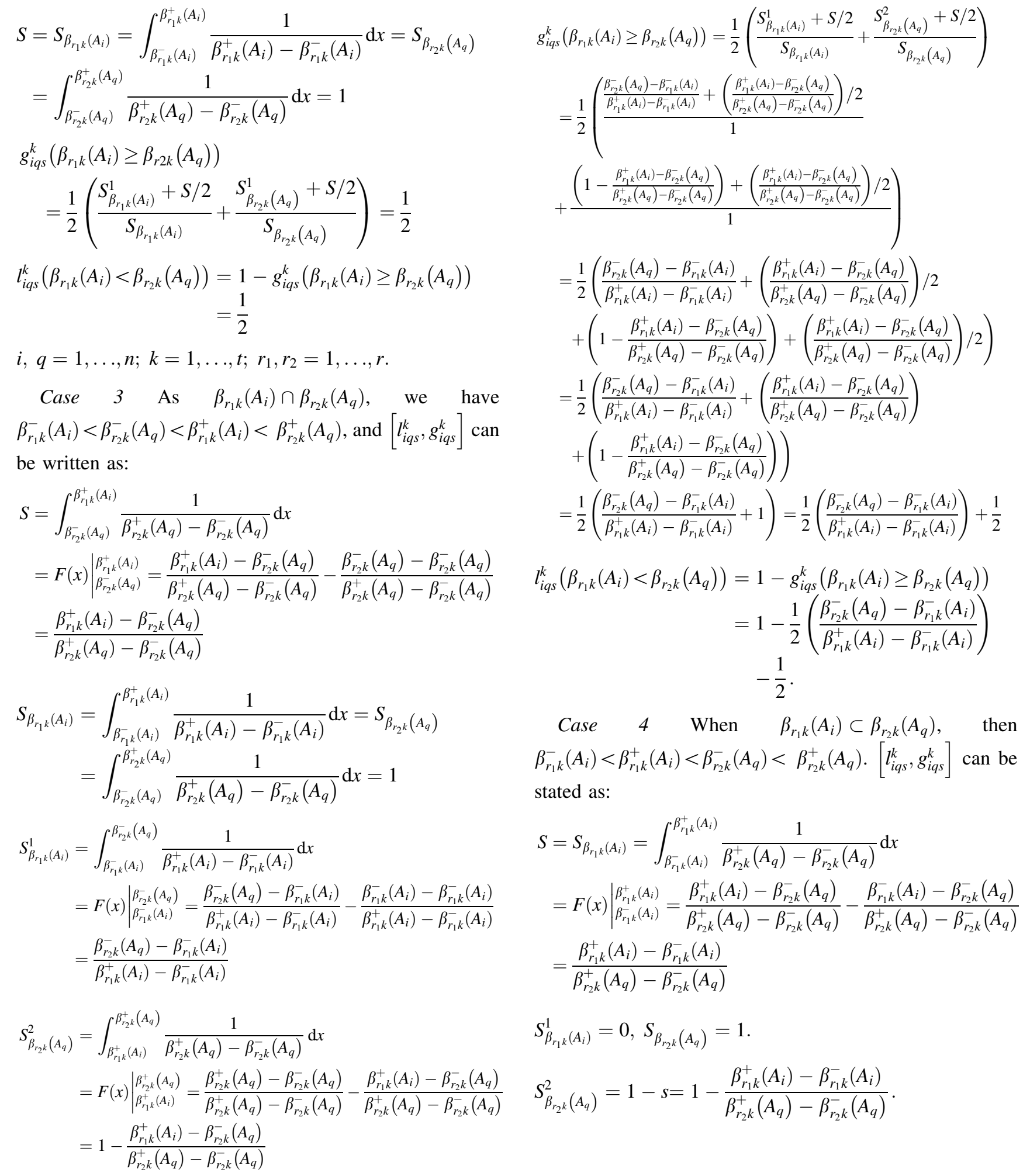

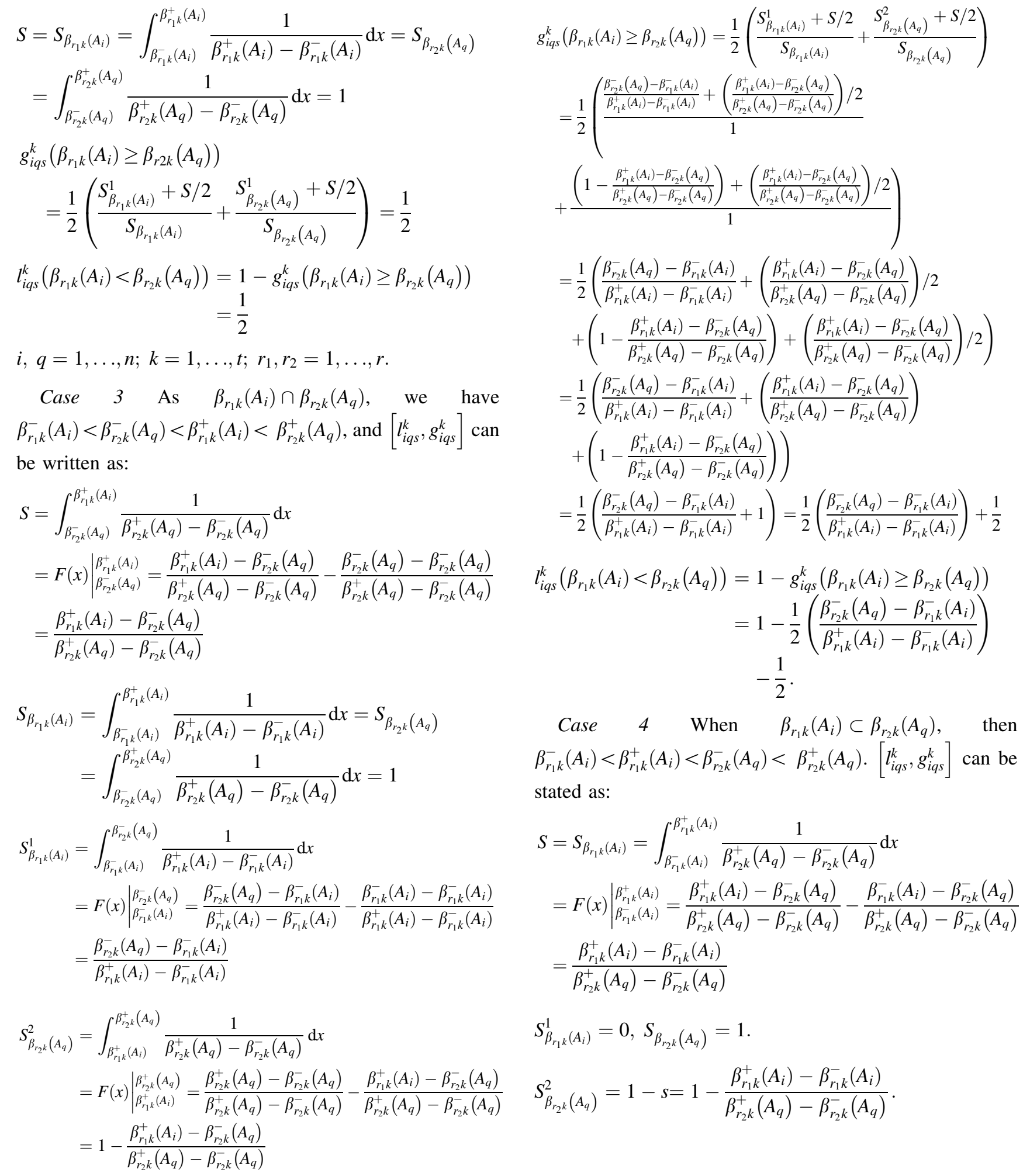

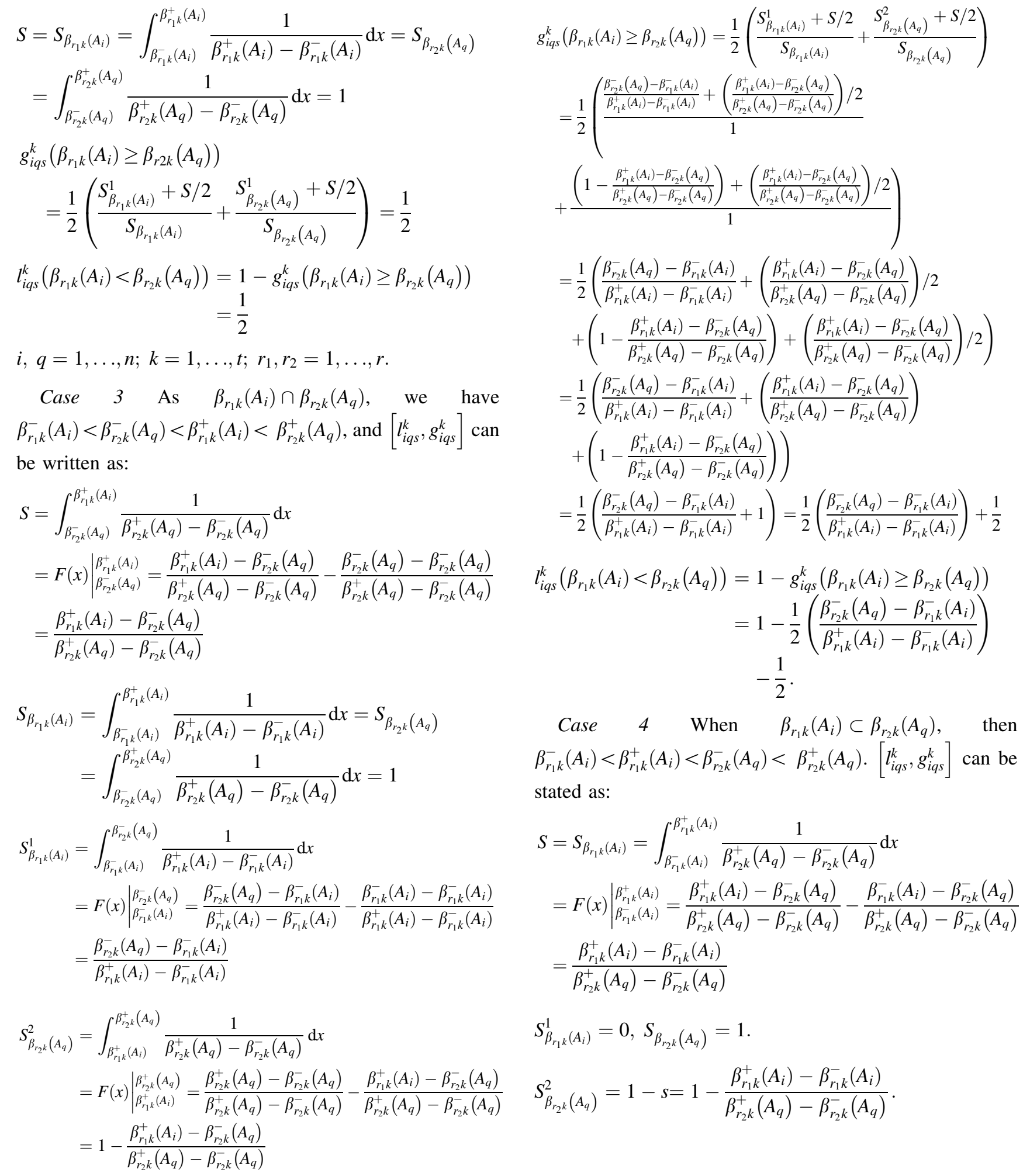

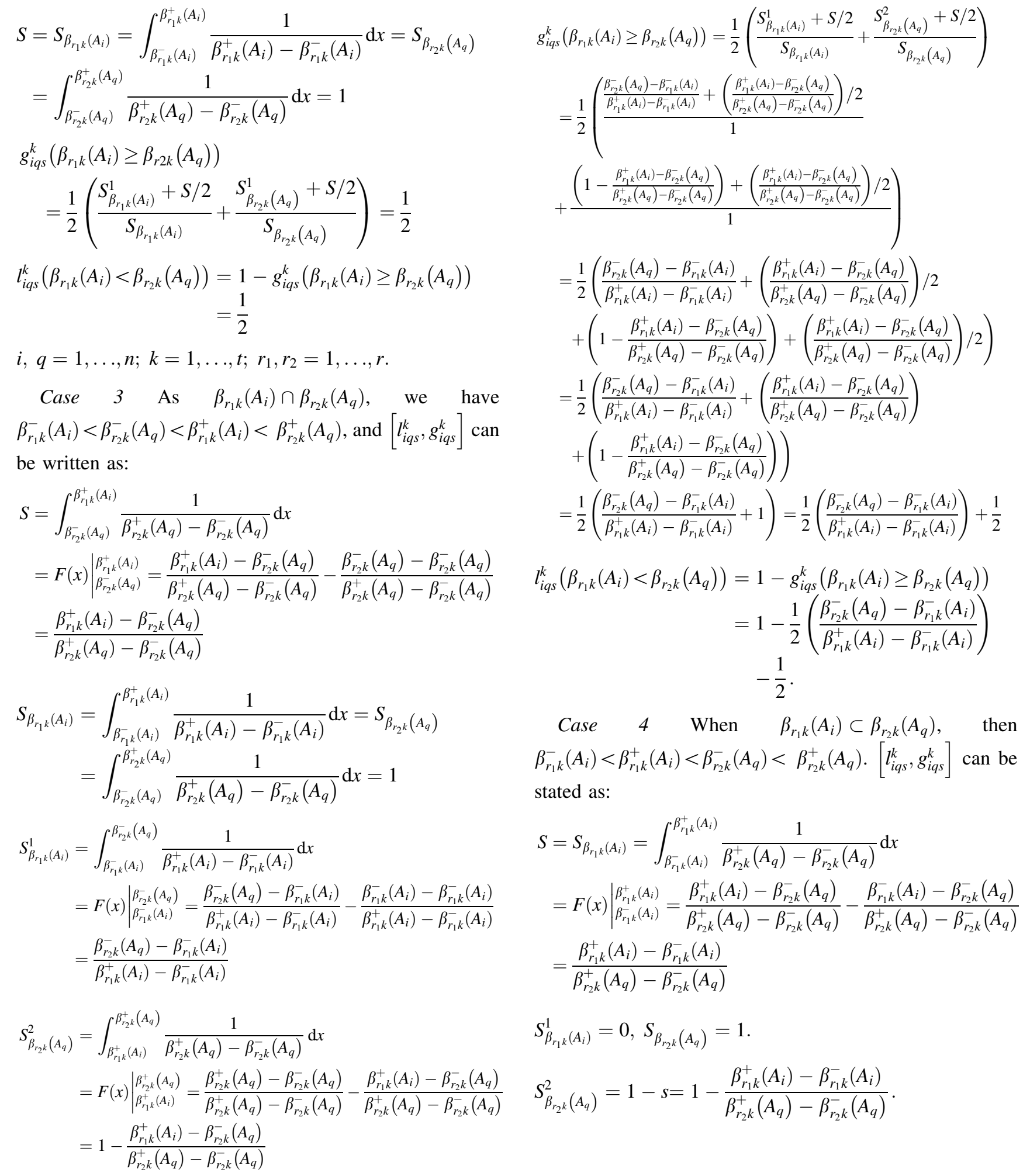

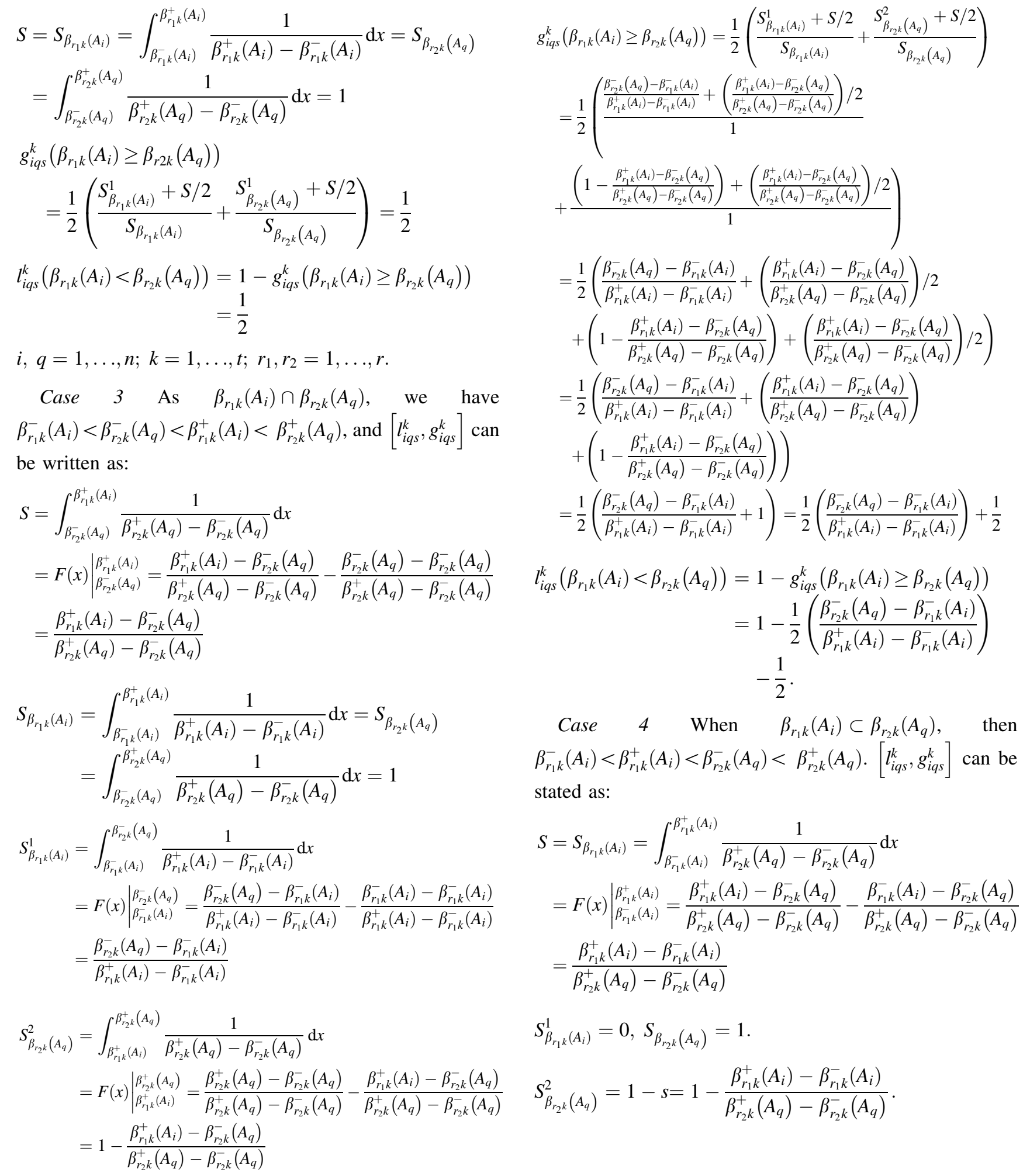

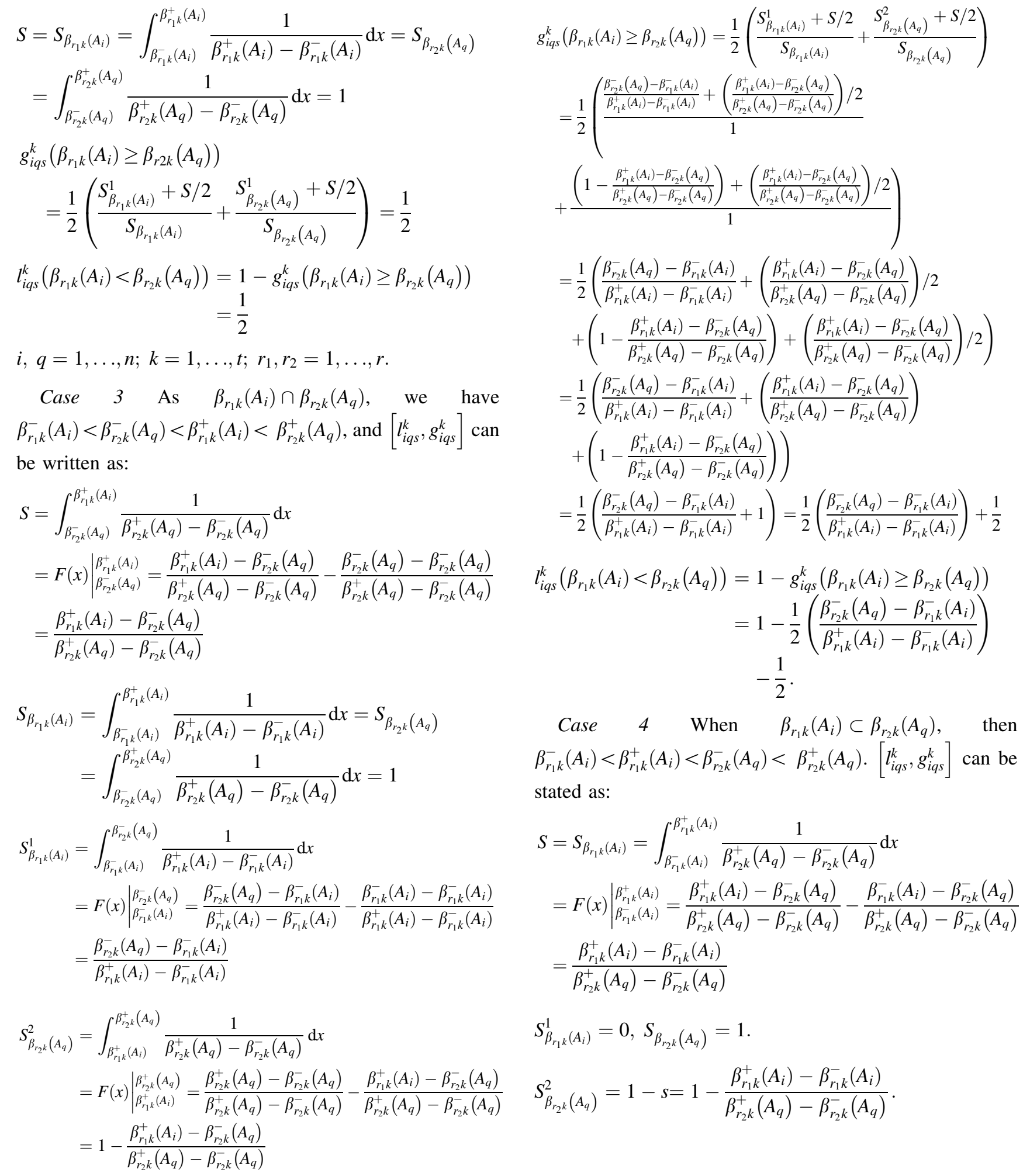

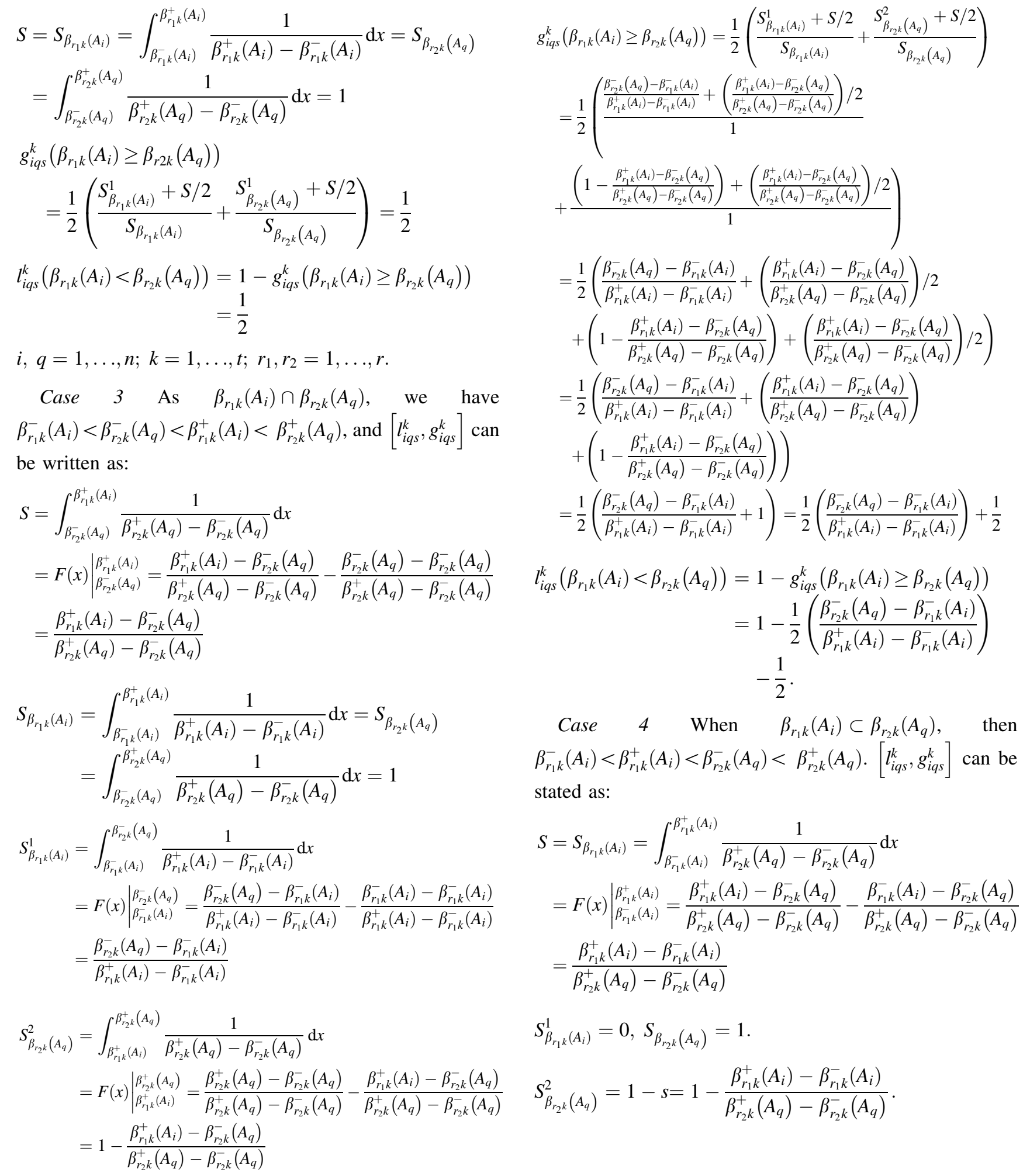

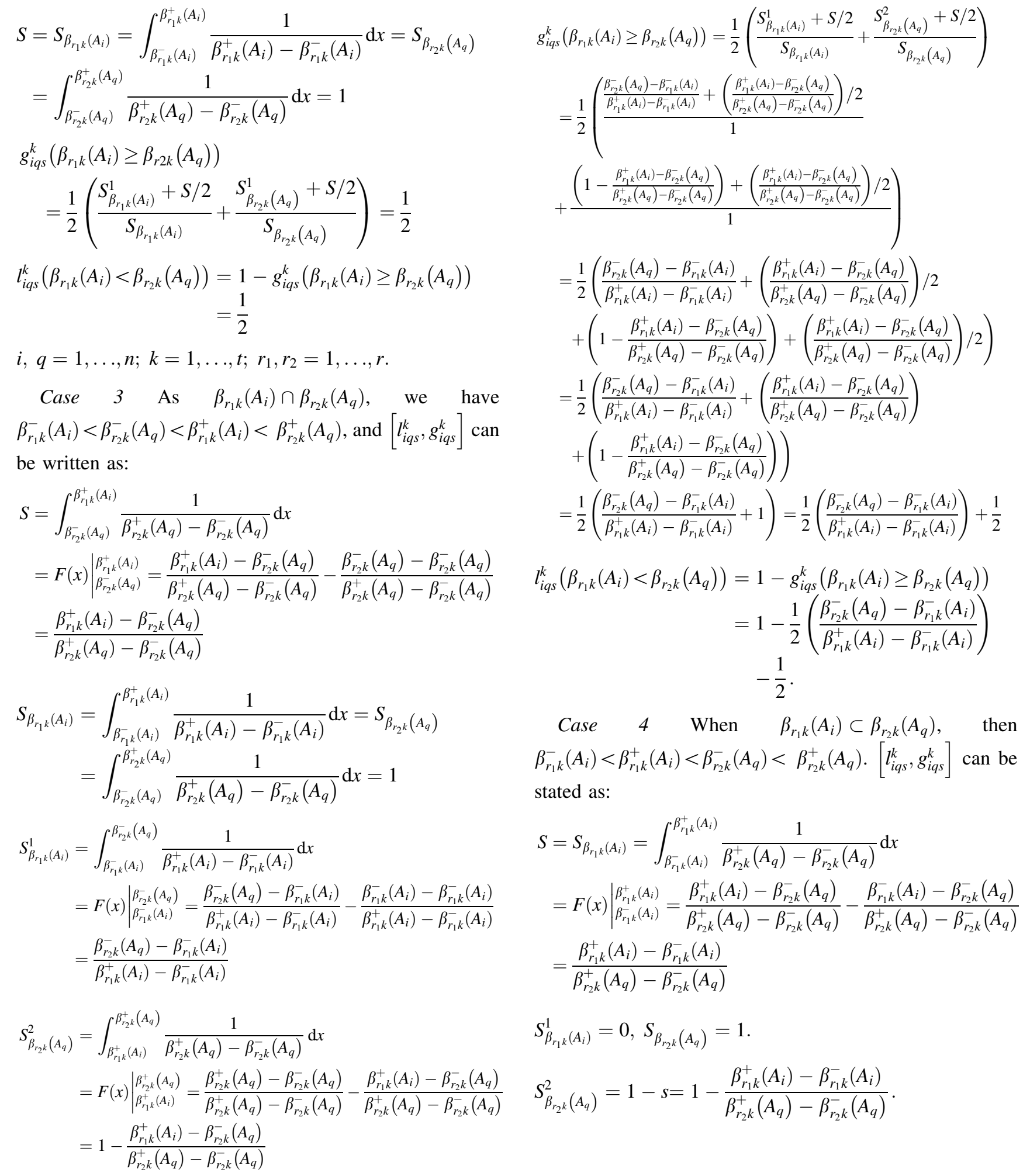

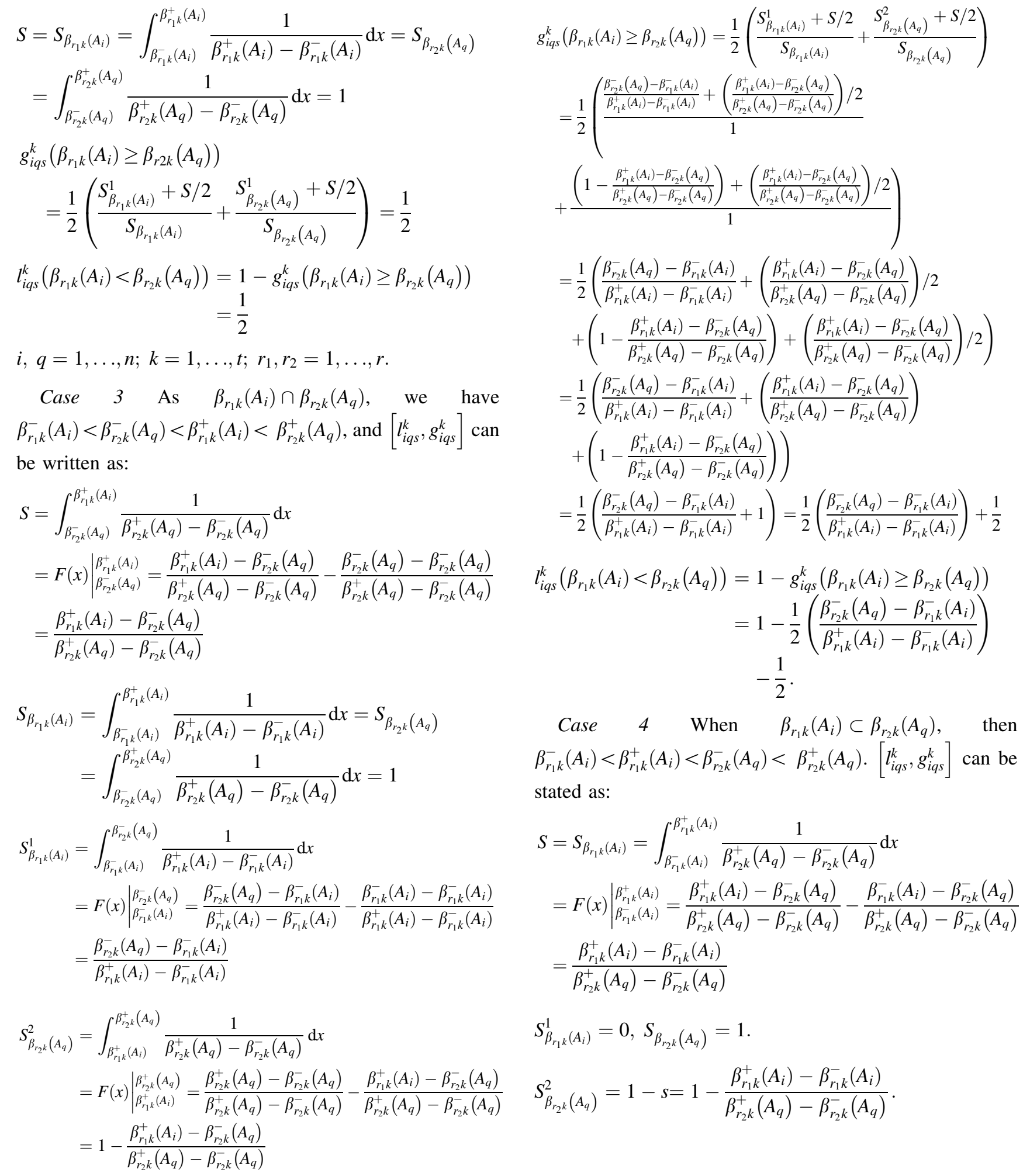

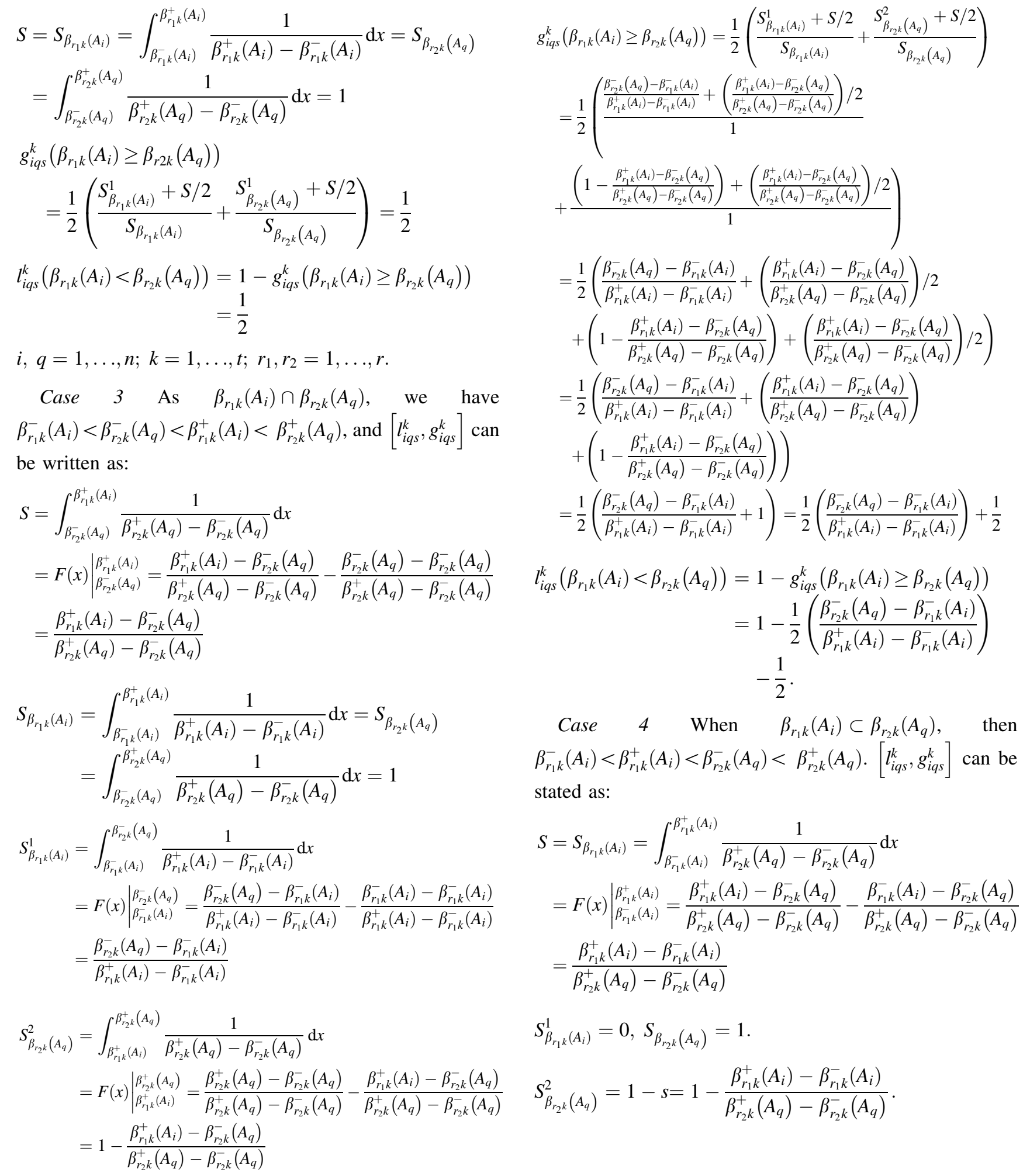

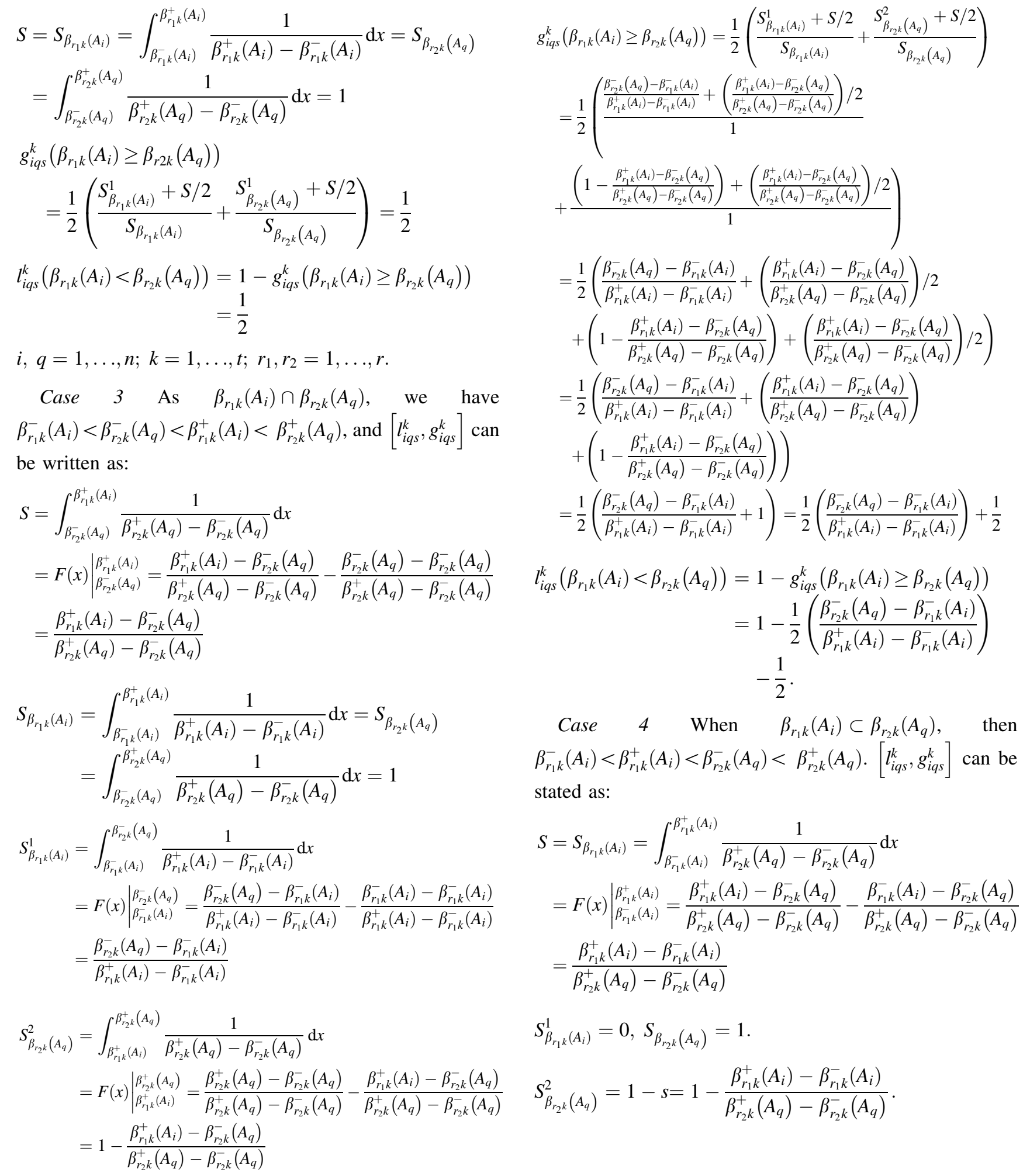

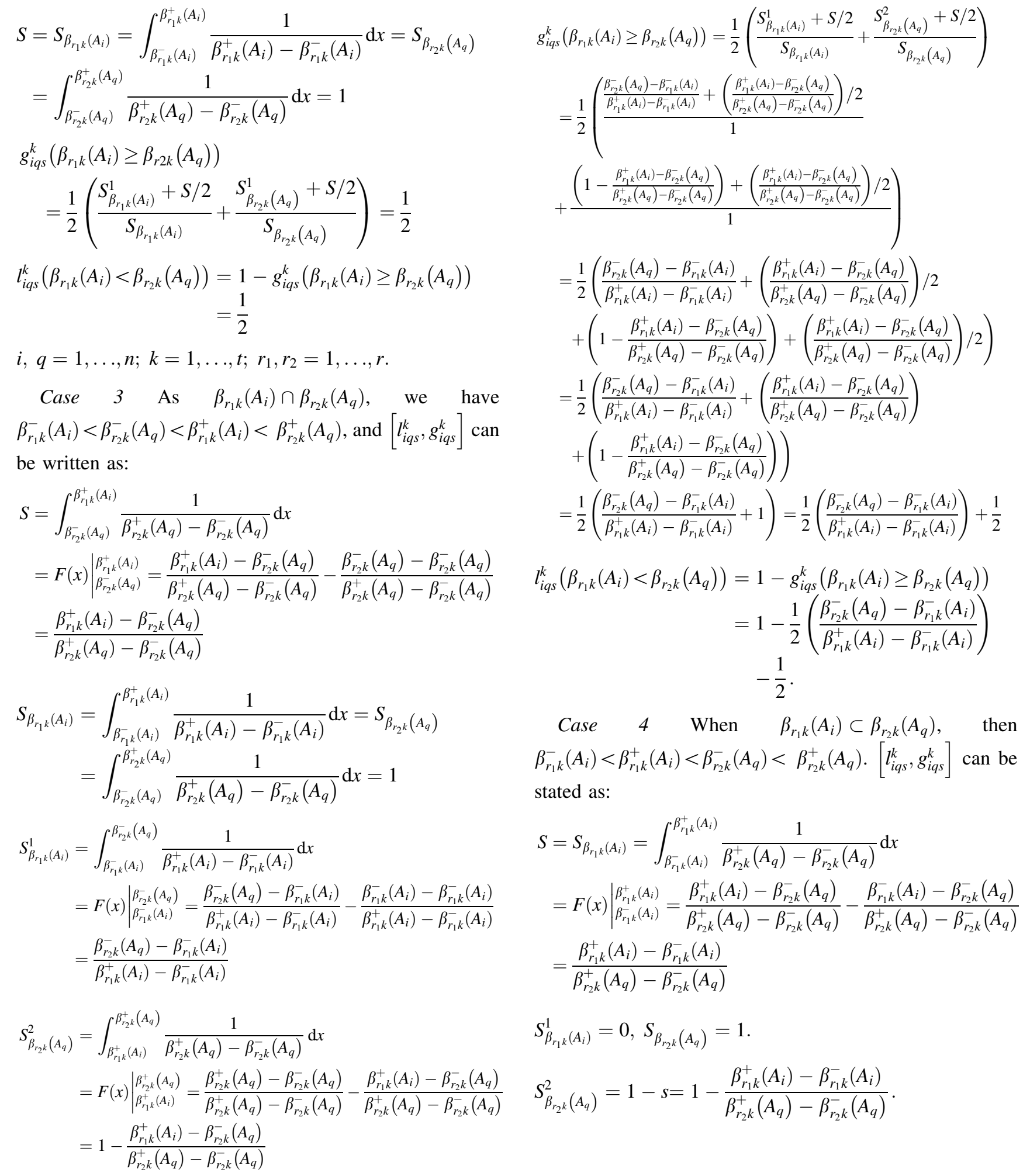

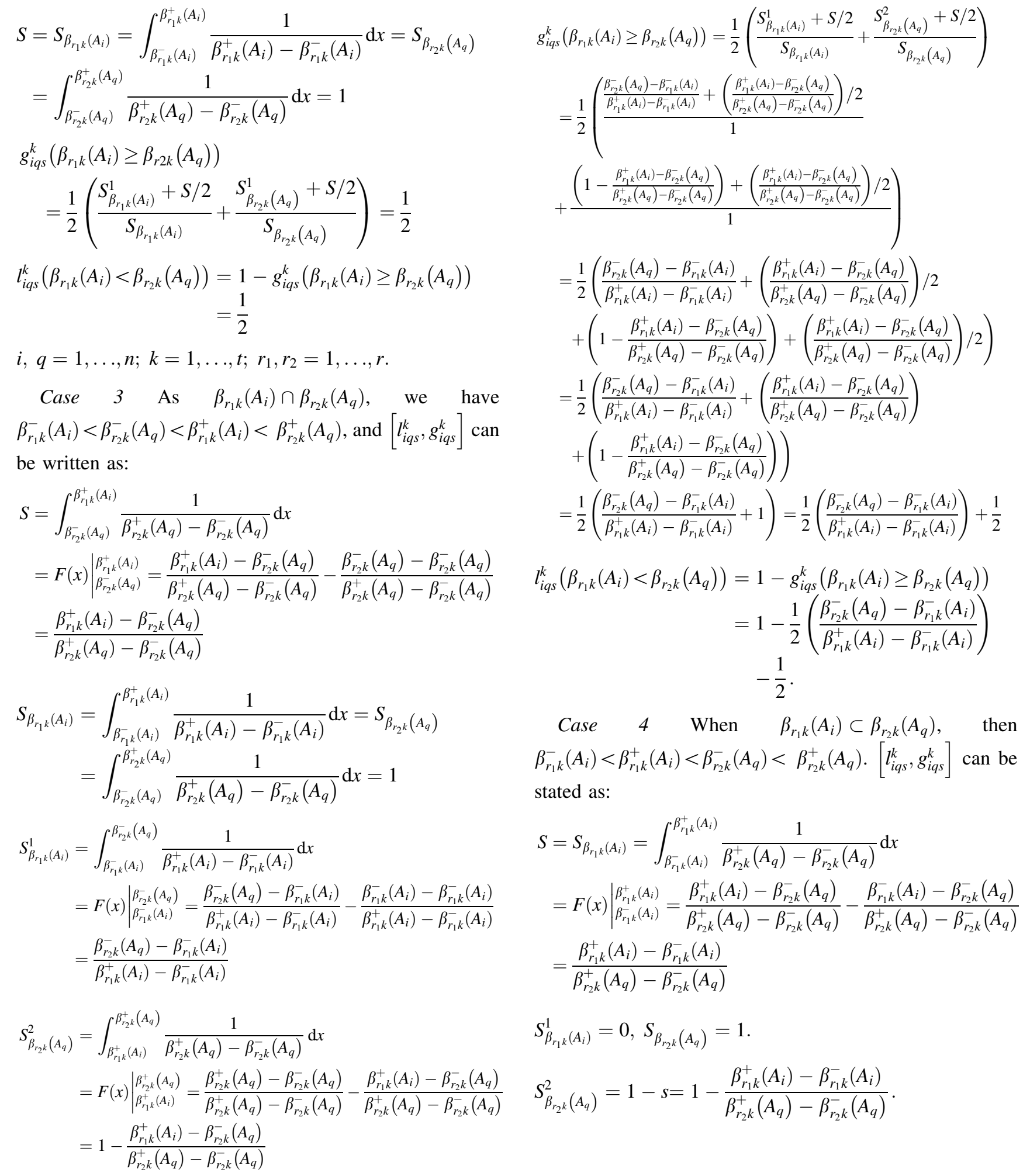

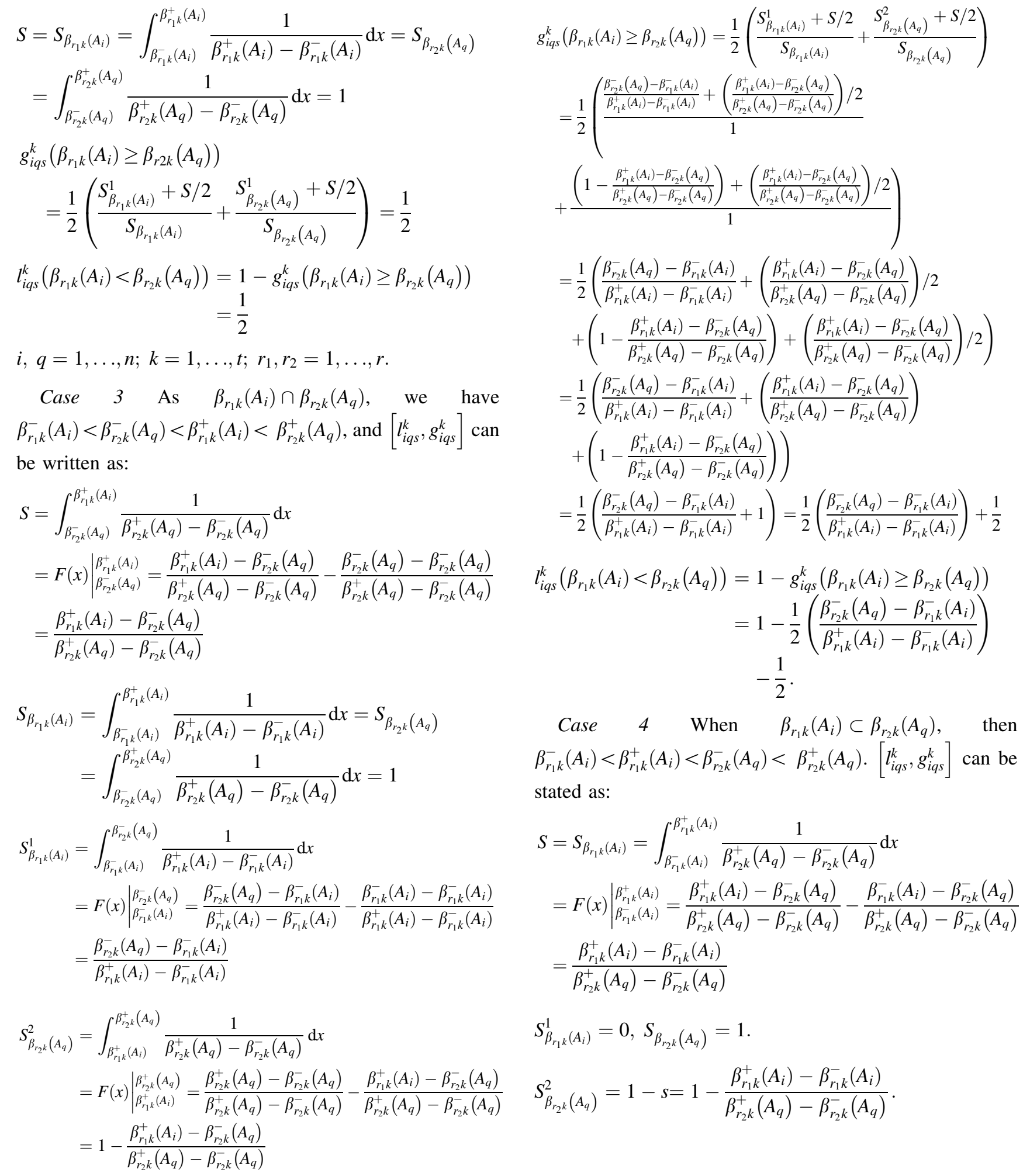

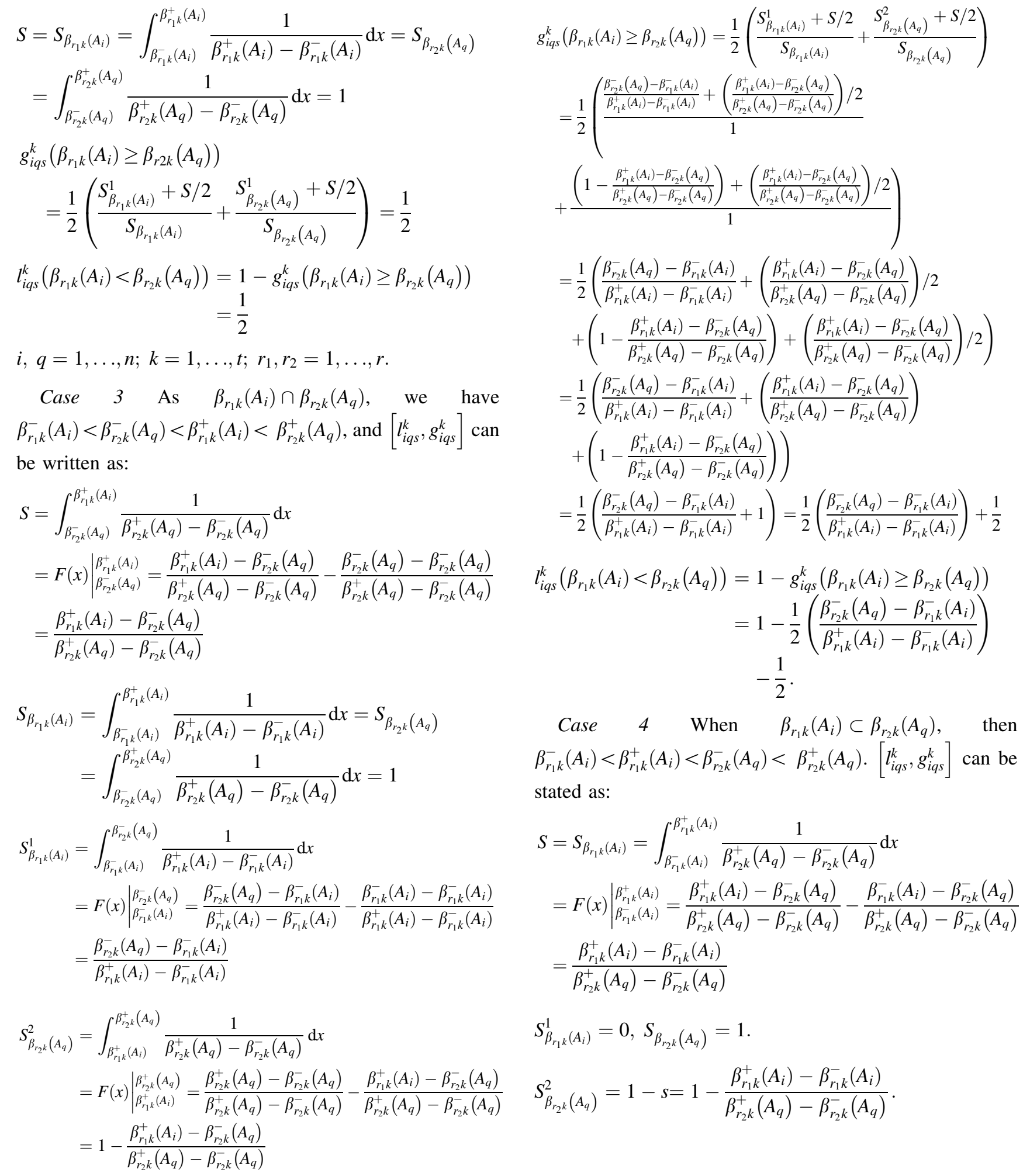

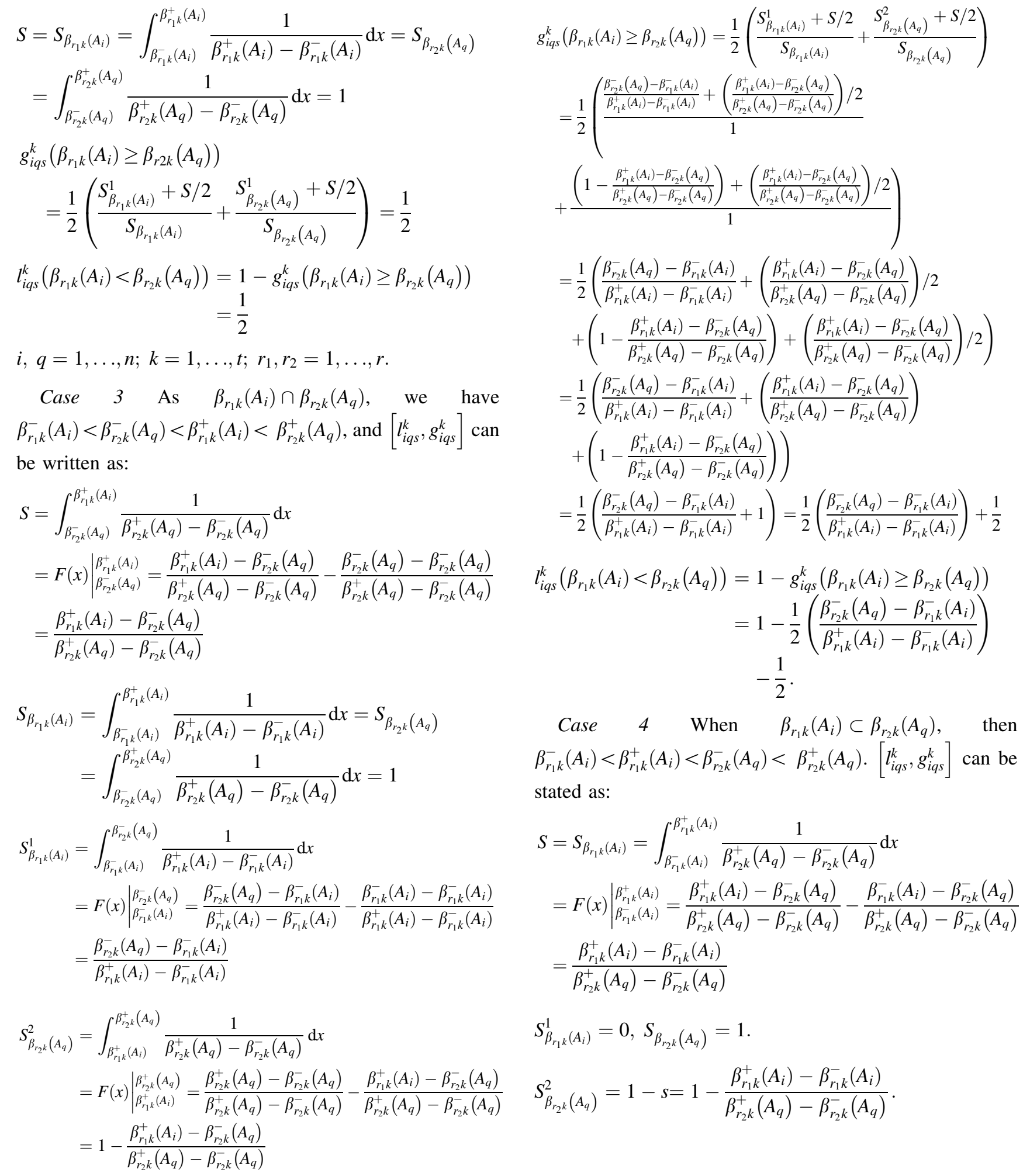

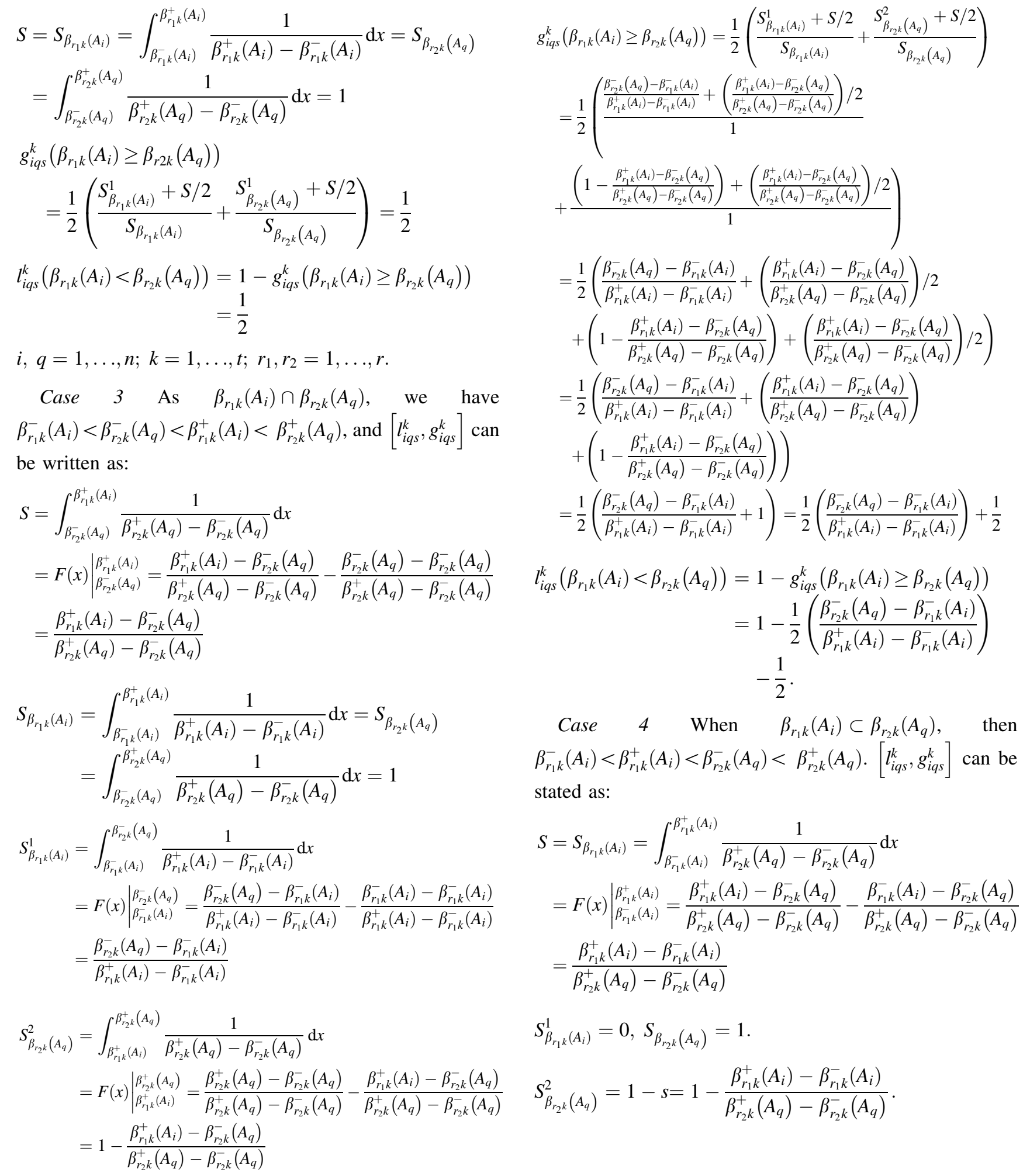

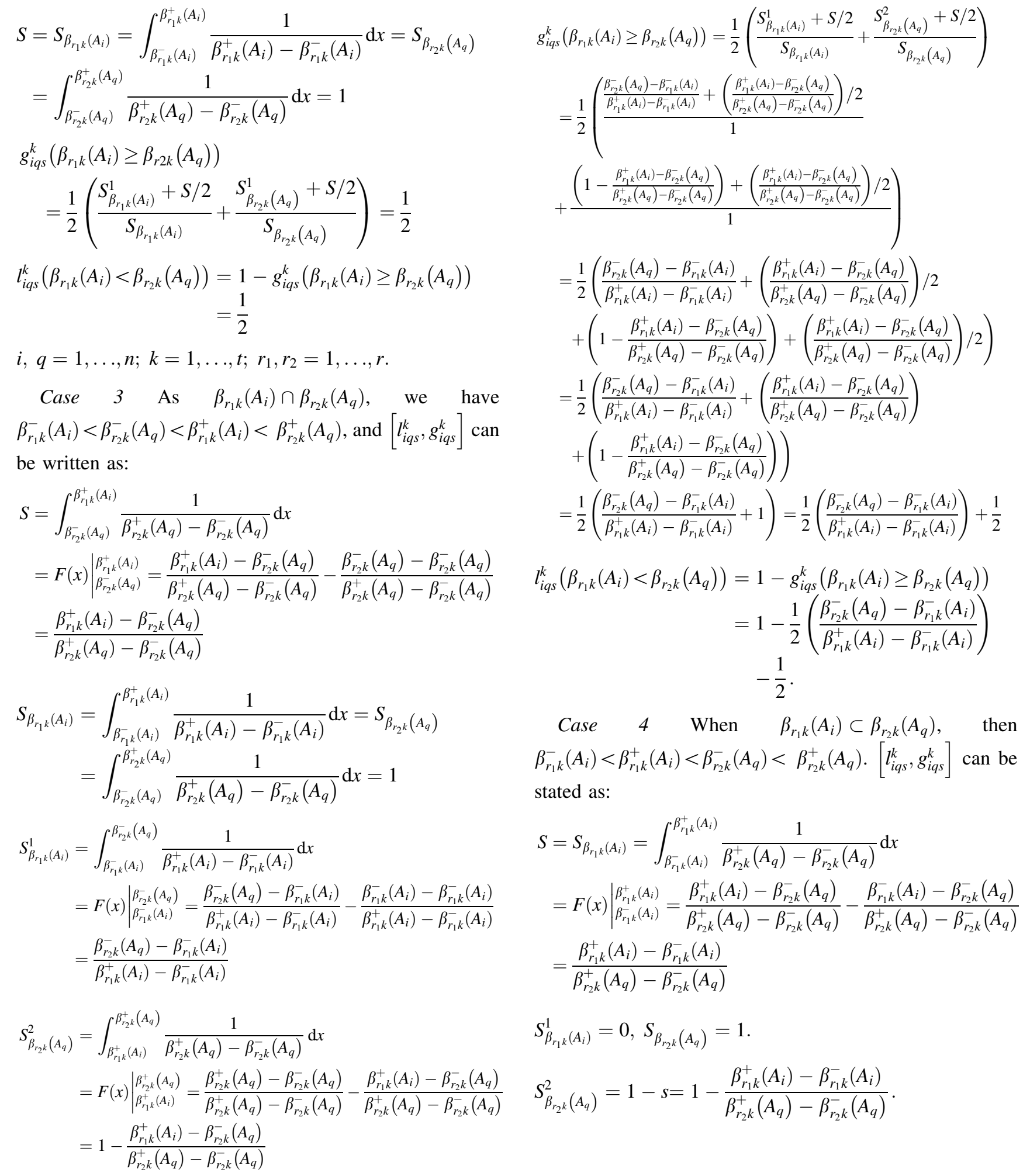

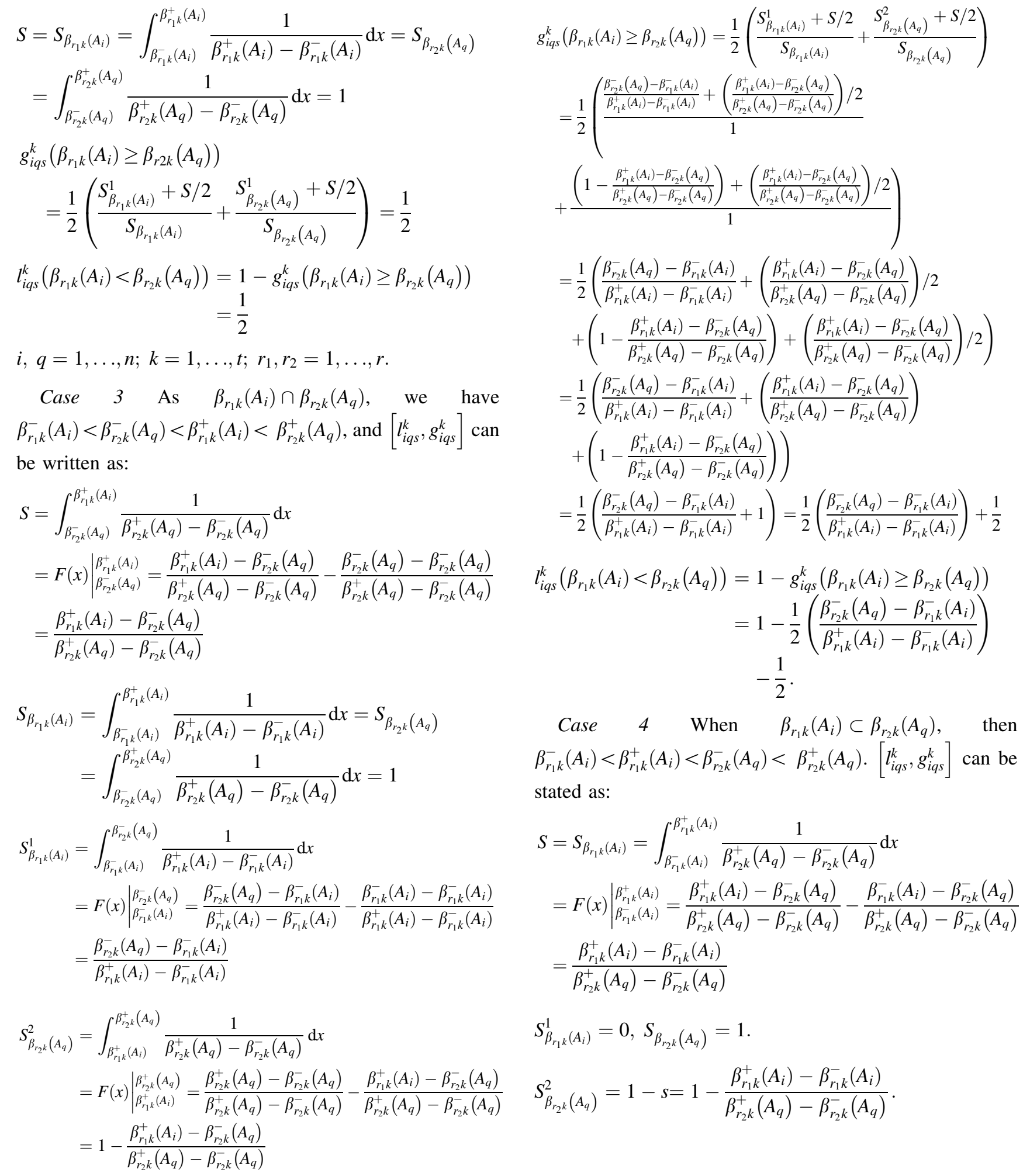

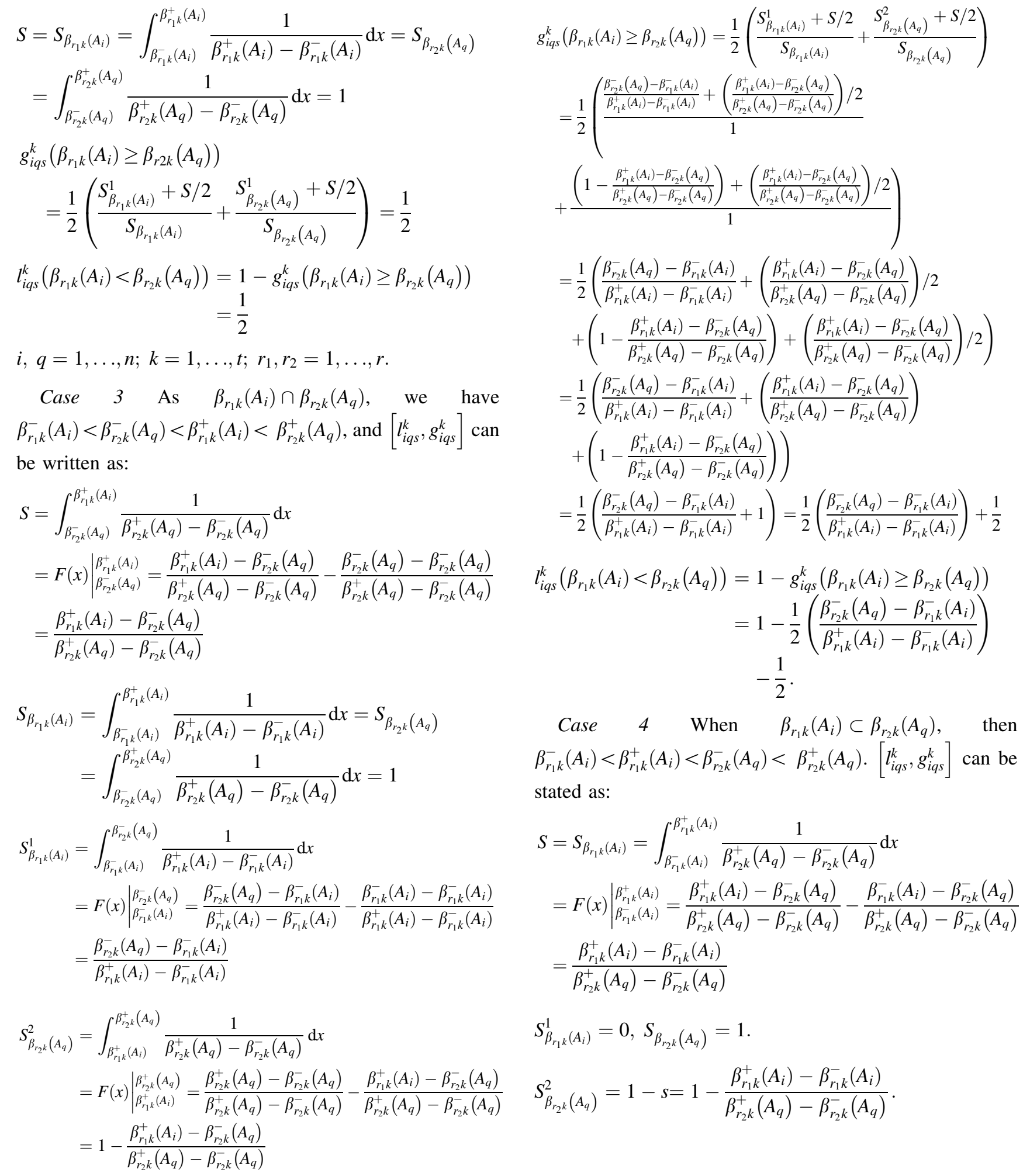

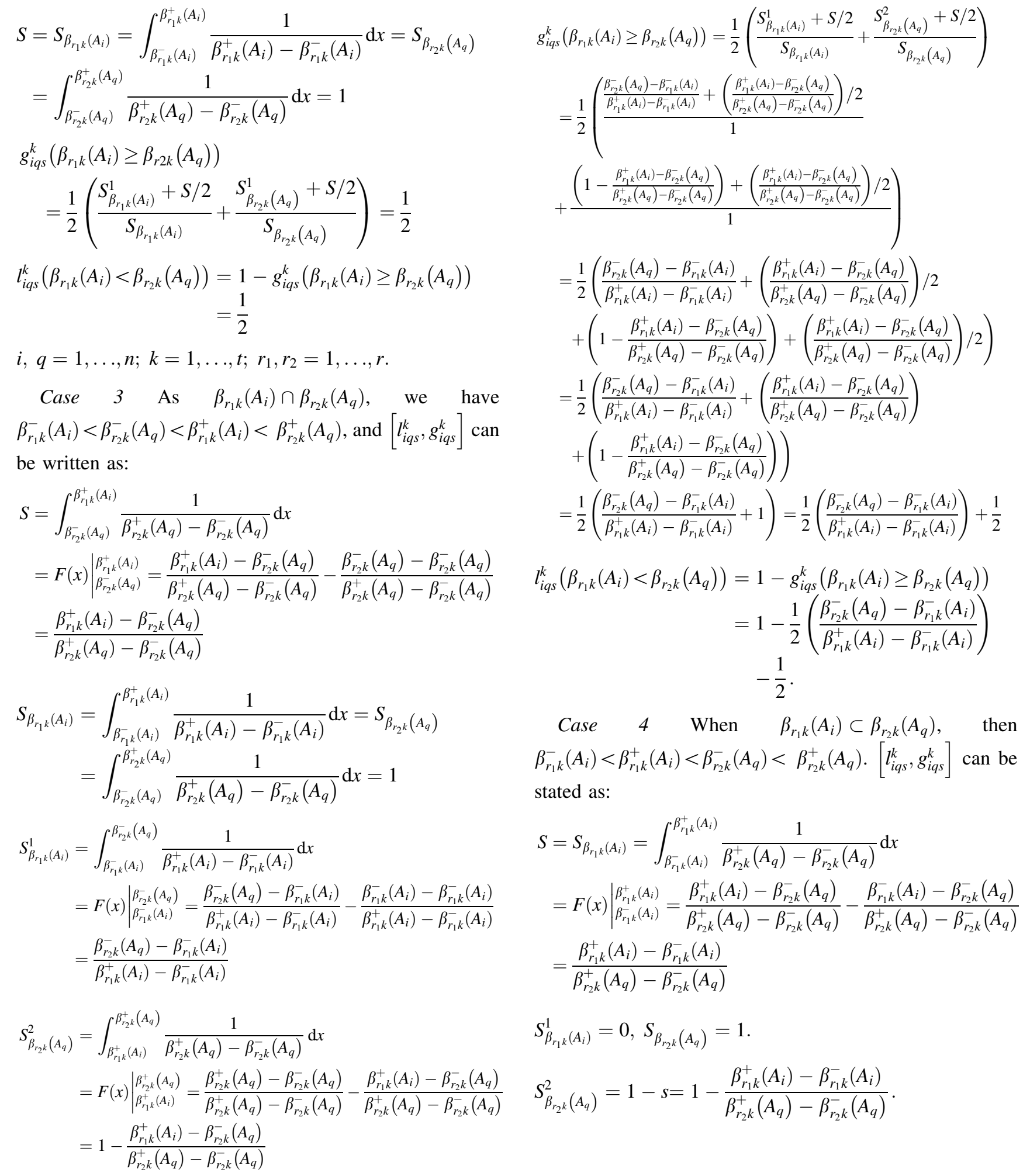

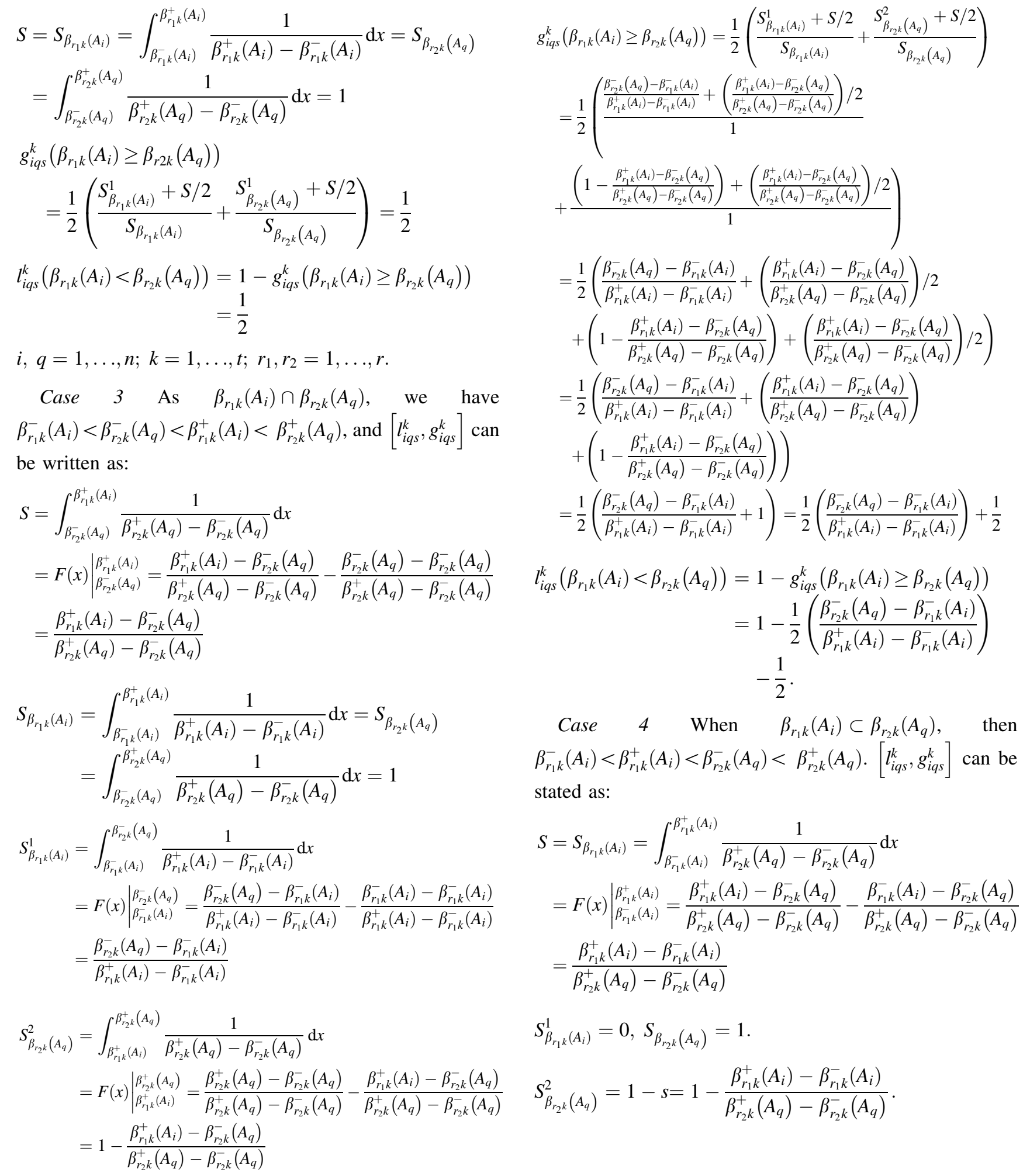

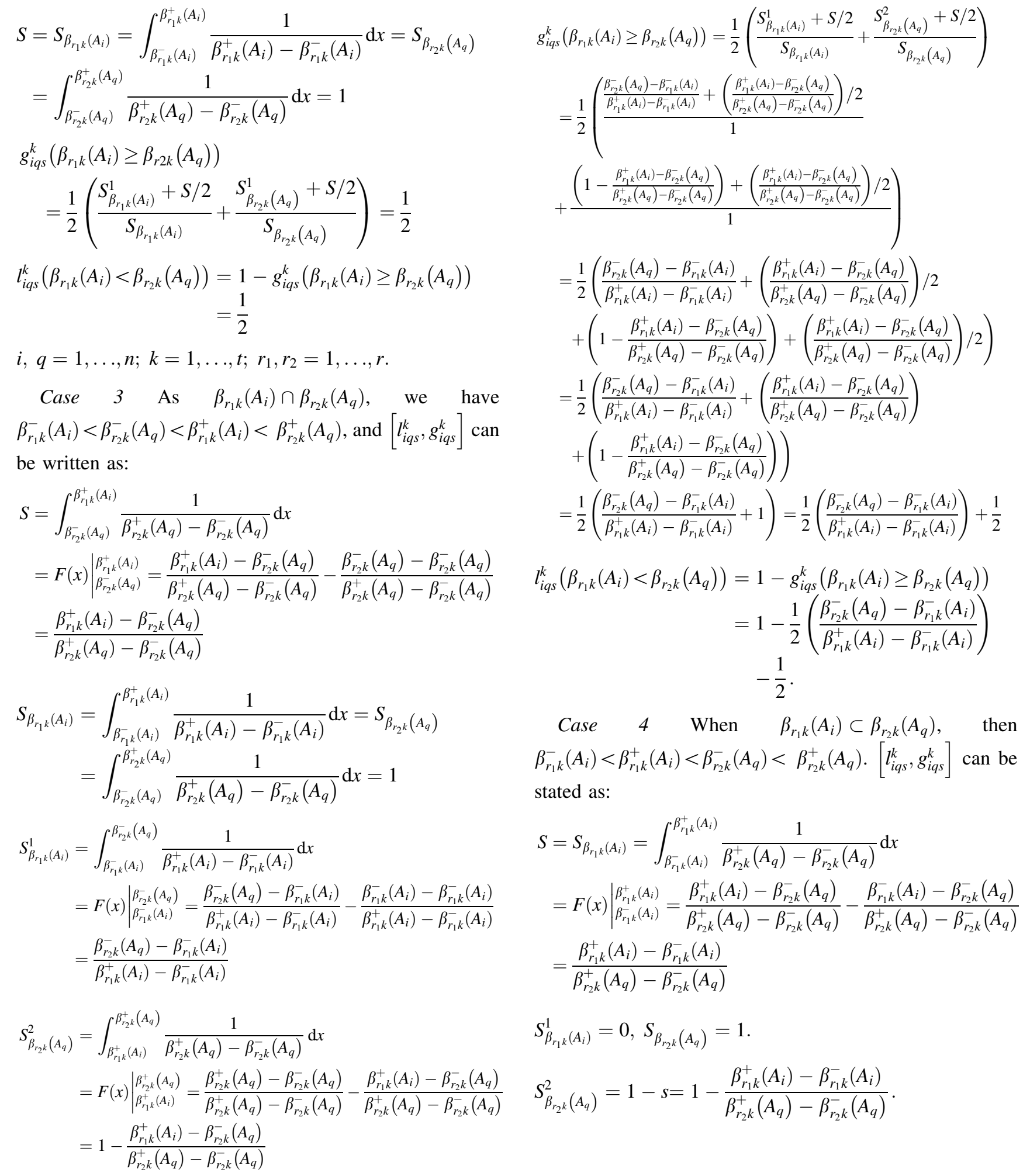

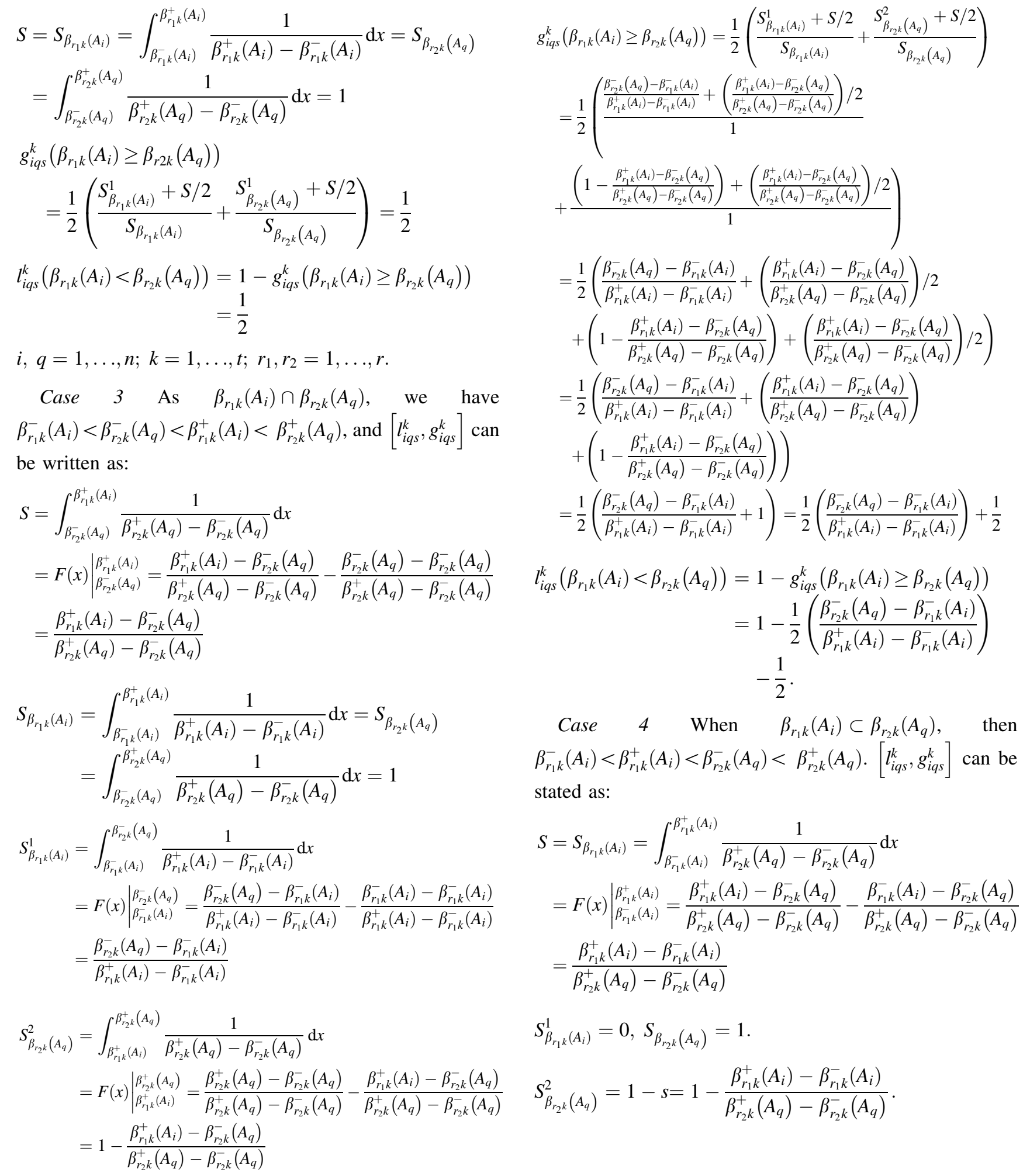

Case 4 When $\quad \beta_{r_{1} k}\left(A_{i}\right) \subset \beta_{r_{2} k}\left(A_{q}\right)$, then $\beta_{r_{1} k}^{-}\left(A_{i}\right)<\beta_{r_{1} k}^{+}\left(A_{i}\right)<\beta_{r_{2} k}^{-}\left(A_{q}\right)<\beta_{r_{2} k}^{+}\left(A_{q}\right)$. [ $\left[l_{i q s}^{k}, g_{i q s}^{k}\right]$ can be stated as:

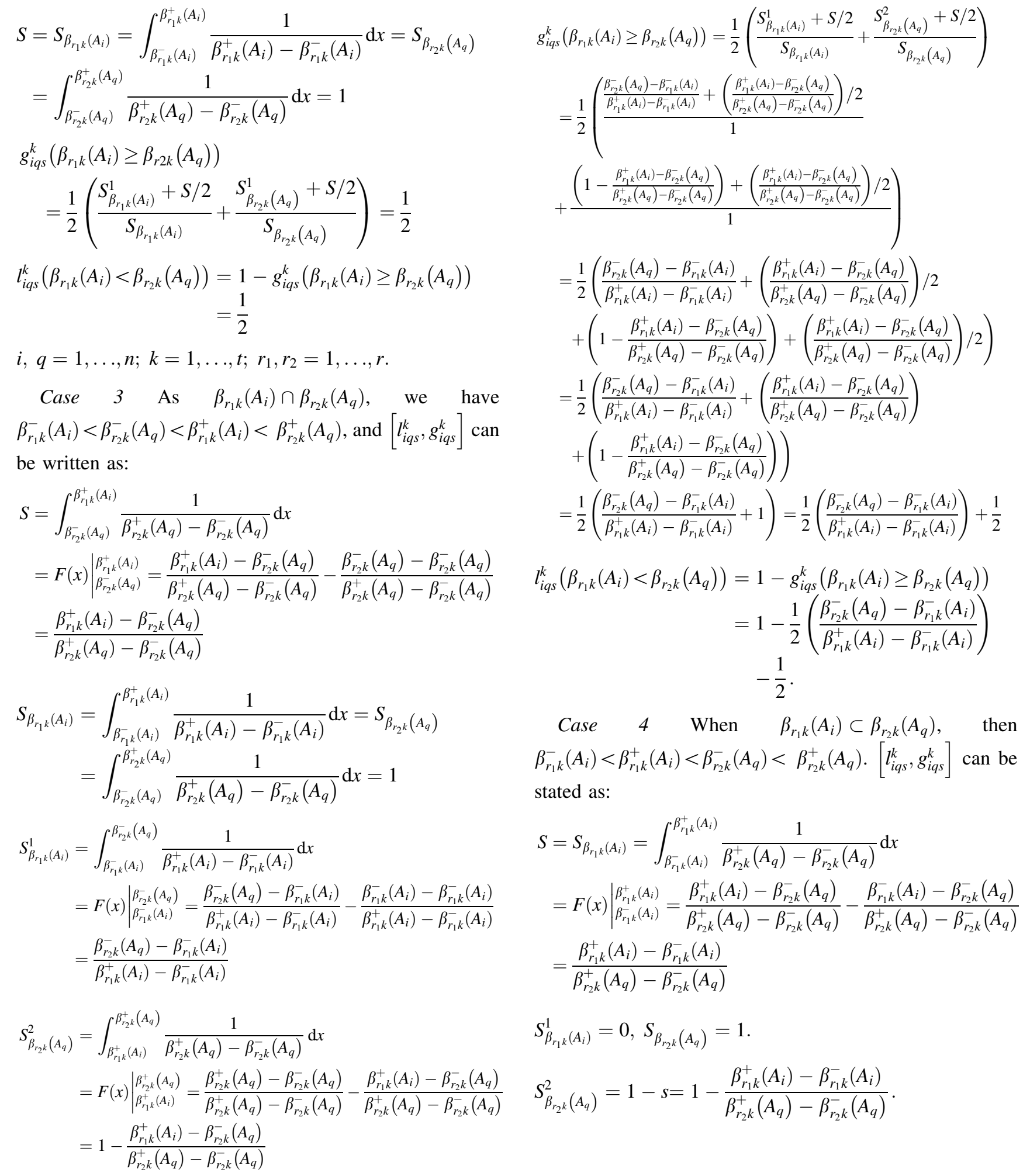

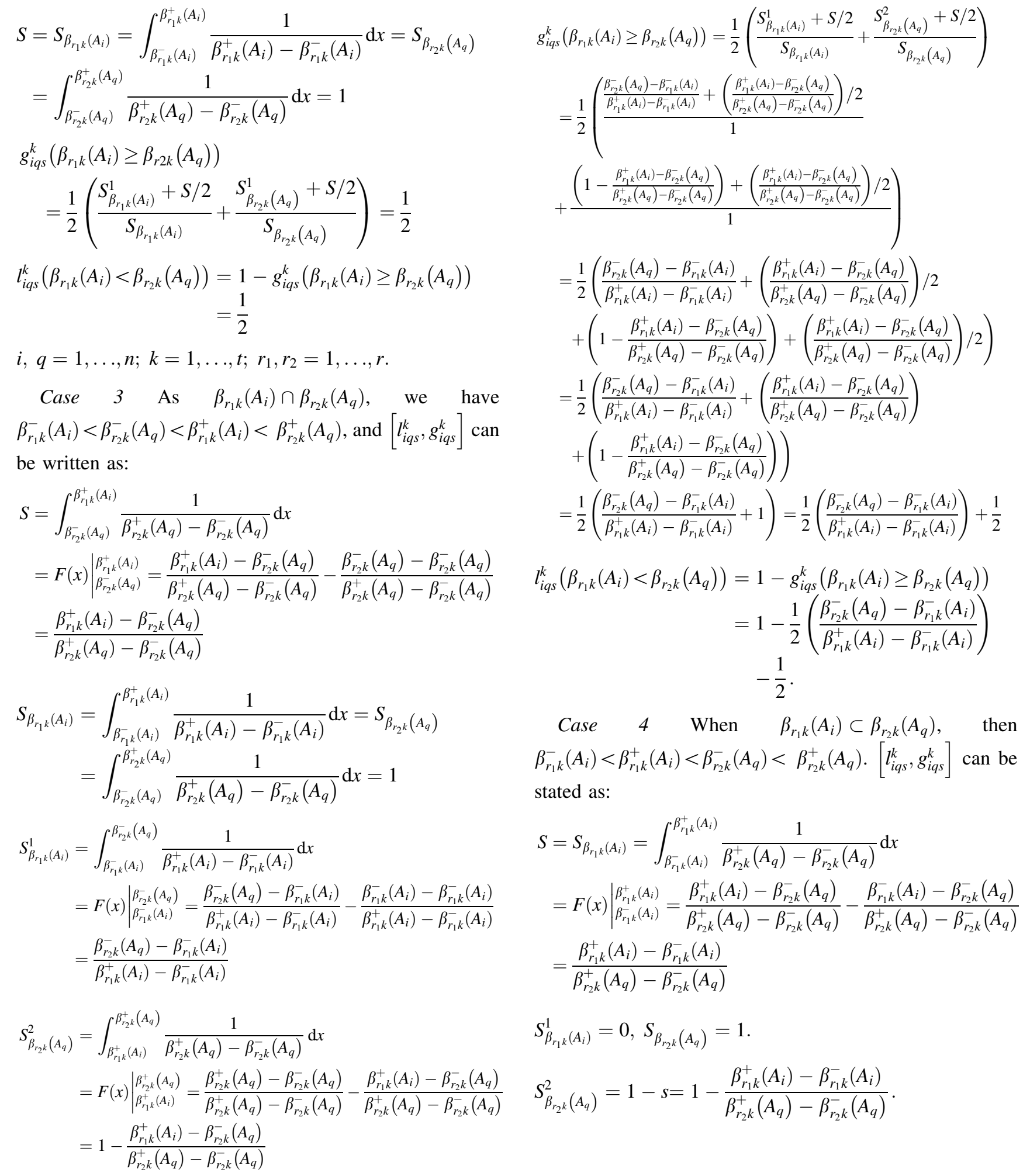

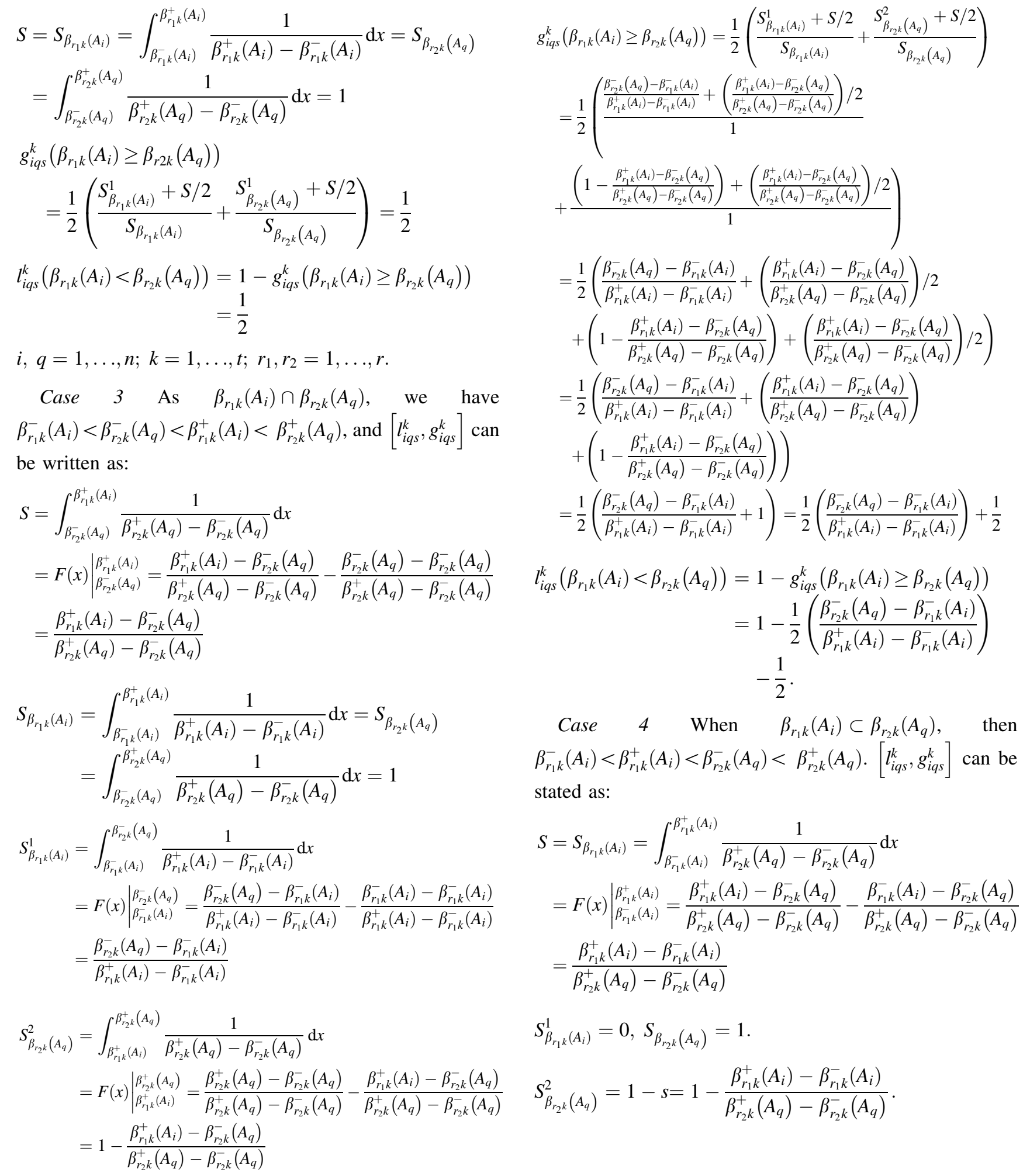




$$
\begin{aligned}
& g_{i q s}^{k}\left(\beta_{r_{1} k}\left(A_{i}\right) \geq \beta_{r_{2} k}\left(A_{q}\right)\right)
\end{aligned}
$$

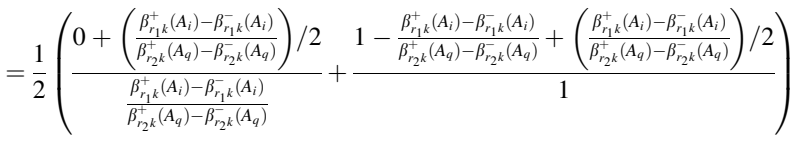

$$
\begin{aligned}
& =\frac{1}{2}\left(\frac{3}{2}-\left(\frac{\beta_{r_{1}}^{+}\left(A_{i}\right)-\beta_{r_{1} k}^{-}\left(A_{i}\right)}{\beta_{r_{2} k}^{+}\left(A_{q}\right)-\beta_{r_{2} k}^{-}\left(A_{q}\right)}\right) / 2\right) \\
& =\frac{3}{4}-\frac{1}{4}\left(\frac{\beta_{r_{1} k}^{+}\left(A_{i}\right)-\beta_{r_{1} k}^{-}\left(A_{i}\right)}{\beta_{r_{2} k}^{+}\left(A_{q}\right)-\beta_{r_{2} k}^{-}\left(A_{q}\right)}\right) \\
& l_{i q s}^{k}\left(\beta_{r_{1} k}\left(A_{i}\right)<\beta_{r_{2} k}\left(A_{q}\right)\right)=1-g_{\text {iqs }}^{k}\left(\beta_{r_{1} k}\left(A_{i}\right) \geq \beta_{r_{2} k}\left(A_{q}\right)\right) \\
& =1-\frac{3}{4}+\frac{1}{4}\left(\frac{\beta_{r_{1} k}^{+}\left(A_{i}\right)-\beta_{r_{1} k}^{-}\left(A_{i}\right)}{\beta_{r_{2} k}^{+}\left(A_{q}\right)-\beta_{r_{2} k}^{-}\left(A_{q}\right)}\right) \\
& =\frac{1}{4}+\frac{1}{4}\left(\frac{\beta_{r_{1} k}^{+}\left(A_{i}\right)-\beta_{r_{1} k}^{-}\left(A_{i}\right)}{\beta_{r_{2} k}^{+}\left(A_{q}\right)-\beta_{r_{2} k}^{-}\left(A_{q}\right)}\right)
\end{aligned}
$$

Acknowledgements The authors thank the reviewers and editors for their constructive comments in improving this paper. This research is supported by the National Natural Science Foundation of China under Grant Nos. 61773123, 71901071, and 71801050.

\section{Declaration}

Conflict of interest The authors declare that they have no conflict of interest.

Ethical approval The authors declare that they have no known competing financial interests or personal relationships that could have appeared to influence the work reported in this paper.

\section{References}

Abdellaoui M, Bleichrodt H, Paraschiv C (2007) Loss aversion under prospect theory: a parameter-free measurement. Manage Sci 53(10):1659-1674

Alcantud JCR, Giarlotta A (2019) Necessary and possible hesitant fuzzy sets: a novel model for group decision making. Inf Fusion 46:63-76

Asan U, Kadaifci C, Bozdag E, Soyer A, Serdarasan S (2018) A new approach to DEMATEL based on interval-valued hesitant fuzzy sets. Appl Soft Comput 66:34-49

Baptista S, Barbosa-Póvoa AP, Escudero LF, Gomes MS, Pizarro C (2019) On risk management of a two-stage stochastic mixed 0-1 model for the closed-loop supply chain design problem. Eur $\mathbf{J}$ Oper Res 274(1):91-107

Chen N, Xu Z, Xia M (2013) Interval-valued hesitant preference relations and their applications to group decision making. Knowl-Based Syst 37:528-540

Cheng X, Gu J, Xu Z (2018) Venture capital group decision-making with interaction under probabilistic linguistic environment. Knowl-Based Syst 140:82-91

Dempster AP (1967) Upper and lower probabilities induced by a multivalued mapping. Ann Math Stat 38:325-339

Ding XF, Liu HC, Shi H (2019) A dynamic approach for emergency decision making based on prospect theory with interval-valued
Pythagorean fuzzy linguistic variables. Comput Ind Eng 131:57-65

Fan ZP, Liu Y (2010) An approach to solve group-decision-making problems with ordinal interval numbers. IEEE Trans Syst Man Cybern Part B (Cybern) 40(5):1413-1423

Farhadinia B, Herrera-Viedma E (2019) Multiple criteria group decision making method based on extended hesitant fuzzy sets with unknown weight information. Appl Soft Comput 78:310-323

Garg H, Kaur G (2020) Quantifying gesture information in brain hemorrhage patients using probabilistic dual hesitant fuzzy sets with unknown probability information. Comput Ind Eng 140:106211

Gomes L, Lima M (1992) TODIM: Basics and application to multicriteria ranking of projects with environmental impacts. Found Comput Decis Sci 16(4):113-127

Hatzisymeon M, Kamenopoulos S, Tsoutsos T (2019) Risk assessment of the life-cycle of the used cooking oil-to-biodiesel supply chain. J Clean Prod 217:836-843

Hong Y, Xu D, Xiang K, Qiao H (2019) Multi-attribute decisionmaking based on preference perspective with interval neutrosophic sets in venture capital. Mathematics 7(3):257

Li MY, Cao PP (2019) Extended TODIM method for multi-attribute risk decision making problems in emergency response. Comput Ind Eng 135:1286-1293

Li P, Wei C (2019) An emergency decision-making method based on DS evidence theory for probabilistic linguistic term sets. Int $\mathbf{J}$ Disaster Risk Reduct 37:101178

Li D, Zeng W, Yin Q (2018) Novel ranking method of interval numbers based on the Boolean matrix. Soft Comput 22(12):4113-4122

Liu Y, Fan ZP, Zhang Y (2014) Risk decision analysis in emergency response: a method based on cumulative prospect theory. Comput Oper Res 42:75-82

Liu Z, Ming X, Song W (2019) A framework integrating intervalvalued hesitant fuzzy DEMATEL method to capture and evaluate co-creative value propositions for smart PSS. J Clean Prod 215:611-625

Mardani A, Saraji MK, Mishra AR, Rani P (2020) A novel extended approach under hesitant fuzzy sets to design a framework for assessing the key challenges of digital health interventions adoption during the COVID-19 outbreak. Appl Soft Comput 96:106613

Nagarajan M, Shechter S (2014) Prospect theory and the newsvendor problem. Manage Sci 60(4):1057-1062

Niu L, Li J, Li F, Wang Z-X (2020) Multi-criteria decision-making method with double risk parameters in interval-valued intuitionistic fuzzy environments. Complex Intel Syst 6:1-11

Peng X, Garg H (2018) Algorithms for interval-valued fuzzy soft sets in emergency decision making based on WDBA and CODAS with new information measure. Comput Ind Eng 119:439-452

Pramanik S, Mallick R (2019) TODIM strategy for multi-attribute group decision making in trapezoidal neutrosophic number environment. Complex Intell Syst 5(4):379-389

Ren P, Xu Z, Hao Z (2017) Hesitant fuzzy thermodynamic method for emergency decision making based on prospect theory. IEEE Trans Cybern 47(9):2531-2543

Shafer G (1976) A mathematical theory of evidence. Princeton University Press

Simon HA (1955) A behavioral model of rational choice. Q J Econ 69(1):99-118

Tang J, Meng F (2018) Ranking objects from group decision making with interval-valued hesitant fuzzy preference relations in view of additive consistency and consensus. Knowl-Based Syst 162:46-61

Torra V (2010) Hesitant fuzzy sets. Int J Intell Syst 25(6):529-539 
Tversky A, Kahneman D (1979) Prospect theory: an analysis of decision under risk. Econometrica 47(2):263-291

Tversky A, Kahneman D (1992) Advances in prospect theory: cumulative representation of uncertainty. J Risk Uncertain 5(4):297-323

Wang YM, Yang JB, Xu DL, Chin K-S (2006) The evidential reasoning approach for multiple attribute decision analysis using interval belief degrees. Eur J Oper Res 175(1):35-66

Wang L, Wang YM, Martínez L (2017) A group decision method based on prospect theory for emergency situations. Inf Sci 418:119-135

Wang T, Guomai S, Zhang L, Li G, Lu Y, Chen J (2019) Earthquake emergency response framework on campus based on multisource data monitoring. J Clean Prod 238:117965

Xue W, Xu Z, Wang H, Ren Z (2019) Hazard assessment of landslide dams using the evidential reasoning algorithm with multi-scale hesitant fuzzy linguistic information. Appl Soft Comput 79:74-86

Yang J, Li S, Xu Z, Liu H, Yao W (2020) An understandable way to extend the ordinary linear order on real numbers to a linear order on interval numbers. IEEE Trans Fuzzy Syst. https://doi.org/10. 1109/TFUZZ.2020.3006557
Yu L, Lai KK (2011) A distance-based group decision-making methodology for multi-person multi-criteria emergency decision support. Decis Support Syst 51(2):307-315

Zeng W, Li D, Yin Q (2019) Weighted interval-valued hesitant fuzzy sets and its application in group decision making. Int J Fuzzy Syst 21(2):421-432

Zhang J (2000) Fuzzy analytical hierarchy process. Fuzzy Syst Math 14(2):80-88

Zhang LJ, Li LS (2019) People-oriented emergency response mechanism - an example of the emergency work when typhoon Meranti struck Xiamen. Int J Disaster Risk Reduct 38:101185

Zhou M, Liu X-B, Chen Y-W, Yang J-B (2018) Evidential reasoning rule for MADM with both weights and reliabilities in group decision making. Knowl-Based Syst 143:142-161

Zhou M, Liu X-B, Yang J-B, Chen Y-W, Wu J (2019) Evidential reasoning approach with multiple kinds of attributes and entropy-based weight assignment. Knowl-Based Syst $163: 358-375$

Publisher's Note Springer Nature remains neutral with regard to jurisdictional claims in published maps and institutional affiliations. 